\title{
Liquid Water Saturation and Oxygen Transport Resistance in Polymer Electrolyte Membrane Fuel Cell Gas Diffusion Layers
}

by

Daniel Muirhead

A thesis submitted in conformity with the requirements for the degree of Masters of Applied Sciences

Department of Mechanical and Industrial Engineering University of Toronto

๑) Copyright by Daniel Muirhead 2017 


\title{
Liquid Water Saturation and Oxygen Transport Resistance in Polymer Electrolyte Membrane Fuel Cell Gas Diffusion Layers
}

\author{
Daniel Muirhead \\ Masters of Applied Science \\ Mechanical and Industrial Engineering \\ University of Toronto
}

2017

\begin{abstract}
In this thesis, the relative humidity $(\mathrm{RH})$ of the cathode reactant gas was investigated as a factor which influences gas diffusion layer (GDL) liquid water accumulation and mass transport-related efficiency losses over a range of operating current densities in a polymer electrolyte membrane (PEM) fuel cell. Limiting current measurements were used to characterize fuel cell oxygen transport resistance while simultaneous measurements of liquid water accumulation were conducted using synchrotron X-ray radiography. GDL porosity distributions were characterized with micro-computed tomography $(\mu \mathrm{CT})$. The work presented here can be used by researchers to develop improved numerical models to predict GDL liquid water accumulation and to inform the design of next-generation GDL materials to mitigate mass transport-related efficiency losses. This work also contributes an extensive set of concurrent performance and liquid water visualization data to the PEM fuel cell field that can be used for validating multiphase transport models.
\end{abstract}




\section{Acknowledgements}

Firstly, I owe a tremendous debt of gratitude to my supervisor, Professor Aimy Bazylak. I have valued your support, encouragement, and your unwavering belief in the talent and knowledge of the team you have built. I also truly admire your ambition and genuine excitement for learning.

To my colleagues in the TEAM lab, you have all played a part in shaping my experience these past two years. James, your curiosity and thirst for knowledge set the precedent for the culture of this research group for the better part of a decade. Thank you for everything you've done for the TEAM, and thank you for vouching for me as a candidate to join. Rupak, thank you for the endless dedication you showed to helping us grad students reach our goals. I know you have volunteered countless hours without hesitation to help us conduct experiments, interpret results, write manuscripts, and complete theses, and I am immensely grateful. To Pranay, Nan, Jongmin, Mike, Stéphane, Chung, Hang, Faraz, Nico, Svenja, Andrew, Dave, Jason, Jack, Bonnie, and Hisan, I have endless cherished memories of my time as a Masters student, and I know I have made a number of lifelong friends. Thank you all.

To Mom and Dad, everything I am today and ever will be is a product of what you have done for me over the past 25 years, and I will always be grateful. Ian, you may deny that I took after you in many ways, but the reality is that thanks to my older brother, I grew up in a household thinking it was cool to be intelligent, dedicated, polite, and humble.

Finally, Ivanna, in the most stressful times through the 2 years of my Masters research and the 5 years of my Bachelor's degree, nothing has lifted the weight off my shoulders like coming home 
to see your face and hear your voice. Knowing I have you in my life gives me more confidence than you know that I will survive and thrive in the toughest challenges I will face in life moving forward. 


\section{Table of Contents}

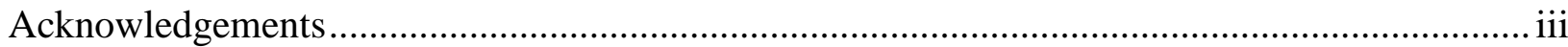

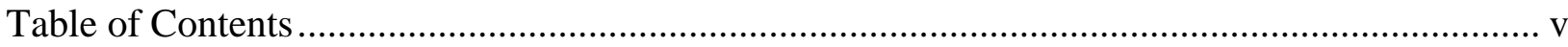

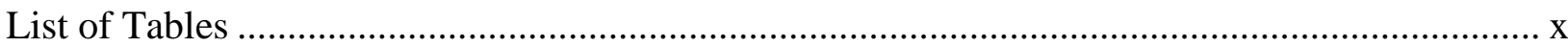

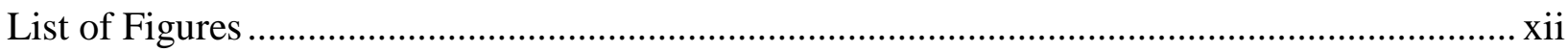

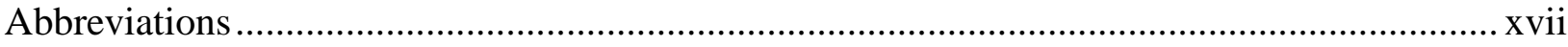

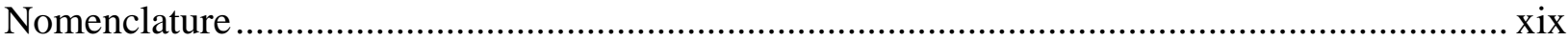

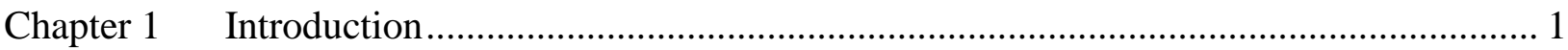

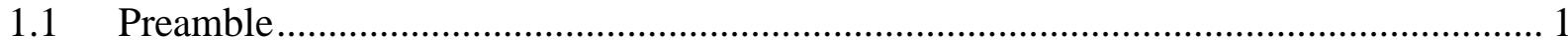

1.2 Electrochemical energy conversion in PEM fuel cells........................................... 2

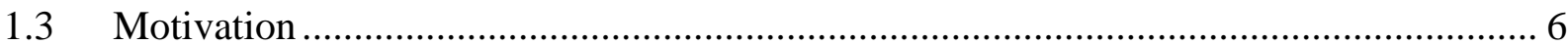

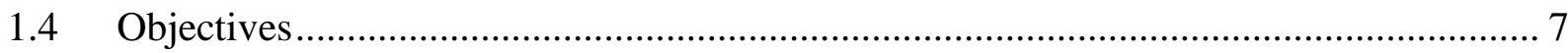

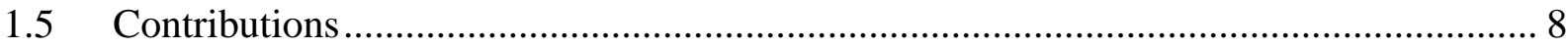

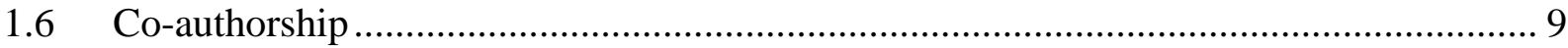

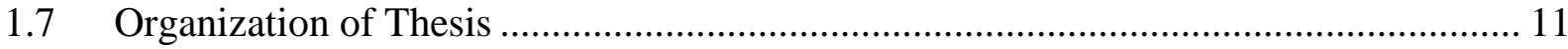

Chapter 2 Background and Literature Review ......................................................... 13

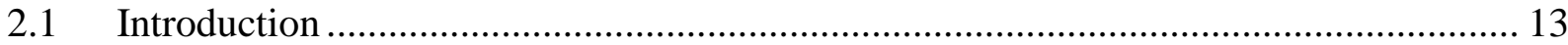

2.2 PEM fuel cell efficiency losses ......................................................................... 13 


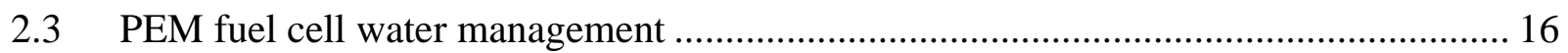

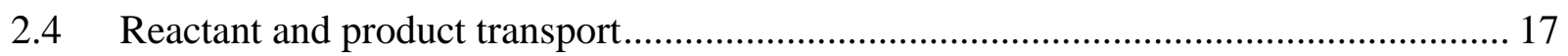

2.4.1 Water transport and liquid water accumulation ................................................. 18

2.4.1.1 Visualizations of liquid water saturation ..................................................... 19

2.4.1.2 Effect of reactant gas relative humidity $(\mathrm{RH})$......................................... 20

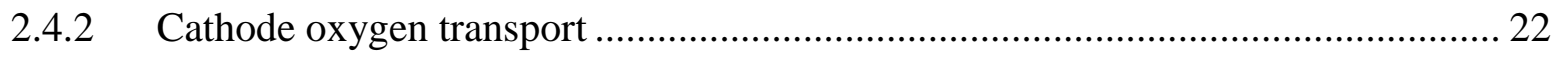

2.4.2.1 Quantifying oxygen transport resistance ……….......................................... 22

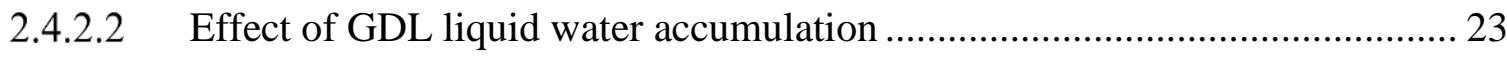

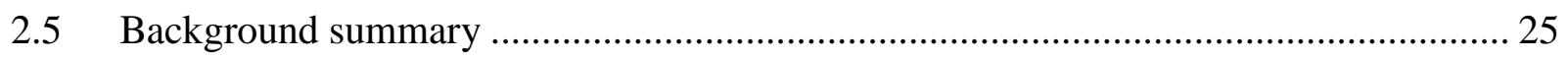

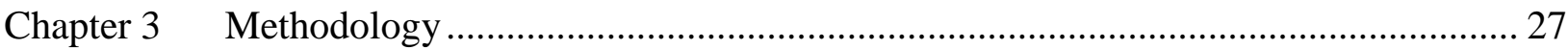

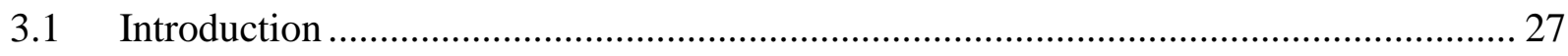

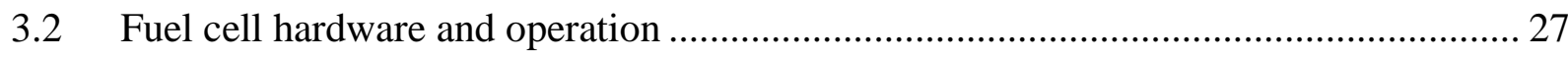

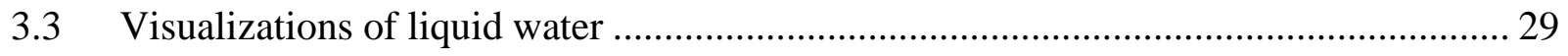

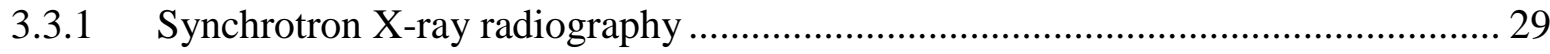

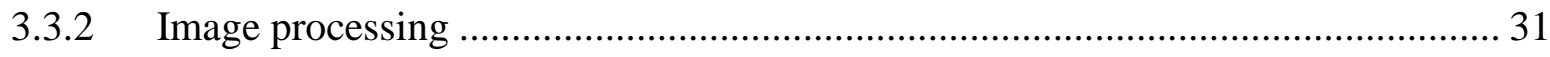

3.4 GDL porosity characterization by X-ray micro-computed tomography ......................... 36

3.5 Calculation of liquid water saturation and effective pore fraction................................ 37

3.6 Quantifying oxygen transport resistance .................................................................... 38

3.6.1 Oxygen transport resistance definition ............................................................... 38 


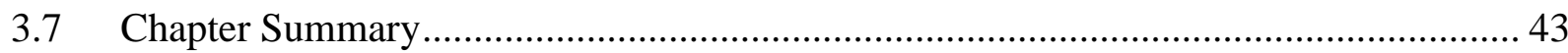

Chapter 4 Oxygen Transport Resistance and Liquid Water Saturation at High Current Density with Varied Cathode Relative Humidity .......................................................................... 45

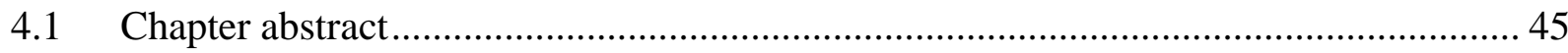

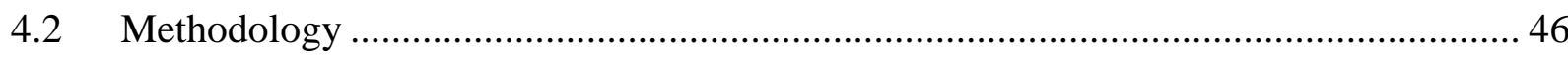

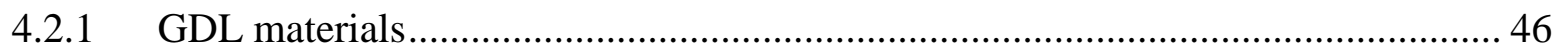

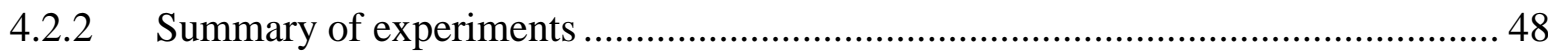

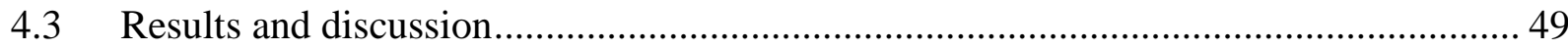

4.3.1 Impact of humidity on water accumulation ........................................... 49

4.3.2 Comment on material movement.................................................................... 58

4.3.3 Oxygen transport resistance .................................................................... 59

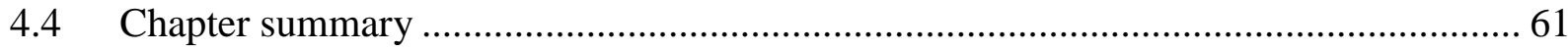

Chapter 5 Oxygen Transport Resistance and Liquid Water Accumulation in Polymer Electrolyte Membrane Fuel Cell Cathode GDLs: Impacts of Current Density and Cathode Inlet

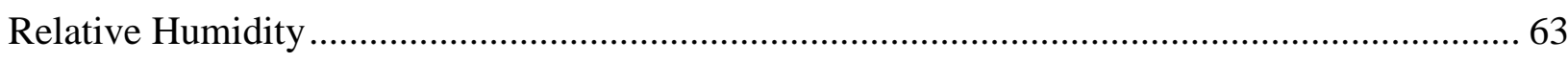

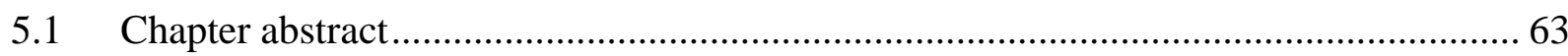

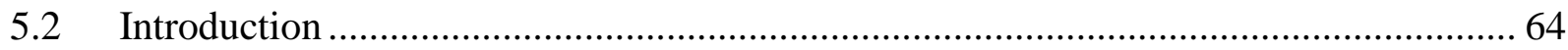

5.3 Brief background: component decomposition of transport resistance ........................ 64 
5.4 Methodology

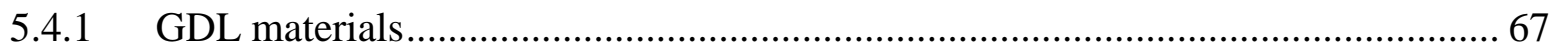

5.4.2 Correlations for GDL substrate effective diffusivity ................................................ 69

5.4.2.1 Calculation of the bulk diffusion coefficient ................................................ 71

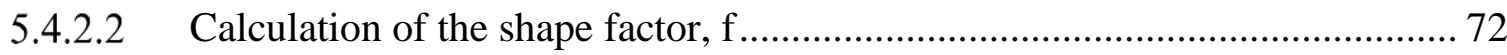

5.4.3 Estimation of MPL transport resistance ............................................................ 73

5.4.4 Estimation of catalyst layer transport resistance ................................................... 74

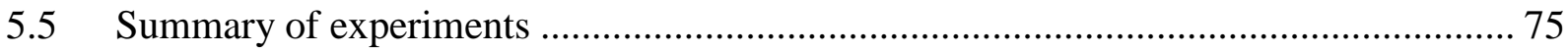

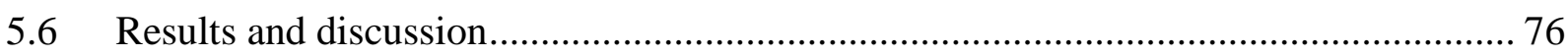

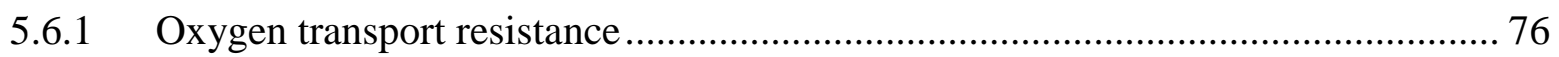

5.6.2 Liquid water accumulation ................................................................................ 79

5.6.2.1 Effects of cathode inlet relative humidity and current density ….................... 79

5.6.2.2 Comment on material movement ............................................................ 84

5.6.2.3 Effect of through-plane porosity profile on liquid water accumulation ........... 85

5.6.3 Relationship of substrate effective pore space to transport resistance.................... 90

5.6.3.1 MPL transport resistance ……………………............................................ 90

5.6.3.2 Pressure-independent component of transport resistance (catalyst layer)....... 92

5.6.3.3 Comparison of experimental results to correlations ....................................... 93

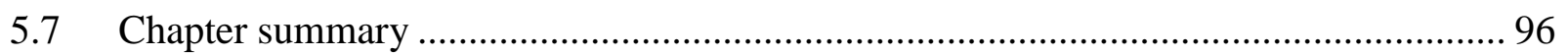

5.8 Appendix: Supplementary performance and water accumulation data.......................... 98 
5.8.1 Measured limiting current densities

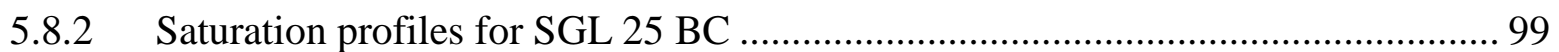

5.8.2.1 Comment on X-ray beam intensity fluctuation ........................................... 100

5.8.3 Through-plane distributions of effective space: effect of current density ............ 101

Chapter 6 Conclusions and Future Work ……………………………………………....... 103

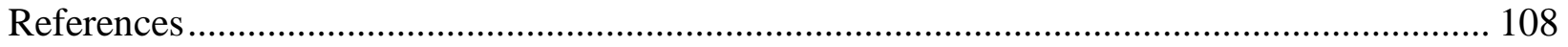




\section{List of Tables}

Table 4-1: GDL materials and properties

Table 4-2: Summary of anode and cathode inlet RH levels used for limiting current experiments

Table 4-3: Measured limiting current densities $\left(i_{L}\right)$ and oxygen transport resistances $\left(R_{T}\right)$ in a PEM fuel cell operating at cathode inlet $\mathrm{RH}$ levels ranging from $0 \%$ to $100 \%$.

Table 5-1: GDL materials and properties 68

Table 5-2: Existing models from the literature for GDL effective diffusivity based on open porosity. The void fraction $\varepsilon_{e f f}$ represents the effective pore fraction in the dry or partiallysaturated GDL substrate 70

Table 5-3: Summary of cathode inlet relative humidity and inlet oxygen mole fractions used for limiting current experiments 76

Table 5-4: Measured oxygen transport resistances during experiments conducted with minimal $(0 \%)$ and maximal $(100 \%)$ cathode inlet relative humidity 78

Table 5-5: Calculation of MPL contribution to total transport resistance and MPL effective diffusion coefficient in SGL 25 BC and SGL 29 BC using low $\mathrm{O}_{2}$ concentration limiting currentbased measurements of total oxygen transport resistance according to Equations (5.15) - (5.17). 
Table 5-6: Pressure-independent transport resistances at 0\%, 50\%, 80\%, and 100\% RH, calculated using the extrapolated zero-pressure intercept of transport resistance plotted as a function of

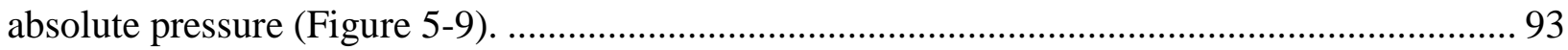




\section{List of Figures}

Figure 1-1: PEM fuel cell schematic 3

Figure 2-1: Illustration of a fuel cell polarization curve and the various fuel cell overpotentials which cause efficiency losses.

Figure 3-1: a) Schematic of synchrotron X-ray radiography experimental set-up (not to scale) b) top view of imaged region of the fuel cell with active area and flow channel dimensions. 30

Figure 3-2: Sample measurement of liquid water at limiting current conditions (with SGL 29 BC employed as the GDL, $60^{\circ} \mathrm{C}, 80 \%$ relative humidity): (a) a raw absorption radiograph, (b) a processed water thickness image using Equation (3.6), with the calculated water thickness depicted on a colour scale, (c) average water thickness vs. through-plane position (Equation 3.7) in the channel regions, indicated by the regions with the dashed green outlines in (b), (d) average water thickness vs. through-plane position (Equation 3.7) in the GDL land regions (indicated by the regions with the solid red outlines in (b)). The zero position on the $\mathrm{x}$-axis of (c) and (d) corresponds

to the cathode CL-MPL interface. 34

Figure 3-3: Illustration of limiting current technique. Left-hand image is an illustration of the i-V curves for two inlet oxygen mole fractions, resulting in mass transport limitation at different current densities. The right-hand figure shows the low-voltage region of selected experimental iV curves measured during limiting current experiments with SGL 29 BC employed as the GDL. Experiments with a 0.21 oxygen mole fraction in the cathode inlet gas were conducted by controlling voltage in discrete, decreasing steps. All other experiments were conducted by controlling operating current density in discrete, increasing steps. 
Figure 4-1: Computed porosity profiles for (a) SGL 25 BC and (b) SGL 29 BC with the MPL region, defined in chapter 3.5 , indicated by grey shading. The zero position on the $\mathrm{x}$-axis corresponds to the CL-MPL interface. 48

Figure 4-2: (a) Example of a processed radiograph for SGL 25 BC containing three land and two channel regions at the center of the flow field (cropped region to enhance readability). The red outline indicates the location of the cathode GDL. (b) Normalized water thickness in the cathode GDL, averaged in the through-plane direction (x), versus in-plane position at cathode inlet relative humidity levels of $0 \% \mathrm{RH}$ and $100 \% \mathrm{RH}$. The position $\mathrm{y}=0$ is located at the horizontal center of the central flow field land region. Water profiles presented represent a 30-second average of recorded images. Shading indicates the uncertainty of the mean normalized water thickness at a particular through-plane position. 50

Figure 4-3: Liquid water saturation and local porosity vs. through-plane position in the cathode GDLs during limiting current operation. Figures (a) and (b) depict saturation in SGL 25 BC, and (c) and (d) depict saturation in SGL 29 BC. Figures (a) and (c) depict saturation in regions above the flow field channels (max. uncertainty \pm 0.005 ) and figures (b) and (d) depict regions above the flow field lands (max. uncertainty \pm 0.012 ). The zero position on the $\mathrm{x}$-axes corresponds to the location of the CL-MPL interface. Saturation profiles depicted represent a 30-second average of recorded images. 54

Figure 4-4: Total water volume per unit active area observed in the cathode carbon fiber substrate region of the GDL for cells operating at limiting current. Liquid water thicknesses used to calculate water volumes represent a 30-second average of recorded images. 56 
Figure 4-5: Oxygen transport resistance vs. limiting current density for the two GDLs studied. Higher limiting current densities correspond to lower humidity test cases. 60

Figure 5-1: Illustration of the series components of oxygen transport resistance on the cathode side of a PEM fuel cell. Figure (a) depicts the fuel cell layers on the cathode side of the fuel cell (not to scale), (b) illustrates the gradient of oxygen concentration between the channels and the catalyst which drives oxygen flux, and (c) depicts a linear resistance network modeling the total oxygen transport resistance 65

Figure 5-2: Through-plane porosity characterization for a) SGL 25 BC, b) SGL 29 BC, and c) SGL $25 \mathrm{BA}$. The zero position on the $\mathrm{x}$-axis corresponds to the CL/MPL interface. The macro effective pore fraction represents the fraction of void voxels identified by the $\mu \mathrm{CT}$ segmentation procedure outlined in chapter 3 . The micro effective pore fraction represents the pore fraction of the MPL assuming a 50\% MPL porosity 69

Figure 5-3: Oxygen transport resistance versus limiting current density for a) SGL 25 BC and b) SGL 29 BC. Lower limiting current densities correspond to experiments with lower inlet oxygen concentrations. Humidity levels are indicated by symbol shape, line style and colour. Low, intermediate, and high current density regimes are indicated by shading. 77

Figure 5-4: Through-plane porosity and saturation profiles in (a) the regions of the SGL 29 BC GDL above the flow field channels (max. uncertainty \pm 0.006 ) and (b) the regions of the GDL above the flow field lands (max. uncertainty \pm 0.006 ) for limiting current experiments with a 0.01 oxygen mole fraction supplied in the dry cathode gas feed, prior to humidification (indicated as $1 \% \mathrm{O}_{2}$ ). The resulting limiting current densities were below $0.5 \mathrm{~A} \cdot \mathrm{cm}^{-2}$ at all humidity levels. See the Appendix for similar figures for SGL 25 BC. 80 
Figure 5-5: Through-plane porosity and saturation profiles in (a) the regions of the SGL 29 BC GDL above the flow field channels (max. uncertainty \pm 0.006 ) and (b) the regions of the GDL above the flow field lands (max. uncertainty \pm 0.015 ) for limiting current experiments with a 0.1 oxygen mole fraction supplied in the dry cathode gas feed, prior to humidification (indicated as $10 \% \mathrm{O}_{2}$ ). The resulting limiting current densities were between 1.5 and $2.1 \mathrm{~A} \cdot \mathrm{cm}^{-2}$. See the Appendix for similar figures for SGL 25 BC. 81

Figure 5-6: Through-plane porosity and saturation profiles in (a) the regions of the SGL 29 BC GDL above the flow field channels (max. uncertainty \pm 0.007 ) and (b) the regions of the GDL above the flow field lands (max. uncertainty \pm 0.016 ) for limiting current experiments with a 0.21 mole fraction of oxygen supplied in the dry cathode gas feed, prior to humidification (indicated as $21 \% \mathrm{O}_{2}$ ). The resulting limiting current densities were greater than $3.0 \mathrm{~A} \cdot \mathrm{cm}^{-2}$ at all humidity levels. See the Appendix for similar figures for SGL 25 BC. 83

Figure 5-7: Through-plane distributions of solid, water, and effective pore (void) volume fractions in the SGL a) $25 \mathrm{BA}$, b) $25 \mathrm{BC}$, and c) $29 \mathrm{BC}$ GDLs during limiting current operation with cathode gas containing an oxygen mole fraction of 0.10 prior to humidification to $80 \%$ cathode inlet relative humidity. Asterisks indicate locations of high porosity where liquid water tended to accumulate preferentially. 87

Figure 5-8: Through-plane distributions of solid, water, and effective pore (void) volume fractions in the SGL a) $25 \mathrm{BC}$, and b) $29 \mathrm{BC}$ GDLs during limiting current operation with cathode gas containing an oxygen mole fraction of 0.10 and no cathode humidification $(0 \% \mathrm{RH})$. The asterisk indicates a location of high porosity in SGL 29 BC where liquid water tended to accumulate preferentially. 89 
Figure 5-9: Extraction of pressure-independent component of transport resistance: total transport resistance versus absolute pressure. The extrapolated intercepts at zero pressure represents an estimate of the contribution of the catalyst layer to the total transport resistance. Experiments conducted using SGL $29 \mathrm{BC}$ with a dry inlet $\mathrm{O}_{2}$ mole fraction of 0.01 . Intercept values are

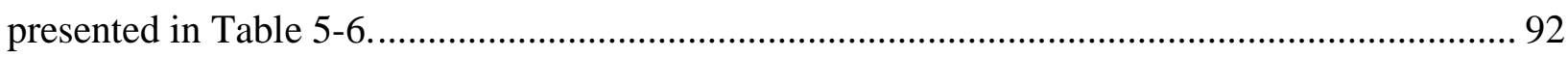

Figure 5-10: $R_{C F}$ plotted as a function of carbon fiber region effective pore fraction for a) SGL 25 BC, b) SGL 29 BC, and c) SGL 25 BA. Differing RH levels in the cathode inlet gas are indicated by symbol shape and colour. Existing correlations in literature for the relationship of transport resistance to carbon fiber void fraction are included for each GDL. An X-ray beam abnormality was experienced during the synchrotron X-ray radiography measurement for the test with a 0.21 inlet oxygen mole fraction and $100 \% \mathrm{RH}$ at the cathode. A discussion of this event can be found in the Appendix. 94 


\begin{tabular}{|c|c|}
\hline \multicolumn{2}{|c|}{ Technical abbreviations: } \\
\hline PEM & Polymer electrolyte membrane \\
\hline DC & Direct current \\
\hline HOR & Hydrogen oxidation reaction \\
\hline ORR & Oxygen reduction reaction \\
\hline GDL & Gas diffusion layer \\
\hline MPL & Microporous layer \\
\hline $\mathrm{CL}$ & Catalyst layer \\
\hline TPB & Triple-phase boundary \\
\hline MEA & Membrane-electrode assembly \\
\hline $\mathrm{CCM}$ & Catalyst-coated membrane \\
\hline BPP & Bi-polar plate \\
\hline PTFE & Polytetrafluoroethylene \\
\hline SR & Stoichiometric ratio \\
\hline $\mathrm{RH}$ & Relative humidity \\
\hline EIS & Electrochemical impedance spectroscopy \\
\hline$\mu \mathrm{CT}$ & Micro-computed tomography \\
\hline PEN & Polyethylene napthalate \\
\hline $\mathrm{CCD}$ & Charge-coupled device \\
\hline $\mathrm{OCV}$ & Open circuit voltage \\
\hline $1-\mathrm{D}, 2-\mathrm{D}, 3-\mathrm{D}$ & One-dimensional, two-dimensional, three-dimensional \\
\hline slpm & Standard litre per minute \\
\hline fps & Frames per second \\
\hline
\end{tabular}




\section{Chemical Abbreviations:}

$\begin{array}{ll}\mathrm{CO}_{2} & \text { Carbon dioxide } \\ \mathrm{H}_{2} & \text { Hydrogen gas } \\ \mathrm{H}^{+} & \text {Hydrogen ion (proton) } \\ \mathrm{e}^{-} & \text {Electron } \\ \mathrm{O}_{2} & \text { Oxygen gas } \\ \mathrm{H}_{2} \mathrm{O} & \text { Water } \\ \mathrm{N}_{2} & \text { Nitrogen gas } \\ \mathrm{R}_{-} \mathrm{SO}_{3}^{-} & \text {Sulfonate ion (aqueous sulfonic acid) } \\ \mathrm{He}^{-} & \text {Helium } \\ \mathrm{Ne}_{\mathrm{Ar}} & \text { Neon } \\ \mathrm{Kr} & \text { Argon } \\ \mathrm{CF}_{4} & \text { Krypton } \\ \mathrm{SF}_{6} & \text { Tetrafluoromethane } \\ \end{array}$




\section{Nomenclature}

\section{Variables}

$a$

$b$

Aactive

$c_{O_{2}}$

$c_{C H}$

$D^{e f f}$

$D_{C F}^{e f f}$

$D_{M P L}^{e f f}$

$D_{A B}$

$D_{\text {bulk }}$

E

$E_{\text {ideal }}$

$f$

F

$\Delta G$

$h_{C F}$

$h_{M P L}$

$i$

$i_{L}$

I
Channel half-width [cm] (calculation of shape factor, Chapter 5)

Land half-width [cm] (calculation of shape factor, Chapter 5)

Fuel cell active area $\left[\mathrm{cm}^{-2}\right]$

Oxygen concentration $\left[\mathrm{mol} \cdot \mathrm{cm}^{-3}\right]$

Reactant concentration in the gas channel $\left[\mathrm{mol} \cdot \mathrm{cm}^{-3}\right]$

Effective diffusion coefficient $\left[\mathrm{cm}^{2} \cdot \mathrm{s}^{-1}\right]$

Effective diffusion coefficient of the carbon fiber substrate $\left[\mathrm{cm}^{2} \cdot \mathrm{s}^{-1}\right]$ (Chapter 5)

Effective diffusion coefficient of the MPL $\left[\mathrm{cm}^{2} \cdot \mathrm{s}^{-1}\right]($ Chapter 5)

Binary diffusion coefficient for gas molecule A in gas molecule B $\left[\mathrm{cm}^{2} \cdot \mathrm{s}^{-1}\right]$

Diffusion coefficient of oxygen in the bulk cathode gas mixture of $\mathrm{O}_{2}, \mathrm{~N}_{2}$, and $\mathrm{H}_{2} \mathrm{O}\left[\mathrm{cm}^{2} \cdot \mathrm{s}^{-1}\right]$

Cell potential [V]

Theoretical ideal cell potential [V]

Substrate thickness shape factor (Chapter 5)

Faraday's constant. $F=96485\left[\mathrm{C} \cdot \mathrm{mol}_{\mathrm{e}}^{-1}\right]$

Gibbs free energy change of reaction $\left[\mathrm{J} \cdot \mathrm{mol}^{-1}\right]$

Through-plane thickness of the carbon fiber substrate [cm] (Chapter 5)

Through-plane thickness of the MPL [cm] (Chapter 5)

Current density $\left[\mathrm{A} \cdot \mathrm{cm}^{-2}\right]$

Limiting current density $\left[A \cdot \mathrm{cm}^{-2}\right]$

Current $[\mathrm{A}]$ 


\begin{tabular}{|c|c|}
\hline$I_{i}$ & Incident radiant intensity $\left[\mathrm{W} \cdot \mathrm{m}^{-2}\right]$ \\
\hline$I_{t}$ & Transmitted radiant intensity $\left[\mathrm{W} \cdot \mathrm{m}^{-2}\right]$ \\
\hline$I_{d r y}$ & Pixel intensity in the dry reference state image \\
\hline$I_{\text {wet }}$ & $\begin{array}{l}\text { Pixel intensity in the measured wet-state image (during fuel cell } \\
\text { operation) }\end{array}$ \\
\hline$L_{z}$ & Length of the GDL in the z-direction (parallel to X-ray beam path) $[\mathrm{cm}]$ \\
\hline$M_{A}$ & Molecular weight of molecule A (Chapman-Enskog Theory, Chapter 5) \\
\hline$n$ & $\begin{array}{l}\text { Number of moles of electrons exchanged in the fuel cell reaction } \\
{\left[\mathrm{mol}_{\mathrm{e}^{-}} \cdot \mathrm{mol}_{\mathrm{j}}^{-1}\right]}\end{array}$ \\
\hline$N_{t}$ & Number of consecutive frames averaged in X-ray radiography \\
\hline$N_{x}$ & $\begin{array}{l}\text { Number of through-plane pixels spanning through-plane thickness of } \\
\text { GDL }\end{array}$ \\
\hline$N_{y}$ & $\begin{array}{l}\text { Number of in-plane pixels spanning in-plane width of the GDL } \\
\text { perpendicular to channels }\end{array}$ \\
\hline$\dot{N}_{j}$ & Molar production or consumption rate of molecule $j\left[\mathrm{~mol}_{\mathrm{j}} \cdot \mathrm{s}^{-1}\right]$ \\
\hline$p$ & Operating pressure $[\mathrm{kPa}]$ \\
\hline$p_{w}$ & Water vapour pressure $[\mathrm{kPa}]$ \\
\hline$R_{C H}$ & $\begin{array}{l}\text { Gas channel component of oxygen transport resistance }\left[\mathrm{s} \cdot \mathrm{cm}^{-1}\right] \\
\text { (Chapter 5) }\end{array}$ \\
\hline$R_{C F}$ & $\begin{array}{l}\text { Carbon fiber substrate component of GDL oxygen transport resistance } \\
{\left[\mathrm{s} \cdot \mathrm{cm}^{-1}\right](\text { Chapter 5) }}\end{array}$ \\
\hline$R_{C L}$ & $\begin{array}{l}\text { Catalyst layer component of oxygen transport resistance }\left[\mathrm{s} \cdot \mathrm{cm}^{-1}\right] \\
(\text { Chapter 5) }\end{array}$ \\
\hline$R_{G D L}$ & GDL component of oxygen transport resistance $\left[\mathrm{s} \cdot \mathrm{cm}^{-1}\right]($ Chapter 5) \\
\hline$R_{M P L}$ & $\begin{array}{l}\text { MPL component of GDL oxygen transport resistance }\left[\mathrm{s} \cdot \mathrm{cm}^{-1}\right](\text { Chapter } \\
\text { 5) }\end{array}$ \\
\hline$R_{P I}$ & $\begin{array}{l}\text { Pressure-independent component of oxygen transport resistance } \\
{\left[\mathrm{s} \cdot \mathrm{cm}^{-1}\right](\text { Chapter } 5)}\end{array}$ \\
\hline
\end{tabular}




$\begin{array}{ll}R_{T} & \text { Total oxygen transport resistance }\left[\mathrm{s} \cdot \mathrm{cm}^{-1}\right] \\ \boldsymbol{R} & \text { Universal gas constant. } R=8314\left[\mathrm{kPa} \cdot \mathrm{cm}^{3} \cdot \mathrm{mol}^{-1} \cdot \mathrm{K}^{-1}\right] \\ s & \text { Liquid water saturation } \\ t & \text { Thickness [cm] } \\ t_{w} & \text { Liquid water thickness [cm] } \\ \overline{t_{w}} & \text { Normalized liquid water thickness } \\ T & \text { Operating temperature [K] } \\ v_{j} & \text { Stoichiometric coefficient of molecule } j \text { in balanced reaction equation } \\ x_{O_{2}}^{d r y-i n} & \text { Inlet oxygen mole fraction, prior to humidification }\end{array}$




\section{Greek characters:}

\begin{tabular}{|c|c|}
\hline$\alpha_{M P L}$ & MPL effective diffusivity (chapter 5) \\
\hline$\beta$ & $\begin{array}{l}\text { Ratio of land width to channel width (calculation of shape factor, Chapter } \\
\text { 5) }\end{array}$ \\
\hline$\varepsilon$ & Porosity \\
\hline$\varepsilon_{e f f}$ & Effective pore fraction \\
\hline$\varepsilon_{A B}$ & $\begin{array}{l}\text { Lennard-Jones parameter for potential-well depth }\left[J^{-1}\right] \text { (Chapman- } \\
\text { Enskog Theory, Chapter 5) }\end{array}$ \\
\hline$\eta_{\text {act }}$ & Activation overpotential [V] \\
\hline$\eta_{\text {conc }}$ & Concentration overpotential [V] \\
\hline$\eta_{\text {ohmic }}$ & Ohmic overpotential [V] \\
\hline$\kappa$ & Boltzmann constant (Chapman-Enskog Theory, Chapter 5) \\
\hline$\lambda$ & $\begin{array}{l}\text { Dimensionless anisotropy of effective diffusion coefficient (calculation of } \\
\text { shape factor, Chapter 5) }\end{array}$ \\
\hline$\mu$ & Attenuation coefficient $\left[\mathrm{cm}^{-1}\right]$ \\
\hline$\mu_{w}$ & Attenuation coefficient of liquid water $\left[\mathrm{cm}^{-1}\right]$ \\
\hline$\sigma_{A B}$ & $\begin{array}{l}\text { Lennard-Jones parameter for inter-particle distance }[\AA] \text { (Chapman-Enskog } \\
\text { Theory, Chapter 5) }\end{array}$ \\
\hline$\tau$ & Optical depth \\
\hline$\Omega_{D, A B}$ & Dimensionless collision integral (Chapman-Enskog Theory, Chapter 5) \\
\hline
\end{tabular}




\section{Chapter 1 Introduction}

\subsection{Preamble}

Renewable energy technologies are a critical endeavour in the pursuit of sustainable development. In the foreseeable future, fossil fuel dependence should decline, and climate change concerns will increase in severity. These forces will necessitate a drastic increase in the scale of the world's utilization of renewable energy resources. Recognizing the importance of this movement, I have conducted research at the Thermofluids for Energy and Advanced Materials (TEAM) laboratory at the University of Toronto that will contribute to the eventual technical viability and profitability of hydrogen fuel cells. Hydrogen fuel cells have the potential for extensive implementation in transportation and small scale heating and power generation applications. They are attractive because they do not produce $\mathrm{CO}_{2}$ at the point of operation. In particular, I am investigating polymer electrolyte membrane (PEM) fuel cells, which are a class of fuel cells that is commonly considered as a viable alternative to the internal combustion engine for automotive applications [1].

This chapter outlines the fundamental mechanism of electrochemical energy conversion in PEM fuel cells. The general goals of fuel cell research, which aim to make PEM fuel cells reliable and cost-competitive against internal combustion engines, are described in this chapter along with the specific objectives of the research presented in this thesis. The research contributions from my Masters research are also listed. Finally, section 1.7 of this chapter outlines the organization of this thesis. 


\subsection{Electrochemical energy conversion in PEM fuel cells}

PEM fuel cells are energy conversion devices that produce direct current (DC) electricity through the electrochemical oxidation of hydrogen and reduction of oxygen. The half-cell chemical reactions involved are as follows.

$$
\begin{gathered}
\mathrm{H}_{2} \rightarrow 2 \mathrm{H}^{+}+2 e^{-} \\
\frac{1}{2} \mathrm{O}_{2}+2 \mathrm{H}^{+}+2 e^{-} \rightarrow \mathrm{H}_{2} \mathrm{O}
\end{gathered}
$$

Equation (1.1) is the anode half-cell reaction and equation (1.2) is the cathode half-cell reaction. By isolating these two reactions, the chemical energy stored in hydrogen gas molecules can be converted into useful electrical work by transporting the produced electrons from the anode halfcell reaction (hydrogen oxidation reaction, or HOR) to the cathode via an external circuit. A schematic of a single PEM fuel cell is presented in Figure 1-1. As shown in the figure, the hydrogen ions (protons) produced at the anode conduct through an ionically conductive and electronically insulating electrolyte to reach the cathode. The hydrogen ions re-combine with the electrons and oxygen gas at the cathode to produce water. 


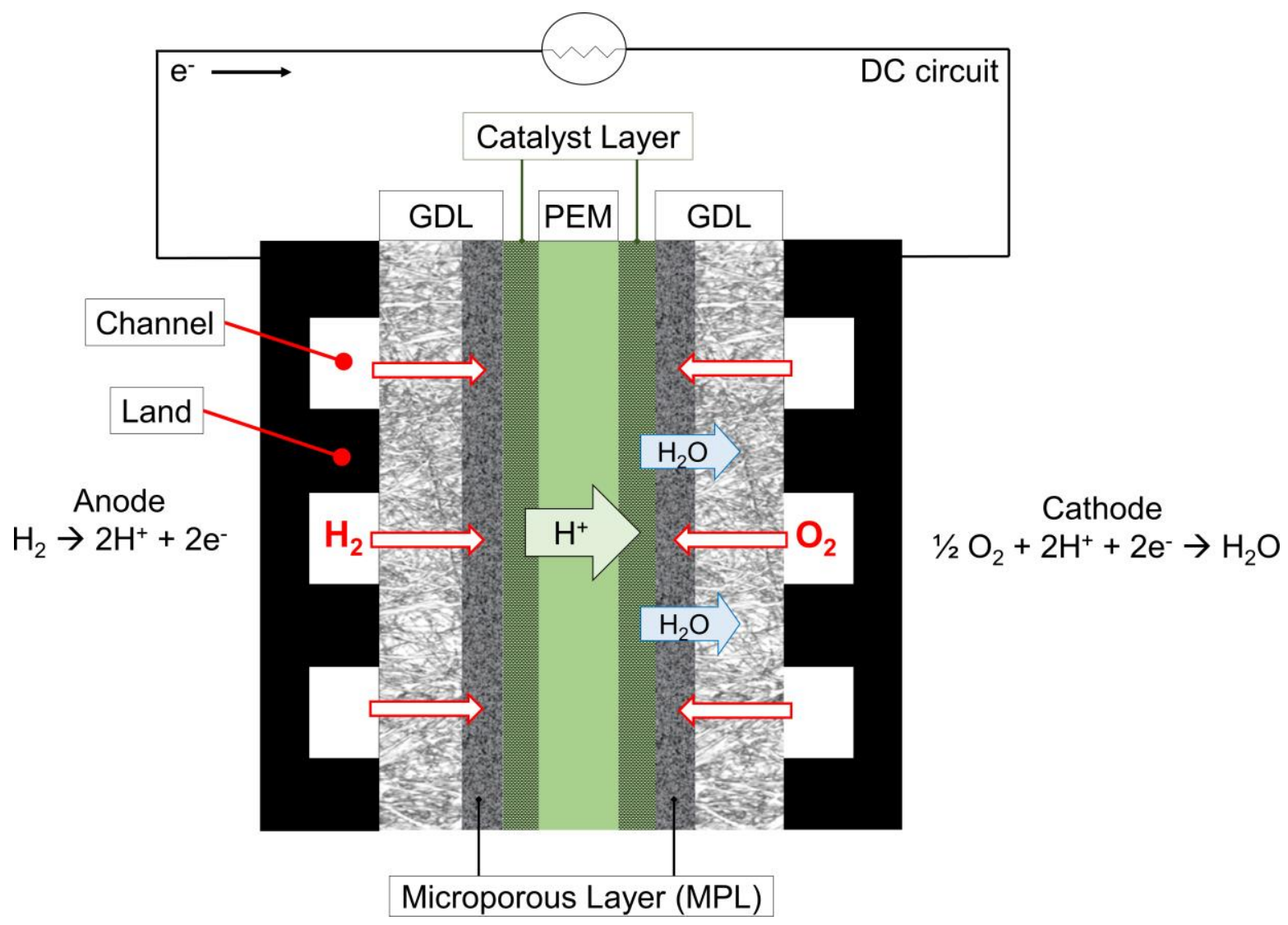

Figure 1-1: PEM fuel cell schematic

The cathode half-reaction is known as the oxygen reduction reaction, or ORR. The overall reaction is as follows:

$$
\mathrm{H}_{2}+\frac{1}{2} \mathrm{O}_{2} \rightarrow \mathrm{H}_{2} \mathrm{O}+\mathrm{Heat}
$$

This energy conversion process does not produce any local carbon emissions; heat and water are the only by-products at the point of use. If the hydrogen fuel is produced by renewable energy sources, this technology presents a viable pathway to reduce carbon emissions from transportation, industrial, and small-scale stationary power generation applications. In particular, PEM fuel cells are being considered as a promising alternative to internal combustion engines for automobiles. 
As Figure 1-1 demonstrates, PEM fuel cells employ a solid polymer membrane as the electrolyte, usually composed of Nafion. The Nafion membrane is coated on either side with a catalyst layer (CL), which is typically composed of platinum particles suspended in an ionomer-carbon dispersion. However, for an electrode reaction to proceed, the reactant gas molecules must interact with a catalyst particle at a triple-phase boundary (TPB), defined as a location where the electronically conductive carbon phase, the ionically conductive Nafion ionomer phase, and the gas (pore) phase are all adjacent or in close proximity [2].

Together, the PEM and catalyst layers are often referred to as the membrane-electrode assembly (MEA) or the catalyst-coated membrane (CCM). The MEA is supported on either side by a porous backing layer known as the gas diffusion layer (GDL). The MEA and GDLs are compressed between electronically-conductive bi-polar plates (BPPs). Flow channels are machined into the bipolar plates to allow the delivery of hydrogen and air to the anode and cathode sides of the fuel cell, respectively. The spaces of the BPPs which contact the GDLs between the gas flow channels are typically referred to as the field lands or as the flow field ribs. In this thesis, the regions of the GDL adjacent to the lands are referred to as the GDL land regions and the regions of the GDL adjacent to the flow field channels are referred to as the GDL channel regions.

Of these components, the GDL was the primary focus of the research conducted in this thesis. The GDL serves several essential functions to ensure the efficient operation of the PEM fuel cell. The GDLs provide pathways for reactant gases to be transported from the gas channels to the catalyst, and for electrochemically produced water to be transported from the cathode catalyst layer to the gas channels, where it exits the fuel cell. In addition, the GDLs must be electronically conductive, 
so as to allow electron transport from the external circuit (via the BPPs) to the electrodes. The GDLs also conduct heat from the electrodes to the BPPs. Finally the GDL provides structural support to the MEA. State-of-the-art GDLs employed in PEM fuel cells have a bi-layered structure composed of a carbon fiber substrate and a microporous layer (MPL) [3,4]. A carbon-based binder material is used to hold the randomly oriented carbon fibers of the substrate together. The substrate is generally treated with polytetrafluoroethylene (PTFE) to impart hydrophobicity to the fiber surfaces, discouraging liquid water condensation and accumulation. The MPL has become a common addition to modern GDLs due to its desirable effects on CL-GDL contact, membrane hydration and liquid water management [5-10]. Generally, the MPL is composed of carbon black nanoparticles and PTFE, and has pore sizes in the range of 10-100 nm. The MPL is applied either as a coating or a thin standalone sheet on the side of the GDL substrate that interfaces with the catalyst layer.

The rates of hydrogen consumption, oxygen consumption, and liquid water production are directly proportional to the rate that electrical current is produced by the fuel cell, according to Faraday's Law of electrolysis, given by the following equation:

$$
\dot{N}_{j}=\frac{v_{j} \cdot i \cdot A_{\text {active }}}{n \cdot F}
$$

Where the index $j$ indicates a particular reactant or product molecule, $\dot{N}_{j}\left[\mathrm{~mol}_{\mathrm{j}} \cdot \mathrm{s}^{-1}\right]$ is the molar consumption rate of a reactant molecule or the molar production rate of a product molecule, and $v_{j}$ is number of moles of molecule $j$ consumed or produced in the balanced reaction equation. The value $n\left[\mathrm{~mol}_{\mathrm{e}^{-}} \cdot \mathrm{mol}_{\mathrm{j}}^{-1}\right]$ is the number of moles of electrons exchanged in the reaction. For 
example, to calculate the rate of hydrogen consumption in the hydrogen fuel cell reaction described in Equations (1.1) to (1.3), a value of 1 would be used for $v_{j}$ and a value of $2 \mathrm{~mol}_{\mathrm{e}^{-}} \cdot \mathrm{mol}_{\mathrm{H}_{2}}^{-1}$ would be used for $n$. The quantity $i$ is the current density $\left[\mathrm{A} \cdot \mathrm{cm}^{-2}\right]$. The surface area of the electrode is denoted as $A_{\text {active }}\left[\mathrm{cm}^{2}\right]$, and is also known as the active area of the fuel cell. The value $F[\mathrm{C}$. $\operatorname{mol}_{\mathrm{e}^{-1}}^{-1}$ is Faraday's constant.

Generally, more reactant gas is supplied to the fuel cell than what is stoichiometrically required in order to ensure sufficient reactant coverage over the entire active area and to help clear product water from the cathode gas channels. The leftover hydrogen and air exit the cell with the exhaust. The stoichiometric ratio for a particular electrode, SR, is defined as the ratio of the rate of reactant supply to the rate of reactant consumption.

$$
S R=\frac{\dot{N}_{\text {supplied }}}{\dot{N}_{\text {consumed }}}
$$

\subsection{Motivation}

In order to displace internal combustion engines as a low-carbon alternative in the automotive transportation market, there are key improvements which must be made in PEM fuel cell systems. Generally speaking, PEM fuel cell researchers are focused on the following goals:

1. To reduce the total cost of PEM fuel cell systems

2. To improve the long-term durability of fuel cell systems

3. To improve energy conversion efficiency and operating power density 
The total cost is restricted by the requirement of platinum in the catalyst layer and by the manufacturing cost of the fuel cell's bipolar plates. In a fuel cell system, several fuel cells could be connected in series or in parallel, known as a stack. The cost of a stack could therefore be reduced by decreasing the number of cells within the unit. However, a higher current density would be required in each cell to achieve the same output power. Ensuring stable and efficient fuel cell performance at high current density requires the effective management of fuel cell mass transport phenomena; in particular, the delivery of oxygen gas and the removal of product water through the cathode gas diffusion layer.

Another means of reducing total stack cost is through the improvement or removal of balance-ofplant components such as humidifiers [11]. Reactant gases are often humidified in order to maintain adequate hydrate of the Nafion membrane. However, it is possible to operate the fuel cell at low or zero relative humidity $(\mathrm{RH})$ conditions. Investigating this means of cost reduction requires a thorough study of the mass-transport management implications of fuel cell operation at a wide range of relative humidity conditions.

\subsection{Objectives}

The primary objective of the research in this thesis is improve our understanding oxygen and water mass transport phenomena in PEM fuel cells. In particular, through a combination of electrochemical performance measurements and visualizations of liquid water, I have sought to develop a comprehensive study of the effects of cathode $\mathrm{RH}$ and operating current density as factors which affect the accumulation (i.e. ineffective removal) of liquid water in the fuel cell. I also intend, though this research, to quantify the effect of the liquid water saturation distribution 
in the cathode GDL to the oxygen transport resistance. In doing so, this work will enable future researchers to better predict the mass transport-related efficiency losses of PEM fuel cells.

\subsection{Contributions}

The research presented in this thesis has led to the following first-authored contributions:

1. Muirhead, D., Banerjee, R., Lee, J., George, M.G., Ge, N., Liu, H., Chevalier, S., Hinebaugh, J., Han, K., Bazylak, A. "Simultaneous characterization of oxygen transport resistance and spatially resolved liquid water saturation at high-current density of polymer electrolyte membrane fuel cells with varied cathode relative humidity." International Journal of Hydrogen Energy, Submitted July 252017.

2. Muirhead, D., Banerjee, R., George, M.G., Ge, N., Lee, J., Liu, H., Shrestha, P., Bazylak, A. "Oxygen transport resistance and spatially resolved liquid water accumulation in a PEM fuel cell cathode GDL under wide ranges of current density and cathode inlet humidification." Under Internal Review.

Contribution 1 was completed with insight and collaboration from co-author K. Han, Fuel Cell Vehicle Team 1, Fuel Cell Engineering Design Team, Research and Development Division, Hyundai Motor Company, Korea.

A subset of the study performed for contribution 2 was presented at the $7^{\text {th }}$ International Conference on Fundamentals and Development of Fuel Cells (FDFC) in Stuttgart, Germany in February 2017. 


\subsection{Co-authorship}

In addition to the first-authored manuscripts arising from the work in this thesis, I have co-authored 10 manuscripts with members of the Thermofluids for Energy and Advanced Materials Lab, of which eight are published in peer-reviewed journals and two are under internal review. Many experimental studies performed in Professor Bazylak's research group involve synchrotron X-raybased imaging techniques. Conducting these experiments involves extensive planning and a coordinated team effort, involving many members of Professor Bazylak's team. For the works listed below, I contributed as an experimental lead for electrochemical performance characterizations and X-ray radiographic imaging at the Canadian Light Source synchrotron. In addition, the limiting current experimental methodology developed for this thesis was an integral component of study 4 .

1. Chevalier, S., Ge, N., Lee, J., Banerjee, R., Liu, H., George, M.G., Shrestha, P., Muirhead, D., Hinebaugh, J., Tabuchi, Y., Kotaka, T., Bazylak, A. (2017) "Synchrotron X-ray radiography as a highly precise and accurate method for measuring the spatial distribution of liquid water in operating PEM fuel cells". Journal of the Electrochemical Society, 164(2), F107-F114.

2. Banerjee, R., Ge, N., Lee, J., George, M.G., Chevalier, S., Liu, H., Shrestha, P., Muirhead, D., Bazylak, A. (2017) "Transient liquid water distributions in polymer electrolyte membrane fuel cell gas diffusion layers observed through in-operando synchrotron X-ray radiography" Journal of the Electrochemical Society, 164(2), F154-F162. 
3. Chevalier, S., Ge, N., Lee, J., George, M.G., Liu, H., Shrestha, P., Muirhead, D., Lavielle, N., Hatton, B.D., Bazylak, A. (2017) "Novel electrospun gas diffusion layers for polymer electrolyte membrane fuel cells: II. In operando synchrotron imaging for microscale liquid water transport characterization.” Journal of Power Sources, 352, 281-290.

4. Liu, H., George, M.G., Banerjee, R., Ge, N., Lee, J., Muirhead, D., Shrestha, P., Chevalier, S., Hinebaugh, J., Zeis, R., Messerschmidt, M., Scholta, J., Bazylak, A. (2017) “Accelerated Degradation of Polymer Electrolyte Membrane Fuel Cell Gas Diffusion Layers: Part 2 - Steady State Liquid Water Distributions with in Operando Synchrotron X-ray Radiography.” Journal of the Electrochemical Society, 164(7), F704-F713.

5. George, M.G., Liu, H., Muirhead, D., Banerjee, R., Ge., N., Shrestha, P., Lee, J., Chevalier, S., Hinebaugh, J., Messerschmidt, M., Zeis, R., Scholta, J., Bazylak, A. (2017) “Accelerated Degradation of Polymer Electrolyte Membrane Fuel Cell Gas Diffusion Layers Part 3: Mass Transport Resistance and Liquid Water Accumulation at Limiting Current Density with in operando Synchrotron X-ray Radiography.” Journal of the Electrochemical Society, 164(7), F714-F721.

6. Ge, N., George, M.G., Lee, J., Muirhead, D., Chevalier, S., Banerjee, R., Liu, H., Wysokinski, T.W., Belev, G., Webb, M.A., Zhu, N., Bazylak, A. (2017) “Considering Photon Scattering and Harmonics for Synchrotron X-ray Radiographic Imaging of Polymer Electrolyte Membrane Fuel Cells." Focus Issue: Mathematical Modeling of Electrochemical Systems at Multiple Scales. Journal of the Electrochemical Society, 164(11), E3215-E3224. 
7. Lee, J., Banerjee, R., George, M.G., Muirhead, D., Shrestha, P., Liu, H., Ge, N., Chevalier, S., Bazylak, A. (2017) "Multiwall carbon nanotube-based microporous layers for polymer electrolyte membrane fuel cells." Journal of the Electrochemical Society. 164(12), F1149F1157.

\subsection{Organization of Thesis}

This thesis is divided into six chapters. This chapter included a brief introduction to PEM fuel cell technology and presented the motivation and objectives which guided the research contributions presented in this thesis. Chapter 2 presents a literature review focused on liquid water saturation and oxygen transport in the cathode GDL of a PEM fuel cell. Chapter 3 describes the experimental techniques used to develop the research contributions in this thesis. This includes a description of the experimental fuel cell and testing apparatus, an explanation of the synchrotron X-ray radiography methodology used to quantify GDL liquid water accumulation, and a brief explanation of the micro-computed tomography methodology used to characterize GDL porosity. In addition, Chapter 3 contains an explanation of the limiting current measurement technique used to quantify oxygen transport resistance with controlled relative humidity and inlet oxygen mole fraction.

Chapters 4 and 5 contain the findings of the two main studies that were performed. These studies aimed to provide novel insights into water accumulation and oxygen transport phenomena in PEM fuel cell cathode GDLs. Chapter 4 presents a study of the effects of relative humidity on liquid water saturation and oxygen transport at high operating current-densities. This work identified a sensitivity of channel water accumulation to inlet relative humidity in high current density 
operation. Chapter 5 expands upon the research conducted in chapter 4 by thoroughly investigating electrochemical water production rate, cathode inlet RH, and GDL through-plane porosity profile as factors controlling GDL liquid water saturation and oxygen transport resistance. Chapter 6 provides a summary of the research contributions presented in this thesis and suggests future work to expand upon these findings. 


\section{Chapter 2 Background and Literature Review}

\subsection{Introduction}

This chapter contains the necessary background and literature review to provide context for the research presented in chapters 4 and 5. A background is presented on polymer electrolyte membrane (PEM) fuel cell transport phenomena, with particular focus on the delivery of oxygen gas to the reaction sites and the removal of product water from the fuel cell. The oxygen transport resistances posed by the fuel cell layers are discussed, and the implications of liquid water management on oxygen transport and the research gaps therein are presented.

\subsection{PEM fuel cell efficiency losses}

The performance of a fuel cell is typically described with a polarization curve, which depicts cell potential, $E[\mathrm{~V}]$ plotted as a function of current, $I[\mathrm{~A}]$, or current density, $i\left[\mathrm{~A} \cdot \mathrm{cm}^{-2}\right]$. The current density is defined as the current divided by the active area, $A_{\text {active }}\left[\mathrm{cm}^{2}\right]$. The maximum theoretical cell potential of the electrochemical conversion of hydrogen and oxygen to water is determined from the change in the Gibbs free energy of the fuel cell reaction:

$$
E_{\text {ideal }}=-\frac{\Delta G}{n F}
$$

Where $\Delta G\left[\mathrm{~J} \cdot \mathrm{mol}^{-1}\right]$ is the reaction Gibbs free energy change and $n\left[\mathrm{~mol} \cdot \mathrm{mol}_{\mathrm{e}}^{-1}\right]$ is the stoichiometric coefficient of the electron term in the balanced fuel cell reaction equation, which is 2 for the hydrogen fuel cell reaction in Equation (1.3).

Real fuel cells do not achieve the ideal cell potential during operation, as there are several sources of inefficiency which create voltage losses, known as overpotentials. Generally speaking, as the 
current density increases, the overpotential increases as well, thereby causing a decrease in cell potential. At lower cell potentials, a greater proportion of the chemical energy within the fuel is lost rather than being converted to electrical work. The three overpotentials typically used to describe PEM fuel cell efficiency losses are described as follows, and are depicted in the polarization curve illustration of Figure 2-1:

- Activation overpotential, $\eta_{a c t}[\mathrm{~V}]$ : When the fuel cell is producing current, some energy is required to overcome the reaction activation energy barrier, resulting in a reduction of cell potential. As current density is increased from zero, $\eta_{\text {act }}$ increases quickly at first, then ceases to increase significantly once the excess heat produced by the reaction is sufficient to overcome the activation barrier. An activation overpotential is also created by any crossover of reactants through the polymer membrane, as this causes the overall reaction (Equation 1.3) to take place locally at a single electrode. This can occur even in open circuit conditions, when current is not produced by the fuel cell. In a well-assembled PEM fuel cell with adequate gaskets and absence of electrolyte damage, the reactant cross-over rate should be small, and the open-circuit cell potential should be nearly equal to the ideal potential.

- Ohmic overpotential, $\eta_{\text {ohmic }}[\mathrm{V}]$ : The resistance to the flow of electrons and hydrogen ions within the electronically and ionically conductive components of the fuel cell and external circuit causes the Ohmic overpotential. This overpotential is commonly determined from Ohm's Law, which states that the overpotential is directly proportional to the operating current density; therefore the polarization curve (Figure 2-1) has a linear region in the center of the operating range. 
- Concentration overpotential, $\eta_{\text {conc }}[\mathrm{V}]$ : As current density increases, the reactant concentration gradient between the gas flow field and the catalyst becomes steeper. The concentration overpotential is incurred when the reactant concentrations at the reaction sites approach zero (starvation). Even if the rate of supplied reactants are sufficient to satisfy the reaction stoichiometry, low local concentrations impact reaction kinetics and the equilibrium state of the reaction, resulting in additional voltage losses. Reactant starvation is caused by mass-transport resistance in the gas flow field, GDLs, and catalyst layer. The current density at which the surface reactant concentration reaches zero is known as the limiting current density, $i_{L}\left[\mathrm{~A} \cdot \mathrm{cm}^{-2}\right]$. The cell potential also approaches zero at $i_{L}$.

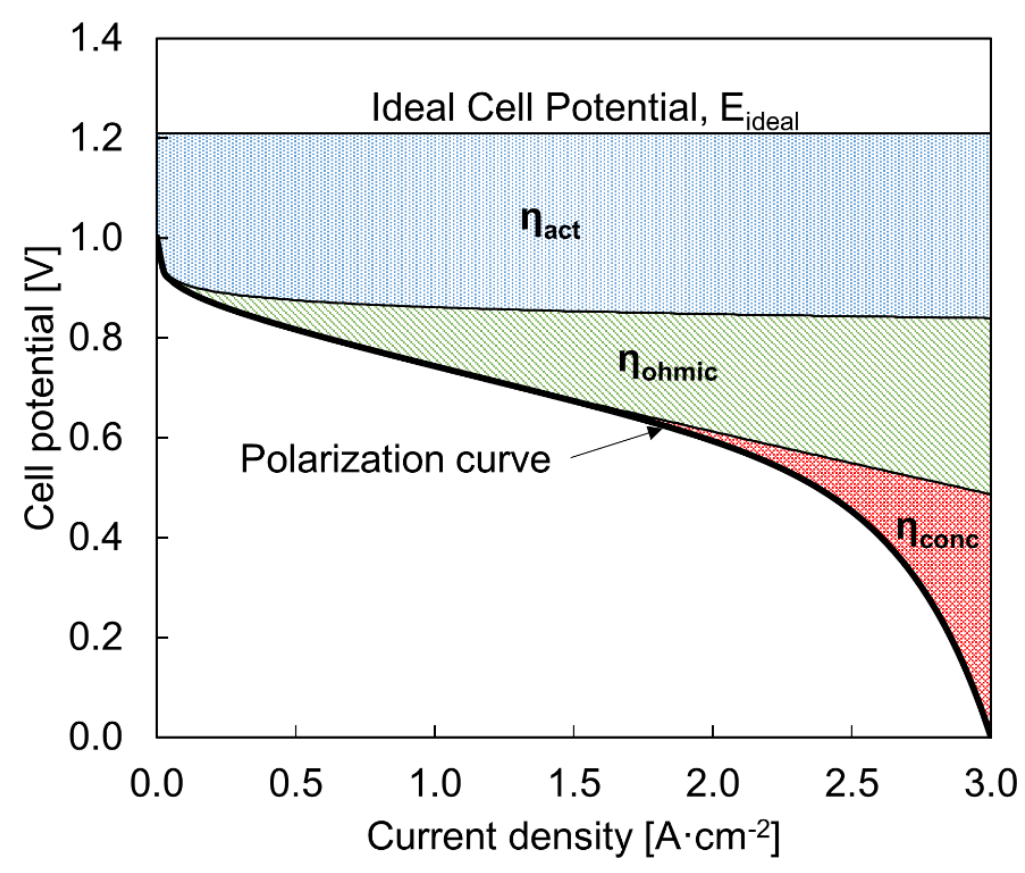

Figure 2-1: Illustration of a fuel cell polarization curve and the various fuel cell overpotentials which cause efficiency losses. 
The focus of this thesis is the right-hand side of Figure 2-1, where significant fuel cell efficiency losses are caused by mass transport phenomena. In particular, this research focuses on the resistance that the cathode GDL poses to the diffusive transport of oxygen.

\subsection{PEM fuel cell water management}

The Nafion polymer structure consists of a polytetrafluoroethylene (PTFE) backbone with perfluorovinyl ether sub-chains terminated by sulfonic acid $\left(\mathrm{R}_{-} \mathrm{SO}_{3}{ }^{-}\right)$groups [12]. Hydration of the Nafion tends to increase the internal pressure, dilating the pore structure and enhancing pore connectivity. In addition, water molecules can dissociate at the sulfonic acid groups in the Nafion polymer chain, which increases the number of available protons to transfer through the membrane's pore structure [13-16]. Due to these two mechanisms, water is essential to enables proton conductivity within the membrane.

The membrane can be hydrated by two sources: humidified reactant gases and electrochemical production of water. If there is an excess of gaseous water, condensation can occur, leading to liquid water accumulation within the gas diffusion layer and gas channels. This could lead to masstransport related efficiency losses because the liquid water impedes reactant transport pathways to their respective catalyst. As such, water management in a PEM fuel cell becomes a delicate balance between the competing natures of these phenomena. Sufficient amounts of water are needed to ensure adequate hydration of the ionomer membrane. However, excessive amounts of water lead to efficiency losses caused by reactant starvation. In this thesis, the primary focus is the efficiency loss related to reactant starvation. One of the main factors causing oxygen starvation in the cathode is the oxygen transport resistance in the GDL. Under high current-density operation, the GDL 
oxygen transport resistance is exacerbated by the filling of pore space with liquid water (saturation). Therefore, understanding and being able to predict reactant oxygen and product water transport in the cathode GDL is an important research endeavour.

\subsection{Reactant and product transport}

Management of mass transport is critical for maintaining high performance during operation at high current densities because large fluxes of products and reactants must be accommodated through the GDL. In particular, on the cathode side of the PEM fuel cell, oxygen molecules must be transported from the reactant flow channels, through the gas diffusion layer, to the reaction sites at the triple-phase boundaries in the catalyst layer. As the operating current density of the fuel cell increases, the concentration gradient between the gas channels and the catalyst increases, increasing the diffusive flux of oxygen gas. Additionally, the accumulation of electrochemically produced liquid water within the pore space of the GDL restricts transport pathways for reactant gases. Under high current-density operation, oxygen mass transport can become the performance limiting factor in the fuel cell $[17,18]$. It is therefore a worthy research goal to understand the factors that affect oxygen transport limitations, as this will inform the design of next-generation GDLs and flow fields to mitigate mass transport performance losses.

This section discusses the existing literature focused on water and oxygen transport in PEM fuel cells. In the discussion of water transport, examples in the literature are discussed wherein liquid water was visualized in situ, and the effect of reactant gas relative humidity is discussed as an important and industrially relevant factor which may control the liquid water saturation level of the GDL. In the discussion of oxygen transport, several works are discussed which sought to 
measure and dissect the various sources of oxygen transport resistance, including the gas channels, the carbon fiber substrate, the MPL, and the catalyst layer. Some literature has also been identified which establishes a very strong qualitative link between liquid water accumulation and oxygen transport resistance.

\subsubsection{Water transport and liquid water accumulation}

Water transport in the GDL is typically characterized via two mechanisms, liquid percolation and vapour diffusion. Liquid percolation is a capillary-force dominated process [19-21], wherein liquid water advances into a pore through a connecting throat, when the difference between the invading liquid pressure and the defending gas phase pressure exceeds the threshold capillary pressure of the throat. The GDL's liquid water saturation gradually increases until a breakthrough event occurs, which is defined as the moment when a connected water pathway through the thickness of the GDL is formed [22]. Once a connected breakthrough pathway is established, electrochemically produced liquid water can be transported through this pathway and leave the cell through the gas channels.

The electrochemically produced water can also be transported out of the fuel cell in the vapour form. Heat is produced at the CCM from the electrochemical reaction and due to the ohmic resistance of the ionomer and support material (e.g., carbon) [23]. The result is a temperature gradient between the CCM and the gas flow field. Since water's vapour pressure is temperaturedependent, this in turn creates a gradient in water vapour partial pressure which drives vapourphase diffusion of water [24]. 


\subsubsection{Visualizations of liquid water saturation}

In recent years, researchers have conducted studies which have visualized liquid water during fuel cell operation. A review by Bazylak [25] highlights these efforts. Optical visualizations of liquid water are possible in the gas flow channels if specialized, transparent fuel cell architectures are employed [26-28]. The utility of optical visualizations, however, are limited by the opacity of the gas diffusion media in the visible spectrum of light. GDL liquid water quantifications are therefore infeasible by this method, and studies of this nature focus only on water appearing in the channels or on the GDL surface. In addition, the customized transparent fuel cell designs required for in situ optical visualization of liquid water may not have equivalent electron and heat transfer properties to typical PEM fuel cells, which can compromise the comparability of the performance of these cells to state-of-the-art designs.

The two most widely adopted techniques to directly measure the GDL liquid water accumulation in operando are neutron imaging and synchrotron X-ray imaging [25,29]. These techniques are based on measurements of the attenuated intensity of a neutron or X-ray beam which is incident on the fuel cell. Neutron and X-ray techniques have the advantage that the incident neutron or photon beams can penetrate the metal, graphite, and polymer fuel cell components. Therefore, the accumulation of water can be identified inside the GDL based on the additional attenuation created by liquid water during fuel cell operation. Neutron radiography is highly sensitive to liquid water in PEM fuel cell studies due to the high attenuation caused by hydrogen-containing atoms. This technique has therefore been very useful in liquid water transport research [30-37]. Neutron-based PEM fuel cell studies are generally limited to spatial resolutions of $25 \mu \mathrm{m}$ at temporal resolutions 
of $5.4 \mathrm{~s}$ [25]. However, researchers have achieved spatial resolutions as small as $15.4 \mu \mathrm{m}$ with a temporal resolution of $54 \mathrm{~s}$ [30] and $2.5 \mu \mathrm{m}$ with a temporal resolution of 5 minutes using specialized detection systems [31].

An alternative to neutron imaging which has also been proven as an excellent tool for PEM fuel cell liquid water visualizations is synchrotron X-ray radiography. Synchrotron X-ray radiography offers high spatial and temporal resolutions (less than $10 \mu \mathrm{m}$ and less than $10 \mathrm{~s}$, respectively) [3857]. Though X-ray photons are not as sensitive as a neutron beam to the presence of liquid water, Chevalier et al [29] demonstrated that synchrotron X-ray radiography can achieve similar accuracy to neutron radiography with a high level of precision. Recent works have improved the accuracy and reliability of this technique for PEM fuel cell visualizations by establishing methodologies for correcting beam position movement artifacts [58], calibrating the attenuation coefficient of liquid water and correcting sample movement artifacts [44], and considering photon scattering and harmonics [59]. In addition, the fast temporal resolutions possible with synchrotron X-ray radiography allow for dynamic visualizations of transient liquid water behaviour $[60,61]$ and enable high-resolution in-situ tomography to resolve liquid water saturation in 3-D [48,52,62].

\subsubsection{Effect of reactant gas relative humidity $(R H)$}

Liquid water may accumulate in the GDL due to condensation at locations where the local temperature is below the dew point of the gas phase [63]. Therefore, the liquid water saturation distribution in the GDL is sensitive to the water vapour concentration distribution between the CLGDL interface and the flow-field channels. Some control can be imposed over this gradient by changing the relative humidity $(\mathrm{RH})$ of the inlet gases. Pore-network modeling studies by 
Hinebaugh et al [64], Straubhaar et al [65], and Gostick et al [19] have demonstrated that condensation rates can have a significant impact on GDL liquid water saturation. Boillat et al. [31] used neutron radiography to observe water accumulation in a PEMFC and reported that liquid water accumulation increased when the relative humidity of reactant gases increased. Chevalier et al. [66] measured liquid water accumulation using synchrotron X-ray radiography and reported the significant sensitivity of liquid water saturation to relative humidity. At an operating current density of $1.5 \mathrm{~A} \cdot \mathrm{cm}^{-2}$, Chevalier et al. [66] observed an increase in peak local liquid water saturation from $<5 \%$ to $86 \%$ when the cathode $\mathrm{RH}$ was varied from $25 \%$ to $100 \%$. In addition to the direct studies of GDL water mentioned above, numerous studies have studied PEM fuel cell liquid water accumulation in the channels via direct visualization or measurement of pressure drop [26-28,67-73]. In the studies by Banerjee et al [67], Hussaini and Wang [68] and Spernjak et al [27], increases in the inlet reactant gas RH were observed to increase the presence of liquid water in the channels.

The studies above established a qualitative link between cathode RH and liquid water accumulation, however only the studies by Chevalier et al [66] and Boillat et al [31] featured direct visualization of GDL liquid water. Neither of these two studies implemented a complete range of RH conditions ( $0 \%$ to $100 \%)$, and the specific impacts of cathode inlet RH were tangential to the main findings of these works. To further understand the relationship between oxygen transport resistance and the relative humidity of the reactant gas, the effects of a broad range of humidity conditions on the liquid water accumulation in the GDL must be established. 


\subsubsection{Cathode oxygen transport}

\subsubsection{Quantifying oxygen transport resistance}

The limiting current technique is an established methodology for directly measuring oxygen transport resistance. Several recent studies [74-78] have focused on measuring the individual transport resistance contributions of the fuel cell layers by performing limiting current measurements with varied pressures, GDL thicknesses, cathode balance gases (also known as oxygen "diluents"), and RH levels. Baker et al. [77] determined the relative contributions of the channels, GDL substrate, MPL, and catalyst layer to total transport resistance by manipulating GDL and MPL thicknesses and the operating pressure. Nonoyama et al. [75] and Oh et al. [78] both used the same method to separate the intermolecular diffusion and Knudsen diffusion components of the oxygen transport resistance. The authors compared their limiting current experiments using cathode gases containing dilute concentrations of oxygen in balance gases of both nitrogen and helium.

Oh et al. further isolated the contribution of dissolution and diffusion through an ionomer film in the catalyst layer by conducting limiting current experiments over a range of cathode RH levels. The isolation of these contributions were made possible by the dependence of oxygen diffusion coefficient of the solid ionomer on its hydration level. Oh et al. further separated the GDL transport resistance into contributions by the MPL and carbon fiber substrate by conducting the above experiments on fuel cells both with and without a microporous layer. In the study by Nonoyama et al. [75], the ionomer layer contribution to transport resistance was isolated by varying the cell temperature, since the impact of temperature on ionomer diffusion coefficient is much larger than the impact of temperature on molecular and Knudsen diffusion. Reshetenko et al. [76] also used a 
limiting current-based methodology to identify the catalyst layer ionomer diffusion contribution. In their study, a wide range of oxygen diluent gases were used: $\mathrm{He}, \mathrm{Ne}, \mathrm{N}_{2}, \mathrm{Ar}, \mathrm{CO}_{2}, \mathrm{Kr}, \mathrm{CF}_{4}, \mathrm{SF}_{6}$, and $\mathrm{C}_{3} \mathrm{~F}_{8}$. The ionomer diffusion component was found by extrapolating to a zero-diluent weight, since the diluent species only affects gas-phase diffusion.

\subsubsection{Effect of GDL liquid water accumulation}

Depending on the chosen experimental conditions and on the GDL materials and catalyst loadings, the GDL has been found to contribute between $32 \%$ and $61 \%$ of the total oxygen transport resistance in the fuel cell [75-78] in when there is no liquid water present. At low RH, the catalyst layer was generally the largest contributor to the oxygen transport resistance, owing to a decrease in oxygen diffusivity through the ionomer layer when the ionomer was poorly hydrated [78]. In references [75-78], however, the limiting current experiments were performed exclusively in low current-density conditions to avoid liquid water condensation in the GDL. Water accumulation in the cathode GDL of a PEM fuel cell reduces the available pore space for oxygen transport, thereby reducing the effective diffusivity of oxygen through the material $[33,79,80]$. Reduced oxygen diffusivities result in a steeper oxygen concentration gradient for a particular oxygen flux. As the demand for oxygen increases with increasing current density, an accumulation of liquid water will tend decrease the oxygen concentration at the cathode catalyst layer. The resulting concentration overpotential increase eventually limits fuel cell performance at high current densities due to the combination of a high demand for oxygen reactant and a high rate of water production. The oxygen transport within the GDL often becomes the performance-limiting factor in the PEM fuel cell at high operating current densities. As such, this topic is the primary focus of the research presented in this thesis. With an improved understanding of the water and oxygen transport mechanisms of 
the GDL, more accurate predictions of fuel cell efficiency losses will be possible. This will enable the design of tailored GDL materials with lower oxygen transport resistances at high current densities.

Caulk and Baker [81] studied the impacts of fuel cell operating pressure and temperature on the oxygen transport resistance over a range of current densities. They established that gas diffusion layers have a dry (minimum) oxygen transport resistance and a wet (maximum) transport resistance, both of which can be measured by performing limiting current density experiments at low and high cathode inlet oxygen concentrations, respectively. Simon et al. [82] observed that the transport resistance at current densities $>2.0 \mathrm{~A} / \mathrm{cm}^{2}$ decreased when cathode GDL compression was increased in the range from $0-20 \%$, postulating that poor thermal contact at low compression resulted in low local temperatures in the GDL, encouraging condensation.

The studies by Caulk and Baker [81] and Simon et al. [82] assumed the presence of liquid water in the fuel cell based on measured performance. However, the liquid water was not measured directly. Numerous studies have linked the presence of liquid water in the GDL to mass-transport efficiency losses, both through numerical modeling efforts $[19,80,83]$ and in-situ visualizations $[17,33,39,66,84]$. Recent studies $[33,39,85]$ performing in operando visualization of liquid water have strongly supported the link between the oxygen transport resistance and the liquid water saturation within the GDL. Antonacci et al. [39] investigated the feasibility of combining synchrotron X-ray radiographic measurements of liquid water with electrochemical impedance spectroscopy (EIS) characterizations of mass transport resistance. The authors identified a strong positive correlation between liquid water saturation and mass transport resistance. Owejan et al. 
[33] correlated the oxygen transport resistance to the liquid saturation by conducting limiting current experiments with concurrent neutron radiography at a range of oxygen concentrations. A variation in the liquid water saturation between GDL regions above the flow field lands and channels has also been observed by multiple studies $[17,31,33,84,86-88]$. Therefore, it is important to consider in-plane variations of liquid water saturation when considering the oxygen transport resistance. These contributions are immensely helpful in understanding liquid water saturation and oxygen transport behaviour. However, significant additional research is still required to develop a deeper understanding of all the factors that may influence GDL liquid water accumulation and the subsequent impacts on oxygen transport resistance.

\subsection{Background summary}

In this chapter, the fundamentals of fuel cell electrochemical energy conversion were presented, along with the current goals of researchers in the field. The transport phenomena within the PEM fuel cell were discussed, with particular emphasis placed on the transport of reactant oxygen gas and product water. While extensive research efforts have been made to visualize liquid water accumulation, there remain research gaps concerning the factors that control liquid water accumulation. Specifically, the sensitivity of the liquid water saturation in the GDL to the cathode inlet relative humidity has been observed in literature. However, this behaviour has not been extensively quantified over a wide range of operating current densities. In addition, while numerous researchers have sought to model the oxygen transport in the cathode GDL, most studies have focused on dry GDLs. As such, the specific relationship between the GDL's liquid saturation and oxygen transport resistance is not well understood. 
The research presented in this thesis constitutes a thorough investigation of cathode inlet relative humidity and operating current density as factors controlling GDL liquid water saturation and oxygen transport. The cathode relative humidity is a relevant consideration for modern fuel cell designs because the removal of the cathode humidifier is an option to reduce the cost of a fuel cell stack. Operating current density defines the rate of electrochemical water production in the cathode, and therefore controls the rates of liquid and vapour transport through the GDL. To assess the GDL liquid water saturation, synchrotron X-ray radiography was conducted to visualize liquid water accumulation, and X-ray micro-computed tomography was conducted to characterize GDL porosity distributions. To assess oxygen transport resistance, limiting current measurements were conducted. These methodologies are presented in the next chapter. 


\section{Chapter 3 Methodology}

\subsection{Introduction}

The research presented in this thesis is organized into two chapters of results which share several experimental methodologies used to assess oxygen transport and GDL liquid water accumulation in PEM fuel cells. The common methodologies are presented in this chapter, which is organized as follows:

- The fuel cell hardware and testing equipment are described in section 3.2.

- The methodology for visualizing and quantifying the presence of liquid water in the GDLs using synchrotron $\mathrm{X}$-ray radiography is presented in section 3.3.

- The GDL porosity characterization technique using X-ray micro-computed tomography $(\mu \mathrm{CT})$ is presented in section 3.4 .

- The calculation of GDL liquid water saturation from the results of the synchrotron X-ray radiographs and porosity characterizations is presented in section 3.5

- The fuel cell oxygen transport resistance is defined in section 3.6, which also describes the limiting current method for experimentally quantifying oxygen transport resistance across a range of cathode inlet oxygen concentrations and relative humidity levels.

\subsection{Fuel cell hardware and operation}

Experiments in this thesis were conducted using a custom, small-scale fuel cell with a $0.68 \mathrm{~cm}^{2}$ active area $(0.8 \mathrm{~cm} \times 0.85 \mathrm{~cm})$, designed specifically for in operando X-ray radiographic imaging. The fuel cell builds in this study were constructed using reinforced, catalyst-coated Nafion ${ }^{\circledR} \mathrm{HP}$ polymer membranes (DuPont), purchased from Ion Power (Newcastle, DE). The membrane thickness was $20.3 \mu \mathrm{m}$ and the platinum loading was $0.3 \mathrm{mg} / \mathrm{cm}^{2}$ on both the anode and cathode 
electrodes. The custom fuel cell contained graphite flow fields with eight parallel gas channels that were machined with nominal dimensions of $0.5 \mathrm{~mm}$ (width) $\times 0.5 \mathrm{~mm}$ (depth), separated by seven $0.5 \mathrm{~mm}$-wide lands. Compressed thickness of the GDLs was controlled in the fuel cell assembly using polyethylene napthalate (PEN) film spacers. GDL compressed thicknesses for particular experiments are presented in chapters 4 and 5. The GDL was assembled by tightening 6 M4 bolts to a torque of $20 \mathrm{in} \cdot \mathrm{lbs}$.

The operation of the fuel cell was controlled using a Scribner 850e test station (Scribner 850e, Scribner Associates Inc., NC). The fuel cell temperature was measured with a thermocouple embedded in the cathode-side graphite flow field. Fuel cell temperature was maintained at $60^{\circ} \mathrm{C}$ with a circulating water loop connected to a temperature-controlled water bath (Isotemp 4100R20, Thermo Fisher Scientific, MA). The relative humidity at the anode and cathode inlets was controlled by setting the dew point temperature of the humidifier bottle within the test station. The anode gas feed (hydrogen) was maintained at $100 \%$ relative humidity in all experiments, unless otherwise indicated. The inlet oxygen concentration was controlled by feeding air and diluent nitrogen through separate mass flow controllers (M100B MASS-FLO® controllers, MKS Instruments, MA, integrated with Scribner 850e system). The back pressure was controlled downstream of the fuel cell with an automatic backpressure unit (Scribner Associates Inc., North Carolina). Unless otherwise indicated, all experiments were conducted with a backpressure maintained at $200 \mathrm{kPa}$ absolute.

Compressed cylinders of air (Grade 0.1), nitrogen (Grade 4.8) and hydrogen (Grade 5.0) were used for the inlet oxidant, diluent/purge, and fuel gases, respectively. Inlet gas flow rates were 
maintained at 1 standard liter per minute (slpm) throughout all experiments. The resulting reactant stoichiometric ratios were greater than 20 on the cathode side for all experiments. High reactant stoichiometric ratios were used in combination with a small active area $\left(0.68 \mathrm{~cm}^{2}\right)$ to achieve nearconstant reactant concentrations within the channels.

\subsection{Visualizations of liquid water}

\subsubsection{Synchrotron $X$-ray radiography}

To visualize liquid water accumulation in operando during limiting current experiments, X-ray radiographic imaging was conducted at the Biomedical Imaging and Therapy (BMIT) Bending Magnet (05B1-1) beamline at the Canadian Light Source synchrotron in Saskatoon, Canada [89]. At this beamline, the fuel cell was exposed to collimated, monochromatic X-rays at an energy level of $24 \mathrm{keV}$. The X-ray energy level was selected to maximize transmitted photon intensity while avoiding beam contamination by higher harmonic X-ray energy levels [44,59]. A schematic of the experimental set-up is shown in Figure 3-1. 


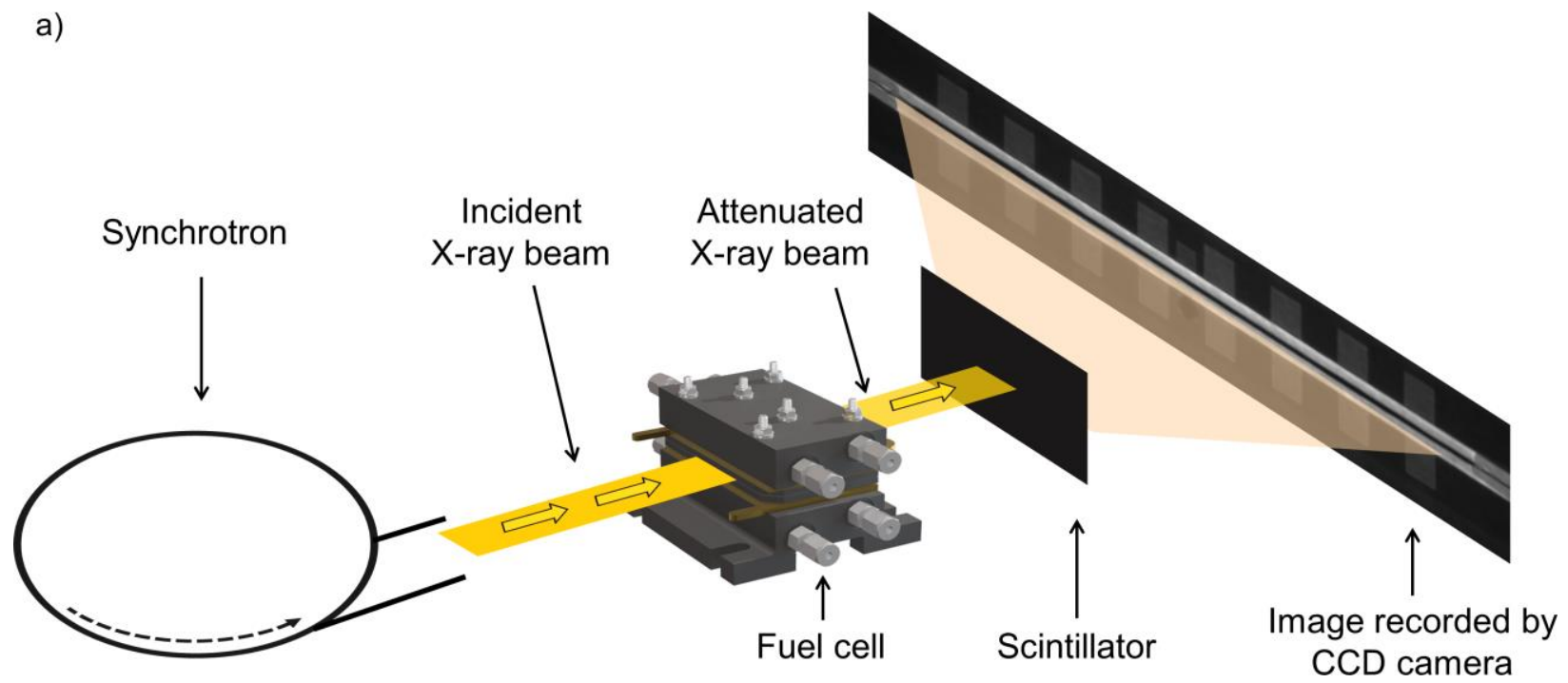

b)

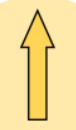

Attenuated X-ray beam

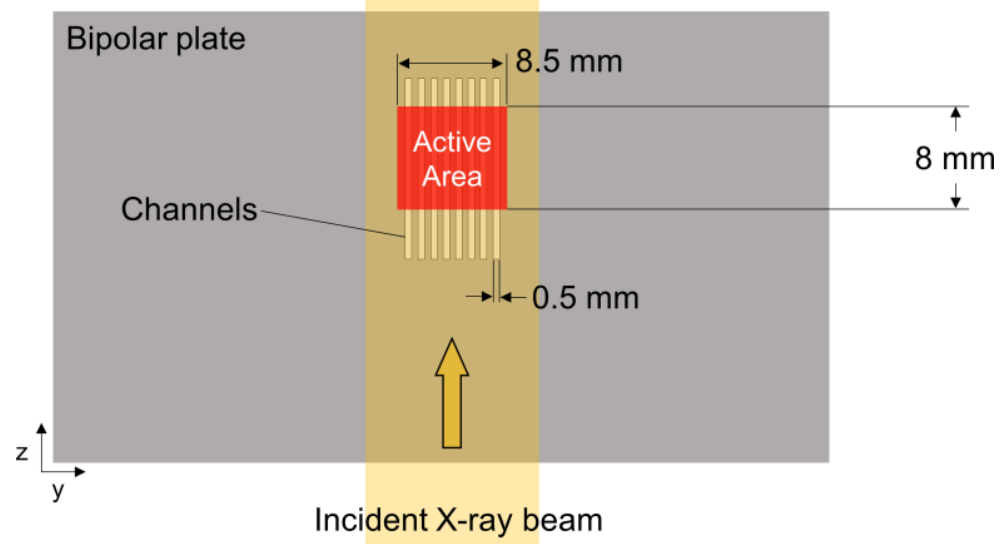

Figure 3-1: a) Schematic of synchrotron X-ray radiography experimental set-up (not to scale) b) top view of imaged region of the fuel cell with active area and flow channel dimensions.

During an experiment, the incident light is attenuated within the fuel cell. The attenuated beam is incident on the scintillator (AA40, Hamamatsu Photonics K.K., Shizuoka, Japan), which emits a proportional amount of visible light to the charge coupled device (CCD) camera (ORCA-Flash 4.0 
C11440-22CU, Hamamatsu Photonics K.K., Shizuoka, Japan). The CCD camera records greyscale pixel values which are directly proportional to the radiant intensity absorbed at the scintillator. To visualize liquid water in the fuel cell, the changes in the intensity of the attenuated X-ray beam were tracked during fuel cell operation. A detailed description of the image processing and liquid water quantification is presented in the following section (3.3.2). The scintillator and CCD camera set-up recorded images with a pixel size of $6.5 \mu \mathrm{m}$. A frame rate $0.33 \mathrm{fps}$ was selected to maximize the signal-to-noise ratio without overexposing any pixels.

\subsubsection{Image processing}

The quantity of liquid water was calculated by applying the Beer-Lambert Law, which relates the attenuation of light in a material to its thickness $[44,45,59]$. The unitless optical depth, $\tau$, is defined as the natural logarithm of the ratio of incident radiant intensity $I_{i}\left[\mathrm{~W} \cdot \mathrm{m}^{-2}\right]$ to the transmitted radiant intensity, $I_{t}\left[\mathrm{~W} \cdot \mathrm{m}^{-2}\right.$ ] (Equation 3.1). According to the Beer-Lambert Law, $\tau$ is directly proportional to material thickness, $t[\mathrm{~cm}]$. The optical depth is often described using an attenuation coefficient, $\mu\left[\mathrm{cm}^{-1}\right]$ (Equation 3.2).

$$
\begin{gathered}
\tau=\ln \left(\frac{I_{i}}{I_{t}}\right) \\
\tau=\mu t
\end{gathered}
$$

For a series of $N$ attenuating materials, the optical depths are additive, as follows:

$$
\ln \left(I_{i}\right)-\ln \left(I_{t, N}\right)=\mu_{1} t_{1}+\mu_{2} t_{2}+\cdots+\mu_{N} t_{N}
$$


To quantify liquid water in a PEM fuel cell, first the transmitted X-ray beam in a dry fuel cell is measured during open circuit voltage (OCV) operation. In OCV conditions, no water is being produced by the fuel cell. The measured pixel intensity, $I_{d r y}$, represents the transmitted intensity of the X-ray beam after experiencing attenuation by all the fuel cell materials in the beam path at a particular pixel location. The attenuating components may include PEN spacers, carbon fibers, MPL material, Nafion, platinum, and graphite. During fuel cell operation, liquid water accumulates in the fuel cell GDLs, adding to the optical depth in the X-ray beam path. The beam intensity under this condition is considered the "wet" beam intensity, $I_{\text {wet }}$. By applying the Beer-Lambert law, the total thickness of liquid water, $t_{w}[\mathrm{~cm}]$ in the beam path can be isolated using Equation (3.4):

$$
\ln \left(\mathrm{I}_{w e t}\right)-\ln \left(\mathrm{I}_{d r y}\right)=-\mu_{w} t_{w} .
$$

The coefficient $\mu_{w}\left[\mathrm{~cm}^{-1}\right]$ in Equation (3.4) is the attenuation coefficient of water, which was calculated for our experimental set-up using a calibration technique described by Ge et al. [44]. Rearranging Equation 3.4, liquid water thickness $t_{w}[\mathrm{~cm}]$ can be calculated using Equation (3.5):

$$
t_{w}=\frac{1}{\mu_{w}} \ln \left(\frac{I_{d r y}}{I_{w e t}}\right) .
$$

The water thickness calculated at each pixel, $t_{w}(x, y)[\mathrm{cm}]$, has been averaged over 10 consecutive frames $\left(t_{k}\right)$, as in Equation (3.6), to mitigate the impact of camera noise:

$$
t_{w}(x, y)=\frac{1}{N_{t}} \sum_{k=1}^{N_{t}} t_{w}\left(x, y, t_{k}\right)
$$

Where $N_{t}$ is the number of frames being averaged (10 frames, or 30 seconds).

A sample raw radiograph is shown in Figure 3-2 (a). In Figure 3-2 (b), the liquid water thickness at each pixel has been calculated through the application of Equation (3.6). The resulting water 
thicknesses have been mapped to a colour scale. Negative values of $t_{w}$ appear on the colour scale of Figure 3-2 due to imaging artifacts related to micron-scale solid material movement which occurred in some experiments. Instances of solid material movement are discussed in chapters 4 and 5. Water accumulation observations are separated into the regions of the GDL above the flow field lands and the regions of the GDL above the flow field channels. The solid red outlined areas in Figure 3-2 (b) are the land regions of the cathode GDL and the dashed-green outlined areas are the channel regions of the cathode GDL. 


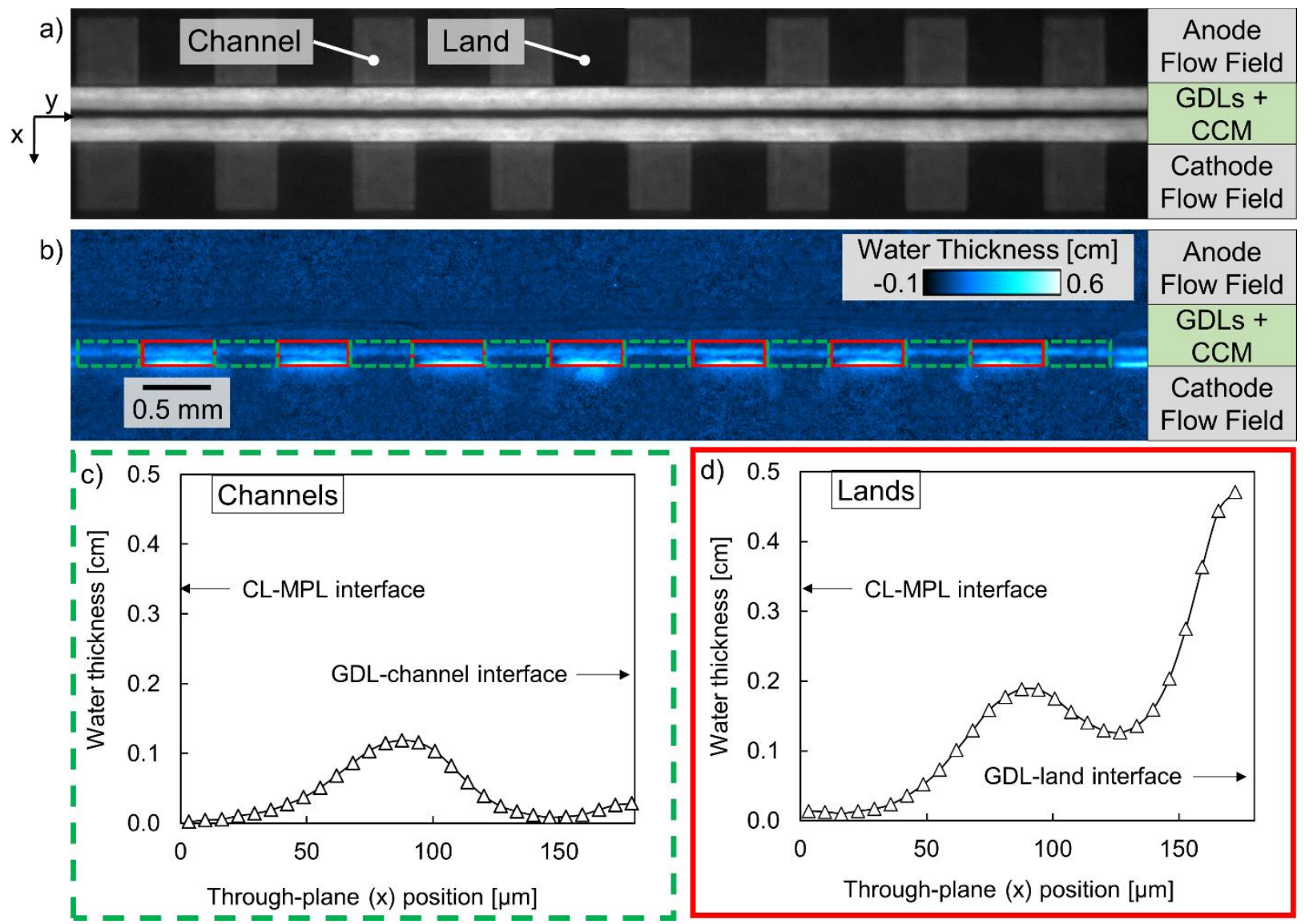

Figure 3-2: Sample measurement of liquid water at limiting current conditions (with SGL 29 BC employed as the GDL, $60^{\circ} \mathrm{C}, 80 \%$ relative humidity): (a) a raw absorption radiograph, (b) a processed water thickness image using Equation (3.6), with the calculated water thickness depicted on a colour scale, (c) average water thickness vs. through-plane position (Equation 3.7) in the channel regions, indicated by the regions with the dashed green outlines in (b), (d) average water thickness vs. through-plane position (Equation 3.7) in the GDL land regions (indicated by the regions with the solid red outlines in (b)). The zero position on the $\mathrm{x}$-axis of (c) and (d) corresponds to the cathode CL-MPL interface.

To generate a through-plane profile of liquid water accumulation, the water thickness was averaged across all in-plane positions $\left(y_{i}\right)$ for a given through-plane position, $(\mathrm{x})$, as in shown in 
Equation (3.7). This equation was applied separately for the GDL channel and land regions, as shown in Figure 3-2 (c) and (d), respectively.

$$
t_{w}(x)=\frac{1}{N_{t} \cdot N_{y}} \sum_{k=1}^{N_{t}} \sum_{i=1}^{N_{y}} t_{w}\left(x, y_{i}, t_{k}\right)
$$

The value $N_{y}$ in Equation (3.7) is the total number of pixels (in-plane) at a particular through-plane position (x) in the region of interest.

The calculated water thickness from Equation (3.7) is the average of a sample of individual pixel measurements, and contains some uncertainty arising from a) statistical variance of liquid water measurements in space (over different pixels) and time (over different frames), and b) noise and uncertainty from the measurement instrumentation. Chevalier et al. [29] presented a method to estimate the precision uncertainty from both sources a) and b) on the resulting average water thickness value for each through-plane position, $\mathrm{x}$. The uncertainty of liquid water saturation was calculated directly from the uncertainty of the liquid water thickness, and it does not attempt to capture possible variations in material properties in the commercially-purchased GDLs between different manufactured batches. A coverage factor of 3 (greater than $99 \%$ confidence) was used in this thesis for the quantification of precision uncertainty. The liquid water visualizations in this thesis were conducted during two separate experimental visits to the Canadian Light Source synchrotron in December 2015 and May 2016. In each experimental visit, the water attenuation coefficient was calibrated and the uncertainty of the water attenuation coefficient was included in the water thickness uncertainty [29]. 
This study considered GDL land and channel regions separately. Separate consideration of the land and channel regions of the GDL removes some of the in-plane variance in the averaged measured water thickness at a given through-plane position because the liquid water accumulation tendencies in the GDL regions above the lands differ from those at the regions above the channels $[17,31,33,84,86-88]$. For the liquid water visualizations in Chapter 4 (December 2015), the liquid water saturation uncertainty was determined to be in the range of \pm 0.002 to \pm 0.005 in the GDL channel regions and between \pm 0.002 and \pm 0.012 in the GDL channel land regions for each position in the through-plane saturation profile $s(x)$. For the liquid water visualizations in Chapter 5 (May 2016), the liquid water saturation uncertainty was found to be in the range of \pm 0.002 to \pm 0.008 in the GDL channel regions and between \pm 0.002 to \pm 0.016 in the GDL channel land regions for each position in the through-plane water thickness profile $t_{w}(x)$.

\subsection{GDL porosity characterization by X-ray micro-computed tomography}

Three-dimensional (3-D) X-ray micro-computed tomography ( $\mu \mathrm{CT}$ ) scans were conducted on each GDL material using a Skyscan 1172 desktop $\mu$ CT machine (Bruker micro CT, Kontich, Belgium). The GDLs were compressed in the sample holder for the $\mu \mathrm{CT}$ scan to the same compressed thickness achieved in the experimental fuel cell using PEN film spacers. Using an X-ray energy level of $36 \mathrm{keV}$, a voxel resolution of $3.23 \mu \mathrm{m}$ was achieved. Using an in-house segmentation algorithm [90], the MPL, carbon fiber, and void voxels were differentiated in a $5 \mathrm{~mm} \times 5 \mathrm{~mm}$ region of the reconstructed greyscale $\mu \mathrm{CT}$ images. The thresholds for identifying each phase in the algorithm were determined based on the areal weights of MPL and carbon fiber in the GDL 
materials, given in the manufacturer's specifications [91]. At each through-plane slice of the material, the total number of voxels of each phase was counted in order to determine the fractions of carbon fiber, MPL, and void space at that through-plane location. The resolution of the tomographic scan was not sufficient to resolve the nano-scale pores in the MPL. The MPL was assumed to have a porosity of $50 \%[90,92,93]$.

When an MPL is coated onto the carbon fiber substrate, the MPL intrudes into the carbon fiber substrate [90,94-97], therefore there is not a clear physical boundary between these layers. The MPL region is characterized by the absence of large pore spaces apart from small cracks. The carbon fiber substrate region is characterized by the existence of larger open pore spaces within the carbon fiber matrix. Based on the phase-differentiated porosity information obtained for each GDL in this study, the boundary of the MPL region (at the MPL-substrate interface) was defined as the location of the last through-plane slice where the fraction of void voxels in the $\mu \mathrm{CT}$ segmentation was less than 0.5 . The void voxels represent micron-scale pore spaces large enough to be detected by the $\mu \mathrm{CT}$ scans.

The volume fraction of void space within a porous material is defined as the porosity. The porosity, $\varepsilon$, at each through-plane (x) position can be calculated as follows:

$$
\varepsilon(x)=\frac{\text { Void Volume }(x)}{\text { Solid Volume }(x)+\text { Void Volume }(x)}
$$

\subsection{Calculation of liquid water saturation and effective pore fraction}


During fuel cell operation, liquid water occupies some fraction of the porosity in the GDL. Liquid water saturation is the volume fraction of liquid water relative to the total pore volume, as calculated by Equation (3.9).

$$
s(x, y)=\frac{t_{w}(x, y)}{L_{z} \varepsilon(x)}
$$

In Equation (3.9), $s(x, y)$ is the liquid water saturation, $t_{w}(x, y)$ is the liquid water thickness, $\varepsilon(x)$ is the porosity, and $L_{z}$ is the length of the GDL in the direction parallel to the X-ray beam path.

Based on the calculated liquid water saturation and porosity, it is possible to determine the effective pore fraction. The effective pore fraction represents the fraction of GDL volume comprised of unsaturated (liquid water-free) pores. This is calculated for the carbon fiber substrate using Equation (3.10), where $N_{x}$ is the number of pixels spanning the through-plane thickness of the carbon fiber substrate in the synchrotron experiment, $\varepsilon(x)$ is the porosity at a particular pixel (indexed by a position value, $x[\mu \mathrm{m}]$ ), and $s(\mathrm{x})$ is the calculated liquid water saturation at that pixel.

$$
\varepsilon_{e f f}=\frac{1}{N_{x}} \sum_{x} \varepsilon(x)(1-s(x))
$$

\subsection{Quantifying oxygen transport resistance}

\subsubsection{Oxygen transport resistance definition}

The oxygen transport resistance is calculated from Fick's First Law in one dimension (the through-

plane direction) $[33,77,78,81,87]$. An oxygen concentration gradient $\frac{d c_{O_{2}}}{d x}$ is created by the 
consumption of oxygen at the cathode catalyst. The oxygen flux, $\frac{\dot{N}_{O_{2}}}{A_{\text {active }}}\left[\mathrm{mol} \cdot \mathrm{s}^{-1} \cdot \mathrm{cm}^{-2}\right]$ is proportional to this concentration gradient:

$$
\frac{\dot{N}_{\mathrm{O}_{2}}}{A_{\text {active }}}=-D^{e f f} \frac{d c_{O_{2}}}{d x},
$$

where $\dot{N}_{O_{2}}\left[\mathrm{~mol} \cdot \mathrm{s}^{-1}\right]$ is the molar consumption rate of oxygen, $A_{\text {active }}\left[\mathrm{cm}^{2}\right]$ is the active area of the fuel cell, and $D^{e f f}\left[\mathrm{~cm}^{2} \cdot \mathrm{s}^{-1}\right]$ is the effective diffusion coefficient of oxygen gas. The effective diffusion coefficient in a porous medium is a function of the pore structure of the medium, liquid water saturation, and the bulk diffusion coefficient of oxygen free of the porous medium [98]. In an operating PEM fuel cell, the gas phase in the cathode GDL consists of $\mathrm{O}_{2}, \mathrm{~N}_{2}$ and $\mathrm{H}_{2} \mathrm{O}$ vapour.

If the concentration gradient in Equation (3.11) is replaced with a discrete concentration difference over a discrete thickness, the effects of the diffusion coefficient and thickness can be combined to calculate the oxygen transport resistance, $R_{T}\left[\mathrm{~s} \cdot \mathrm{cm}^{-1}\right]$, as defined in Equation (3.12):

$$
R_{T}=\frac{\Delta x}{D^{e f f}}=\frac{\Delta c_{O_{2}}}{\dot{N}_{O_{2}} / A_{\text {active }}}
$$

The rate of oxygen consumption can be directly calculated from the operating current density of the fuel cell through Faraday's Law of Electrolysis (Equation 1.4). Consequently, the fuel cell 
transport resistance can be written as a function of concentration difference and operating current density, as in Equation (3.13),

$$
R_{T}=4 F \frac{\Delta c_{O_{2}}}{i}
$$

Where $F\left[96485 \mathrm{C} \cdot \mathrm{mol}_{\mathrm{e}-}^{-1}\right]$ is Faraday's constant.

Direct measurements of the transport resistance are not feasible under normal operating conditions because the concentration of oxygen at the catalyst layer cannot be measured directly. However, under limiting current conditions $\left(i=i_{L}\right)$, the concentration of oxygen can be assumed to approach zero at the catalyst (i.e., $\Delta c=c_{C H}$, where $c_{C H}\left[\mathrm{~mol} \cdot \mathrm{cm}^{-3}\right]$ is the oxygen concentration of the inlet gas in the channels). The high stoichiometric ratios $(>20)$ of oxygen used in this study were chosen to ensure that oxygen concentration did not vary significantly along the length of the channels.

The oxygen concentration in the humidified gas feed can be calculated from the ideal gas law for a given pressure and humidification (Equation 3.14):

$$
c_{C H}=\frac{p-p_{w}}{R T} x_{O_{2}}^{d r y-i n}
$$

In Equation (3.13), $p[\mathrm{kPa}]$ is the operating pressure, $p_{w}[\mathrm{kPa}]$ is the inlet vapour pressure, $x_{\mathrm{O}_{2}}^{d r y-i n}$ is the dry inlet oxygen mole fraction, $\boldsymbol{R}$ is the universal gas constant $\left[8314 \mathrm{kPa} \cdot \mathrm{cm}^{3}\right.$. 
$\left.\mathrm{mol}^{-1} \cdot \mathrm{K}^{-1}\right]$, and $T[\mathrm{~K}]$ is the fuel cell operating temperature. Equations (3.13) and (3.14) are combined, and the resulting equation for oxygen transport resistance, $R_{T}\left[\mathrm{~s} \cdot \mathrm{cm}^{-1}\right]$, is as follows:

$$
R_{T}=4 F \frac{p-p_{w}}{i_{L} R T} x_{O}^{d r y-i n}
$$

The transport resistance can therefore be calculated from a limiting current measurement for a particular humidity and oxygen concentration.

\subsubsection{Limiting current experimental protocol}

To measure the limiting current density used in Equation (3.15), polarization curves (i-V curves) were obtained by one of two functionally equivalent methods: voltage control (potentiostatic) and current control (galvanostatic). In the potentiostatic control method, the cell potential was decreased in small increments to a minimum of $0.03 \mathrm{~V}$. The measured current density at $0.03 \mathrm{~V}$ was recorded as the limiting current density. In the galvanostatic control method, the i-V curves were obtained by increasing the fuel cell current density in small increments. The resulting i-V curve was inspected for a steep (near-vertical) drop-off in voltage corresponding to mass transport limitations (see the illustration in the left image of Figure 3-3). The limiting current density was recorded as the highest current density in the region of the curve exhibiting the steep voltage loss. Generally, I preferred potentiostatic control, since this method does not require advanced knowledge of the $\mathrm{i}-\mathrm{V}$ behaviour of the fuel cell to prepare an automated experimental protocol for the limiting current experiment. In experiments with un-diluted air supplied to the cathode flow field (0.21 dry $\mathrm{O}_{2}$ mole fraction), potentiostatic control was used. 
In experiments with diluted oxygen concentrations in the cathode gas feed, the fuel cell experienced voltage instabilities at low cell potentials due to limitations on the control of internal electrical resistance in the fuel cell test station. Attempting potentiostatic control of fuel cell operating conditions during these instabilities resulted in unstable operating current densities, making a reliable measurement of limiting current density prohibitive. To avoid the uncertainty in the current density measurement arising from this instability, the experiments conducted with reduced oxygen concentrations were conducted with galvanostatic control, which allowed for reliable measurement of current density in spite of the aforementioned voltage fluctuations.

The right-hand image of Figure 3-3 shows the low-voltage region of the i-V curves from sample experiments using the both the potentiostatic and galvanostatic limiting current measurement techniques. The experiments denoted by circular data points were conducted by controlling cell potential down to $0.03 \mathrm{~V}$. The experiments denoted by square data points were conducted by incrementally increasing current density until mass transport limitations were incurred. 

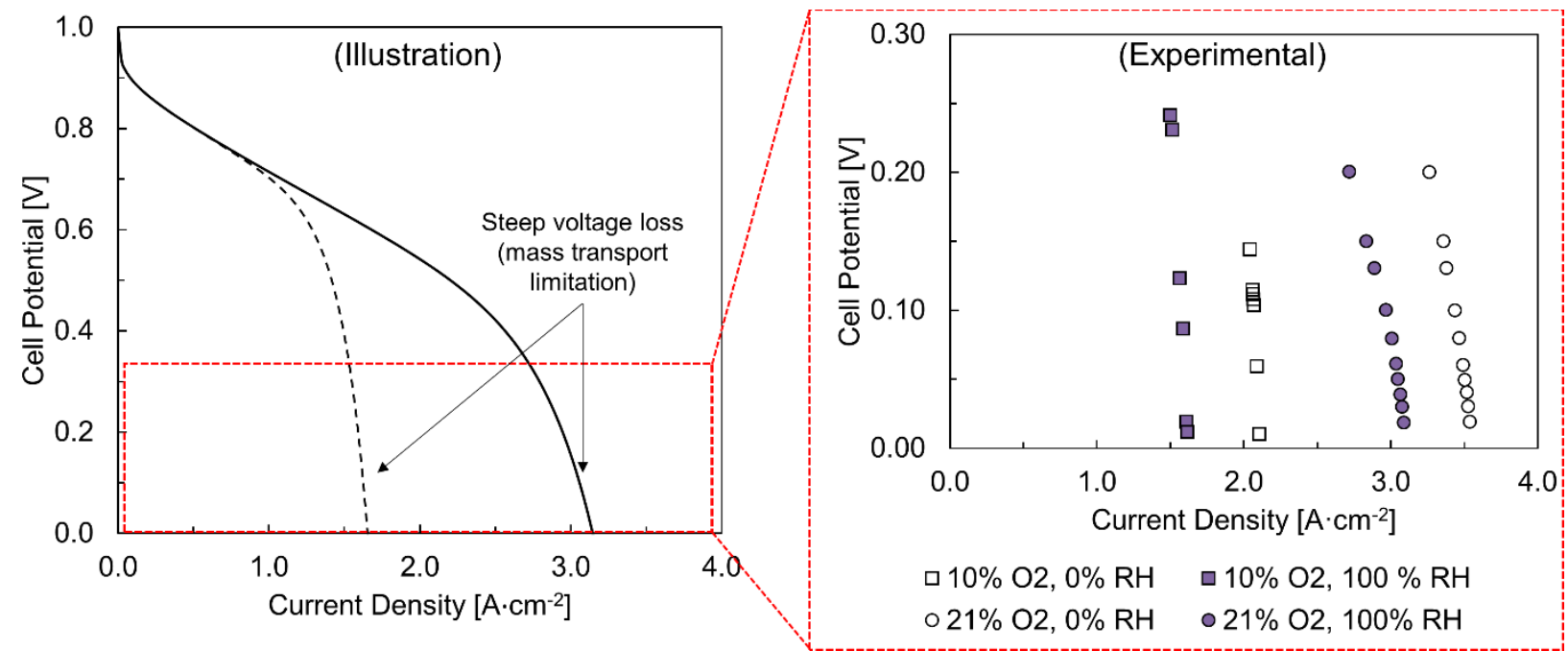

Figure 3-3: Illustration of limiting current technique. Left-hand image is an illustration of the i- $\mathrm{V}$ curves for two inlet oxygen mole fractions, resulting in mass transport limitation at different current densities. The right-hand figure shows the low-voltage region of selected experimental iV curves measured during limiting current experiments with SGL 29 BC employed as the GDL. Experiments with a 0.21 oxygen mole fraction in the cathode inlet gas were conducted by controlling voltage in discrete, decreasing steps. All other experiments were conducted by controlling operating current density in discrete, increasing steps.

\subsection{Chapter Summary}

This chapter described the methodologies employed to collect and analyze the results presented in chapters 4 and 5. Synchrotron X-ray radiography was conducted to measure the liquid water thickness in the GDL. X-ray micro-computed tomography was conducted to measure the throughplane porosity profiles of the GDLs. Limiting current measurements were used to determine GDL oxygen transport resistance. The techniques described in this chapter allowed for the simultaneous measurement of the liquid water saturation in the GDL and oxygen transport resistance in an 
operating PEM fuel cell, with full control of cathode inlet relative humidity and inlet oxygen mole fraction. 


\section{Chapter 4 Oxygen Transport Resistance and Liquid Water Saturation at High Current Density with Varied Cathode Relative Humidity}

\subsection{Chapter abstract}

In this chapter, the impacts of relative humidity $(\mathrm{RH})$ on liquid water accumulation and mass transport resistance at high current densities were investigated for polymer electrolyte membrane (PEM) fuel cell cathode gas diffusion layers (GDLs). Through-plane liquid water saturation distributions were obtained in situ using synchrotron X-ray radiography while limiting currentbased characterizations were performed to determine the oxygen transport resistance. In experiments with inlet cathode reactant gas RH ranging from $0 \%$ to $100 \%$, high local saturations (> 0.6) were consistently observed in the GDL region adjacent to the flow field lands when the fuel cell reached limiting current. High land-region saturation is an indication of low local temperatures. In the carbon fiber substrate portion of the GDL (i.e. excluding the microporous layer, or MPL), the liquid water volume in the regions adjacent to the flow field channels was consistently lower than the water volume adjacent to the land regions. We observed a trend of increasing GDL saturation adjacent to the channels with increasing levels of cathode inlet relative humidity, along with corresponding small increases in oxygen transport resistance. The work presented in this chapter has been submitted as a journal manuscript ${ }^{1}$.

\footnotetext{
${ }^{1}$ Muirhead, D., Banerjee, R., Lee, J., George, M.G., Ge, N., Liu, H., Chevalier, S., Hinebaugh, J., Han, K., Bazylak, A. "Simultaneous characterization of oxygen transport resistance and spatially resolved liquid water saturation at high-current density of polymer electrolyte membrane fuel cells with varied cathode relative humidity". International Journal of Hydrogen Energy (submitted 25 July 2017).
} 


\subsection{Methodology}

This study investigates cathode relative humidity $(\mathrm{RH})$ as a controlling influence on the liquid water saturation and oxygen transport resistance in cathode GDL materials. For descriptions of the fuel cell testing, material characterization, and liquid water visualization methodologies, readers are referred to the following sections of chapter 3 :

- Chapter 3.2: Fuel cell hardware and operation

- Chapter 3.3: Visualizations of liquid water

- Chapter 3.4: GDL porosity characterization by micro-computed tomography $(\mu \mathrm{CT})$

- Chapter 3.5: Calculation of liquid water saturation

- Chapter 3.6: Quantifying oxygen transport resistance.

This section summarizes the GDL materials employed for this study and lists the set of experiments conducted.

\subsubsection{GDL materials}

The GDLs used in this study, SGL 25 BC and SGL 29 BC, were commercially available materials from Sigracet ${ }^{\circledR}$. These materials are composed of a carbon fiber substrate coated with an MPL. Their properties are summarized in Table 4-1. For all fuel cell builds in this study, identical GDLs were used on both the anode and cathode sides. Rigid polyethylene napthalate (PEN) sheets were employed as spacers to control the compressed thickness of each GDL. 
Table 4-1: GDL materials and properties

\begin{tabular}{|c|c|c|}
\hline GDL Name & SGL 25 BC & SGL 29 BC \\
\hline Uncompressed thickness $(\mu \mathrm{m})^{*}$ & 235 & 235 \\
\hline MPL thickness $(\mu \mathrm{m})^{\mathrm{a}}$ & 60 & 50 \\
\hline Areal weight $\left(\mathrm{g} / \mathrm{m}^{2}\right)^{*}$ & 86 & 90 \\
\hline PTFE load of backing (wt. \%)* & 5 & 5 \\
\hline PTFE content of MPL (wt. \%) ${ }^{+}$ & 23 & 23 \\
\hline PEN spacer thickness for compression $(\mu \mathrm{m})^{b}$ & 188 & 188 \\
\hline
\end{tabular}

${ }^{a}$ MPL thickness was determined based on micro-computed tomography scans as described in section 2.2.2.

${ }^{b}$ GDLs are compressed to the thickness of the spacers less the thickness of the catalyst coating of the CCM, which is approximately $15 \mu \mathrm{m}$.

*From manufacturer specifications

${ }^{+}$From manufacturer white paper [91]

Based on the micro-computed tomography methodology presented in chapter 3 , the through-plane porosity characteristics of these materials were computed and are presented in Figure 4-1. In this figure, "Fiber Porosity" is the porosity of the isolated carbon fiber substrate, "Macro Porosity" is the overall fraction of void voxels in the segmented image, and "Micro Porosity" is the final porosity of the segmented GDL with the assigned MPL porosity of 0.5 taken into account. "MPL Porosity" is the porosity of the isolated MPL phase, also after taking the assigned MPL porosity into account. 

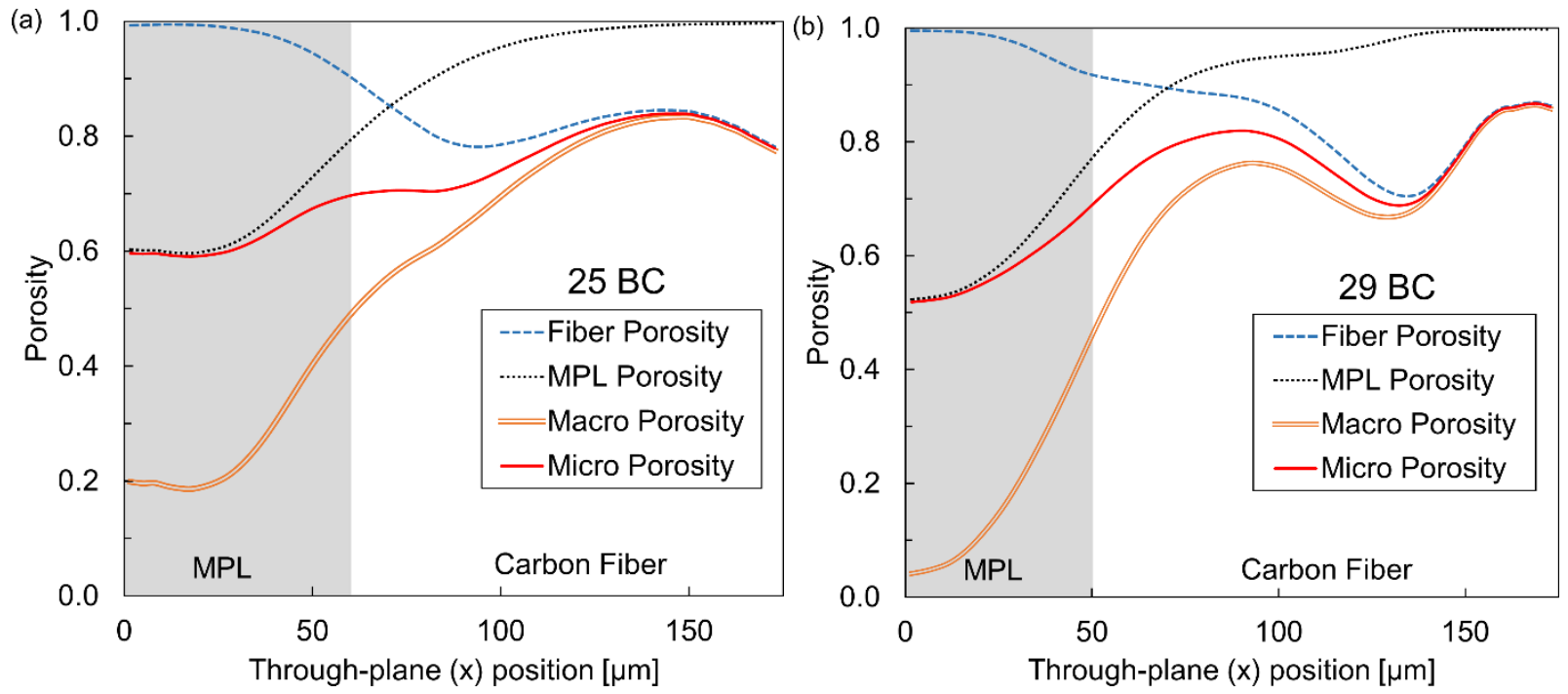

Figure 4-1: Computed porosity profiles for (a) SGL 25 BC and (b) SGL 29 BC with the MPL region, defined in chapter 3.5 , indicated by grey shading. The zero position on the $\mathrm{x}$-axis corresponds to the CL-MPL interface.

\subsubsection{Summary of experiments}

Limiting current measurements were conducted across four cathode inlet RH levels: $0 \%, 50 \%$, $80 \%$, and $100 \%$. In one of the two GDL samples (SGL 29 BC), measurements were also conducted at $90 \% \mathrm{RH}$ in addition to the four RH levels mentioned previously. The anode $\mathrm{RH}$ was set to match the cathode RH in the experiments at $0 \%, 50 \%, 80 \%$, and $90 \% \mathrm{RH}$. When the cathode inlet RH was set to $0 \% \mathrm{RH}$, the anode was kept fully humidified (100\% RH) in order to prevent excessive dry-out and potential damage of the nafion membrane. The full set of measurement conditions are summarized in Table 4-2. Liquid water saturation was quantified during limiting current operation using synchrotron X-ray radiography, as described in chapter 3.3. Transport resistances were calculated from the measured limiting current densities as outlined in chapter 3.6. 
Table 4-2: Summary of anode and cathode inlet RH levels used for limiting current experiments

\begin{tabular}{|c|c|c|c|}
\hline $\begin{array}{c}\text { GDL } \\
\text { Samples }\end{array}$ & $\begin{array}{c}\text { Dry inlet oxygen } \\
\text { mole fraction }\end{array}$ & Cathode inlet RH & Anode inlet RH \\
\hline SGL 25 BC & 0.21 & $0 \%$ & $100 \%$ \\
\cline { 2 - 4 } & 0.21 & $50 \%, 80 \%, 100 \%$ & Matching cathode RH \\
\hline SGL 29 BC & 0 & $50 \%, 80 \%, 90 \%, 100 \%$ & $100 \%$ \\
\hline
\end{tabular}

\subsection{Results and discussion}

\subsubsection{Impact of humidity on water accumulation}

To investigate the effect of humidity on liquid water accumulation, the variations in measured liquid water content were compared in both the in-plane direction (across the lands and channels of the flow field) and the through-plane direction (from the MPL at the catalyst layer interface to the flow field interface with the carbon fiber substrate). The in-plane variation of liquid water is presented in Figure 4-2. 
(a)

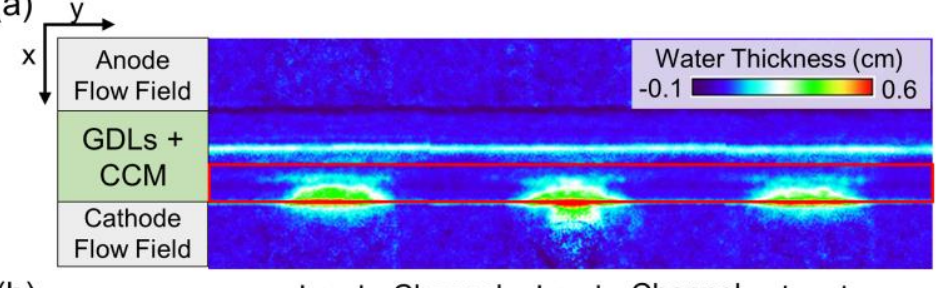

(b)

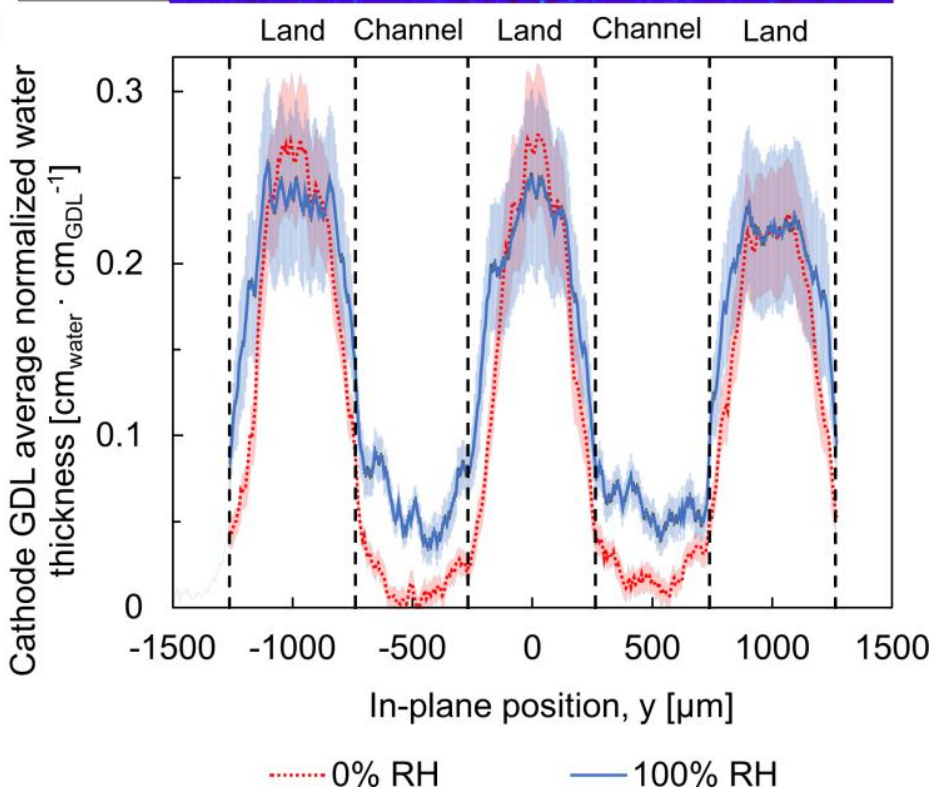

Figure 4-2: (a) Example of a processed radiograph for SGL 25 BC containing three land and two channel regions at the center of the flow field (cropped region to enhance readability). The red outline indicates the location of the cathode GDL. (b) Normalized water thickness in the cathode GDL, averaged in the through-plane direction (x), versus in-plane position at cathode inlet relative humidity levels of $0 \% \mathrm{RH}$ and $100 \% \mathrm{RH}$. The position $\mathrm{y}=0$ is located at the horizontal center of the central flow field land region. Water profiles presented represent a 30-second average of recorded images. Shading indicates the uncertainty of the mean normalized water thickness at a particular through-plane position.

Figure 4-2 (a) shows the central three lands and two channels of a processed radiograph for a fuel cell operating at limiting current with the cathode inlet gas stream set to $0 \%$ relative humidity. The fuel cell in Figure 4-2 (a) was built with SGL 25 BC. The calculated liquid water thickness at each 
pixel, $t_{w}(x, y)[\mathrm{cm}]$, has been averaged over 10 consecutive frames (30 seconds), as in equation (4.1):

$$
t_{w}(x, y)=\frac{1}{N_{t}} \sum_{k=1}^{N_{t}} t_{w}\left(x, y, t_{k}\right)
$$

Where $N_{t}$ is the number of frames being averaged (10 frames, or 30 seconds). In Figure 4-2 (b), the water thickness values displayed in Figure 4-2 (a) were averaged along the through-plane thickness of the cathode GDL for each in-plane (y) location in the region outlined in red. The yaxis was then normalized by the length of the GDL parallel to the beam $\left(L_{z}\right)$ to find the normalized water thickness, $\overline{t_{w}}(y)\left[\mathrm{cm}_{\text {water }} \cdot \mathrm{cm}_{\mathrm{GDL}}{ }^{-1}\right]$, as in equation (4.2):

$$
\overline{t_{w}}(y)=\frac{1}{L_{z}} \cdot \frac{1}{N_{t} \cdot N_{x}} \sum_{k=1}^{N_{t}} \sum_{i=1}^{N_{x}} t_{w}\left(x_{i}, y, t_{k}\right) .
$$

The value $N_{x}$ in equation (4.2) is the total number of pixels (through-plane) at a particular in-plane (y) position in the region of interest.

In Figure 4-2 (b), the average normalized liquid water thickness $\left[\mathrm{cm}_{\mathrm{water}} \cdot \mathrm{cm}_{\mathrm{GDL}}^{-1}\right]$ over the land regions in SGL $25 \mathrm{BC}$ was consistently greater than 0.2 , i.e. more than $20 \%$ of the total GDL volume each in-plane position was occupied with liquid water. On the other hand, the average normalized liquid water thickness over the channel regions was consistently less than 0.1 , even with fully humidified inlet gases. As the relative humidities of the inlet gases were increased, there was an increase in liquid water accumulation over the channel regions of the flow field. The liquid 
water accumulation in the GDL regions over the flow field land remained relatively consistent between experiments at different cathode gas inlet RH levels. Liquid water over the lands impedes the in-plane diffusion of oxygen from the channels to the land regions, potentially limiting the local current densities. This water was present even at $0 \%$ inlet relative humidity at the cathode, therefore either higher temperatures or lower current density operation would be required to eliminate land-region water. The red and blue shaded regions in Figure 4-2 indicate the uncertainty of the mean normalized water thickness at each in-plane position, $y$. The calculated uncertainty is based on a combination of:

a) The spatial and temporal variance of water thickness measurements across the $\mathrm{x}$ dimension (through-plane) and across the 10 frames included in the average, and

b) The noise and uncertainty specifications of the imaging setup.

Since significant variation was observed in the measured water thicknesses in the through-plane direction (x), the standard deviation of the mean normalized water thickness $\overline{t_{w}}(y)$ for a particular in-plane location, $\mathrm{y}$, is larger than the standard deviation of the mean water thickness $\overline{t_{w}}(x)$ or saturation $s(x)$ for a particular through-plane position, $\mathrm{x}$. The uncertainty ranges reported in Figure 4-2 (b) are therefore larger than the those mentioned in the methodology section 3.3.2 and reported in the forthcoming Figure 4-3 for the through-plane (x) saturation profile. This does not reflect a difference in the confidence of the 2-D spatially resolved map of GDL water content, rather, it reflects a physical difference in the nature of the spatial distribution of water content.

Since differences in water accumulation behaviour were observed between the land and channel 
regions of the GDL, we separated these regions when considering the through-plane distribution of liquid water saturation. Figures 4-3 (a) through (d) illustrate the measured liquid water accumulation across the cathode GDL at limiting current densities for the GDLs tested. For each through-plane position, the liquid water thickness was obtained by averaging across the total inplane width of the channels (Figures 4-3 (a) and (c)), or lands (Figures 4-3 (b) and (d)), and the local liquid water saturation was calculated as described in chapter 3.3. 

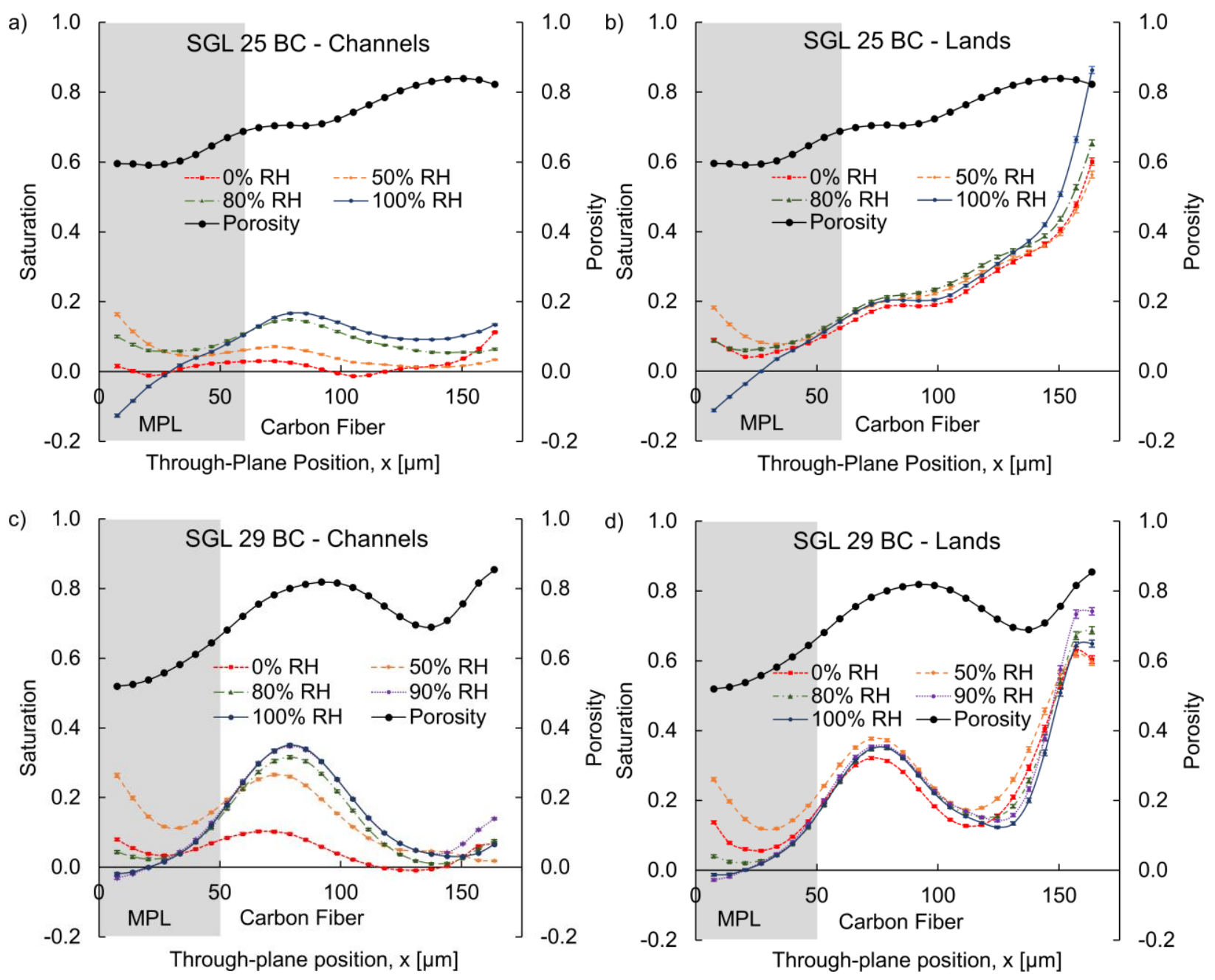

Figure 4-3: Liquid water saturation and local porosity vs. through-plane position in the cathode GDLs during limiting current operation. Figures (a) and (b) depict saturation in SGL 25 BC, and (c) and (d) depict saturation in SGL 29 BC. Figures (a) and (c) depict saturation in regions above the flow field channels (max. uncertainty \pm 0.005 ) and figures (b) and (d) depict regions above the flow field lands (max. uncertainty \pm 0.012 ). The zero position on the $x$-axes corresponds to the location of the CL-MPL interface. Saturation profiles depicted represent a 30-second average of recorded images.

Figure 4-3 shows that water accumulation in the substrate region over the flow channel is more 
sensitive to the increase in relative humidity than the region over the land. For example, in the substrate region of SGL 25 BC under the channels (Figure 4-3 (a)), the saturation level was insignificant under low humidity conditions ( $0 \%$ and 50\%); however, saturations reaching $17 \%$ were observed in these same regions when fully humidified air was supplied. On the other hand, in the regions above the flow field lands for all GDL cases (Figures 4-3 (b) and (d)), we observed that the distribution of liquid water saturation had similar contours regardless of humidity levels. The most saturated region of the four GDLs under limiting current density conditions was the region within $50 \mu \mathrm{m}$ of the flow field lands, with peak saturations greater than 0.6.

The total volume of liquid water in the carbon fiber substrate region of the cathode GDL per unit active area $\left[\mu \mathrm{m}_{\text {water }}^{3} \cdot \mu \mathrm{m}_{\text {active area }}^{-2}\right]$ is shown in Figure 4-4 for fuel cells operating at limiting current density. The liquid water volume in carbon fiber substrate regions adjacent to the flow field channels was consistently small $\left(<18 \mu \mathrm{m}_{\text {water }}^{3} \cdot \mu \mathrm{m}_{\text {active area }}^{-2}\right)$ relative to the water volume adjacent to the land regions ( $>27 \mu \mathrm{m}_{\text {water }}^{3} \cdot \mu \mathrm{m}_{\text {active area }}^{-2}$. Figure $4-4$ also indicates the sensitivity of liquid water accumulation above the channels to cathode inlet relative humidity. 


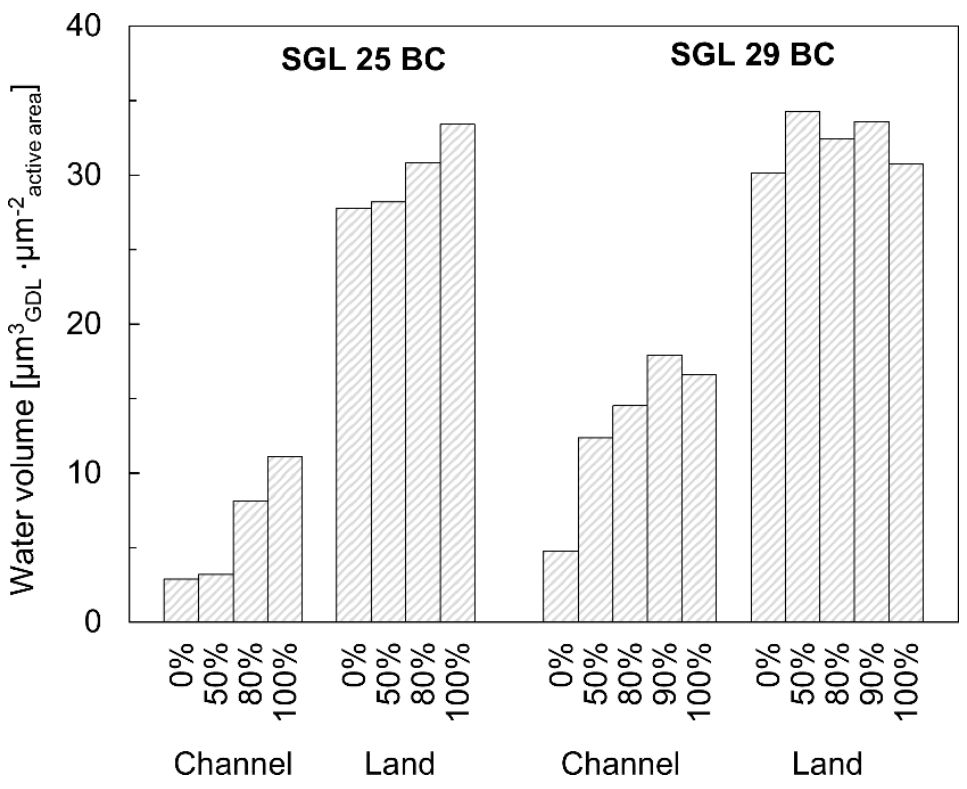

Figure 4-4: Total water volume per unit active area observed in the cathode carbon fiber substrate region of the GDL for cells operating at limiting current. Liquid water thicknesses used to calculate water volumes represent a 30-second average of recorded images.

Figures 4-2 to 4-4 reveal two features of liquid water accumulation behaviour at high current densities. The first feature is that liquid water tends to accumulate adjacent to the flow field lands. This behaviour is associated with lower local temperatures in the GDL immediately adjacent to the lands, which is expected due to the higher thermal conductivity of graphite (flow field material) relative to the air in the reactant channels. The reduced local gas velocities in the GDL land regions also contributes to the observed increased liquid water accumulation. In addition, the surface contact angle of graphite is lower than that of PTFE $[99,100]$. Therefore, if the carbon fibers of the GDL are well-coated in PTFE, the wettability of the lands may contribute to the increased tendency for liquid water accumulation there. The strong tendency for liquid water to appear preferentially over the land regions supports the observations reported by Owejan et al. $[33,86]$ and Boillat et al. 
[31], who both studied fuel cells with similar land and channel widths using in situ neutron radiography.

The second observed feature of high current density water accumulation behaviour was that when cathode gas streams at higher humidities were supplied, more liquid water was observed above the channels as compared to the lower humidity cases. High local water vapour partial pressure in the GDL near the gas channels is expected to encourage condensation while suppressing evaporation. Therefore, greater liquid water saturation is expected at higher humidities, as observed in previous studies [31,66]. Figures 4-3 (a) and (c) indicate that this additional liquid water accumulated specifically in the carbon fiber substrate region, rather than in the MPL. This is attributed to the following considerations. Firstly, the local temperatures in the carbon fiber substrate region are lower than in the MPL due to the physical proximity of the MPL to the site of heat production in the cathode catalyst layer $[8,24,101-103]$. In addition, the MPL has significantly lower porosity and smaller pore sizes than the carbon fiber substrate. Finally, the MPLs of SGL 25 BC and 29 BC contain 23 wt. \% PTFE, rendering them hydrophobic. The high temperature, small pore sizes, and hydrophobicity of the MPL make it an unfavorable site for liquid water to condense, and the small pore sizes restrict capillary-driven liquid water percolation from saturated substrate pores.

Over the flow field channels, we observed larger liquid water saturations in the central region (between $\mathrm{x}=60 \mu \mathrm{m}$ and $\mathrm{x}=120 \mu \mathrm{m}$ ) of $29 \mathrm{BC}$ than in SGL $25 \mathrm{BC}$ (peak saturations of 0.35 and 0.17 , respectively). As shown in Table 4-1, these materials have identical uncompressed thicknesses and their MPLs have similar thickness and composition (23 wt. \% PTFE, 77 wt. \% carbon black). Their through-plane porosity profiles differ slightly, as shown in Figure 4-1. Unlike 
SGL $25 \mathrm{BC}$, SGL $29 \mathrm{BC}$ has a pronounced central peak in porosity (porosity $=0.82$ at $\mathrm{x}=92 \mu \mathrm{m}$ ). The higher local porosity in the center of SGL 29 BC acted as a preferred location for water accumulation. We propose that the lower-porosity regions on either side of the porosity maximum may also have contained smaller local pore sizes, and therefore resisted the percolation of condensed liquid water due to higher threshold capillary pressures.

Due to the high current densities at which these measurements were taken, the GDLs were typically highly saturated at all inlet relative humidities. The magnitude of the change in water volume with increasing humidity was relatively small compared to the total volume of water in the GDL.

\subsubsection{Comment on material movement}

The water thickness quantification presented in the Methodology chapter (Equation 3.5) involves the a priori assumption that the accumulation of liquid water is the only physical change affecting beam attenuation during an experiment. In reality, micron-scale solid material movement may occur during operation, impacting the liquid water calculation. Erroneous water thickness values arising from the micron-sale movement of the entire fuel cell sample were prevented by applying the methodology explained in the work by Ge et al. [44]. However, secondary sources of material movement were possible, and may not have been isolated from the liquid water information. For example, as in the recent study by Ge et al [24], the PEN spacers in our fuel cell had undesirable tapered edges at locations where the material was cut. These edges were prone to micron-scale movements which in turn may have resulted in changes to the pixel intensities which were indistinguishable from changes associated with the appearance of liquid water. The effects of material movements were confined to the interfaces between materials (e.g. CL-MPL and 
substrate-rib/channel). The water quantification in the majority of the GDL material (>2 pixels away from the MPL/CL and GDL/flow field interfaces) was not affected by material movement in this study.

\subsubsection{Oxygen transport resistance}

Table 4-3 summarizes the measured limiting current densities and associated oxygen transport resistances for all test cases in this study. In Figure 4-5, the transport resistance is presented as a function of limiting current to demonstrate the impact of cathode inlet RH on oxygen transport.

Table 4-3: Measured limiting current densities $\left(i_{L}\right)$ and oxygen transport resistances $\left(R_{T}\right)$ in a PEM fuel cell operating at cathode inlet $\mathrm{RH}$ levels ranging from $0 \%$ to $100 \%$.

\begin{tabular}{|c|c|c|c|}
\hline \multirow{4}{*}{ GDL } & RH [\%] & $\begin{array}{c}\boldsymbol{i}_{\boldsymbol{L}} \\
{\left[\mathbf{A} \cdot \mathbf{c m}^{-\mathbf{2}}\right]}\end{array}$ & $\begin{array}{c}\boldsymbol{R}_{\boldsymbol{T}} \\
{\left[\mathbf{s} \cdot \mathbf{c m}^{-\mathbf{1}}\right]}\end{array}$ \\
\hline \multirow{3}{*}{ SGL 25 BC } & $0 \%$ & 3.129 & 1.870 \\
\cline { 2 - 4 } & $50 \%$ & 2.957 & 1.881 \\
\cline { 2 - 4 } & $80 \%$ & 2.861 & 1.883 \\
\cline { 2 - 4 } & $100 \%$ & 2.749 & 1.917 \\
\hline \multirow{3}{*}{ SGL 29 BC } & $0 \%$ & 3.087 & 1.896 \\
\cline { 2 - 4 } & $50 \%$ & 2.917 & 1.906 \\
\cline { 2 - 4 } & $80 \%$ & 2.683 & 2.007 \\
\cline { 2 - 4 } & $90 \%$ & 2.568 & 2.074 \\
\cline { 2 - 4 } & $100 \%$ & 2.524 & 2.087 \\
\hline
\end{tabular}




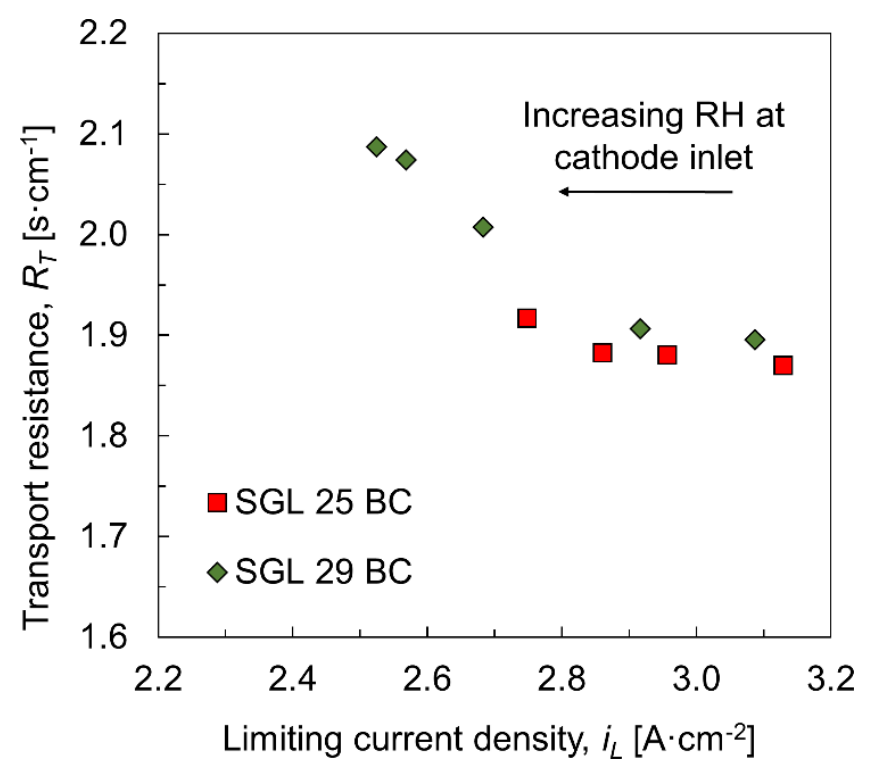

Figure 4-5: Oxygen transport resistance vs. limiting current density for the two GDLs studied. Higher limiting current densities correspond to lower humidity test cases.

As described in chapter 2, a particular GDL material has minimum and maximum (dry and wet) transport resistance plateaus depending on the operating pressure and temperature. In existing published results by Caulk and Baker and by Owejan et al. [33,81], similar operating conditions to those recorded in this study resulted in transport resistances associated with the wet regime. In these studies, relatively consistent transport resistances were observed across a wide range of current densities in the wet regime, which is consistent with our finding that the measured oxygen transport resistance changed marginally across all test cases in our study. The fuel cell constructed with SGL 29 BC GDLs experienced a larger change in transport resistance (from 1.896 to 2.087 $\mathrm{s} \cdot \mathrm{cm}^{-1}$ ) than the cell constructed with SGL $25 \mathrm{BC}$ (from 1.870 to $1.917 \mathrm{~s} \cdot \mathrm{cm}^{-1}$ ) when the cathode inlet relative humidity was increased from $0 \%$ to $100 \%$. This is in agreement with the liquid water accumulation trends presented in Figures 4-3 and 4-4. Higher saturation levels were measured in the channel regions of SGL 29 BC than in SGL 25 BC, especially at high relative 
humidity, and these higher saturations led to larger concentration polarization losses.

As illustrated in section 4.3.1, higher RH levels in the cathode gas streams resulted in the accumulation of additional liquid water in the carbon fiber substrate directly above the channels. Additional liquid water in the carbon fiber regions at higher RH levels was observed and contributed to the increases (though relatively minor) in oxygen transport resistance.

\subsection{Chapter summary}

Synchrotron X-ray radiography at the Canadian Light Source was used to spatially resolve the operando liquid water distribution in PEM fuel cells operating at limiting current density conditions. Based on an assumption of zero oxygen partial pressure at the cathode reaction sites, the oxygen transport resistance was calculated from the measured limiting current density.

The impact of cathode relative humidity on high current density liquid water configurations in the GDLs of operating PEM fuel cells was investigated. The liquid water accumulation patterns in the GDL above the reactant gas channels differed greatly from the regions above the flow field lands. Increasing the relative humidity in the cathode inlet gas stream led to increases in the liquid water saturation of the carbon fiber substrate above the channels. Of the two materials tested, SGL 29 $\mathrm{BC}$ experienced greater liquid water saturations in the GDL regions over the channels, especially at high relative humidity. This behaviour was attributed to a central high-porosity region in the through-plane porosity profile of SGL 29 BC which was not observed in SGL 25 BC. The liquid water saturation over the channels was small relative to the land regions, even in the most humid test cases. Potential reasons for the high observed saturation levels above the lands include lower 
local temperatures, lower local gas velocities, and greater wettability relative to the PTFE-coated carbon fibers.

For the tested conditions, the oxygen transport resistances at limiting current densities were found to be weakly sensitive to relative humidity. Of the two materials tested, high humidity levels had a greater impact on oxygen transport in SGL 29 BC, which agrees with the observation of greater liquid water saturation in the channel region of this material.

The impact of relative humidity and through-plane porosity profile on the spatial distribution of liquid water at high current density may be useful in tailoring materials and flow field designs for mass transport behaviour. The results presented herein may also serve as useful validation data for numerical models of liquid and vapour transport of water in the cathode GDL of a PEM fuel cell. 


\section{Chapter 5 Oxygen Transport Resistance and Liquid Water Accumulation in Polymer Electrolyte Membrane Fuel Cell Cathode GDLs: Impacts of Current Density and Cathode Inlet Relative Humidity}

\subsection{Chapter abstract}

The impacts of relative humidity (RH) and current density on liquid water accumulation and mass transport resistance in polymer electrolyte membrane (PEM) fuel cell cathode gas diffusion layers (GDLs) are presented in this chapter. Through-plane liquid water saturation distributions were measured in situ using synchrotron X-ray radiography while simultaneously, limiting currentbased characterizations of oxygen transport resistance were performed. The measured oxygen transport resistance exhibited significant sensitivity to cathode RH in the intermediate current density range $\left(1.5-2.1 \mathrm{~A} \cdot \mathrm{cm}^{-2}\right)$, which was attributed to GDL liquid water accumulation due to condensation. Cathode GDL liquid water saturation and oxygen transport resistance were both highest when fully humidified (100\% RH) cathode gas was supplied in this current density range. Furthermore, it was established that liquid water tends to preferentially accumulate in regions of higher local porosity within the GDL, identified by combining measured liquid water saturations with micro-computed tomography $(\mu \mathrm{CT})$ characterizations of the through-plane porosity profile. Finally, the strong relationship between oxygen transport resistance and the liquid water-free (effective) pore fraction of the GDL was also observed. The work presented in this chapter has been prepared as a journal manuscript. ${ }^{2}$

\footnotetext{
${ }^{2}$ Muirhead, D., Banerjee, R., Ge, N., Lee, J., Liu, H., Shrestha, P., George, M.G., Bazylak, A. "Oxygen Transport Resistance and Liquid Water Accumulation in Polymer Electrolyte Membrane Fuel Cell Cathode GDLs: Impacts of Current Density and Cathode Inlet Relative Humidity”. (Internal Review).
} 


\subsection{Introduction}

This study leverages the methodologies presented in chapter 3 to investigate cathode relative humidity (RH) and operating current density as factors that control the liquid water saturation and oxygen transport resistance in cathode GDL materials. Oxygen transport resistance was measured using limiting current experiments (chapter 3.6). Liquid water accumulation was visualized using synchrotron X-ray radiography (chapter 3.3). The through-plane porosity profile of the materials was measured by micro-computed tomography $(\mu \mathrm{CT})$ as described in chapter 3.4. Through-plane porosity profile was also considered as a factor which affects the through-plane liquid water saturation distribution in this study.

\subsection{Brief background: component decomposition of transport resistance}

The calculated oxygen transport resistance, $R_{T}\left[\mathrm{~s} \cdot \mathrm{cm}^{-1}\right]$ in Equation (3.14) of chapter 3.6.1 includes contributions from the flow channels, the GDL, and the catalyst layer $\left(R_{C H}, R_{G D L}\right.$ and $R_{C L}$ in Figure 5-1). $R_{T}$ is considered as the sum of these three, discrete components in series [77]. 


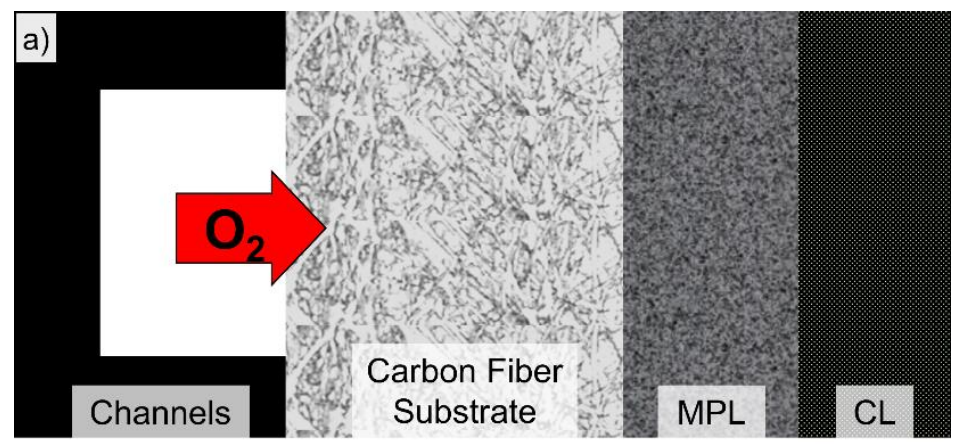

b)

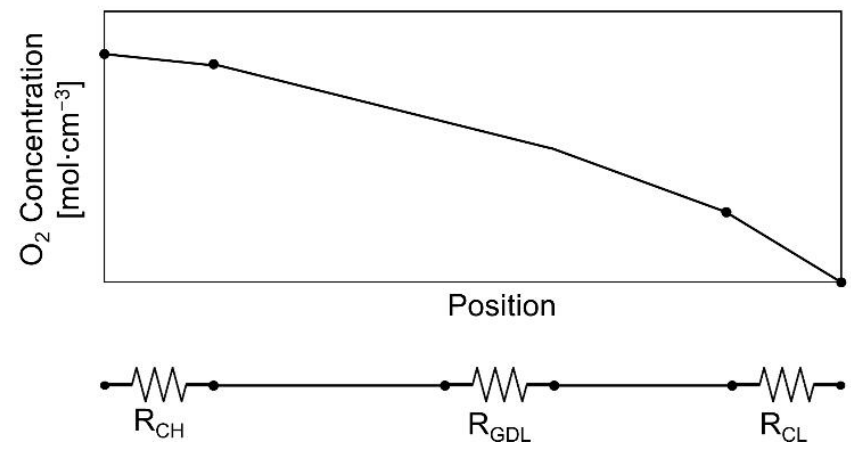

Figure 5-1: Illustration of the series components of oxygen transport resistance on the cathode side of a PEM fuel cell. Figure (a) depicts the fuel cell layers on the cathode side of the fuel cell (not to scale), (b) illustrates the gradient of oxygen concentration between the channels and the catalyst which drives oxygen flux, and (c) depicts a linear resistance network modeling the total oxygen transport resistance.

The first component is the transport resistance in the channels, $R_{C H}\left[\mathrm{~s} \cdot \mathrm{cm}^{-1}\right]$, which causes a concentration differential between the inlet gas and the flow field interface with the GDL. The second component is the transport resistance in the catalyst layer, wherein oxygen gas navigates small pore openings and permeates through a thin film of ionomer [104-106] to reach the catalyst surface. Oxygen transport in the catalyst layer is dominated by Knudsen diffusion and dissolution and diffusion through the ionomer thin film $[75,76,78,104]$; therefore the transport resistance in this layer is primarily independent of pressure. Between the CL and the flow field is the GDL 
$\left(R_{G D L}\right)$. In the GDL, intermolecular diffusion dominates. Due to the nano-scale pores in the MPL, some pressure-independent Knudsen diffusion resistance exists in the GDL, however it has been demonstrated to be relatively negligible compared to the pressure-independent resistance in the catalyst layer [77,78]. The total transport resistance can therefore be approximated by Equation (5.1):

$$
R_{T}=R_{C H}+R_{G D L}+R_{P I},
$$

Where $R_{T}$ is the total transport resistance, $R_{C H}$ is the transport resistance in the channels, and $R_{P I}$ is the pressure-independent component of transport resistance originating primarily in the catalyst layer. A small active area $\left(0.68 \mathrm{~cm}^{2}\right)$ was employed and high cathode stoichiometric ratios $(>20)$ were maintained in all experiments, therefore $R_{C H}$ has been assumed to be negligible. Furthermore, since the GDL is a bi-layered material consisting of a carbon fiber paper substrate and an MPL, the GDL resistance is expressed as follows:

$$
R_{G D L}=R_{C F}+R_{M P L},
$$

Where $R_{C F}\left[\mathrm{~s} \cdot \mathrm{cm}^{-1}\right]$ is the transport resistance in the substrate and $R_{M P L}\left[\mathrm{~s} \cdot \mathrm{cm}^{-1}\right]$ is the transport resistance through the MPL. The boundary between the carbon fiber substrate and MPL is defined based on the $\mu \mathrm{CT}$ characterization. Equation 5.1 can therefore be expressed as follows:

$$
R_{T}=R_{C F}+R_{M P L}+R_{P I} .
$$




\subsection{Methodology}

For descriptions of the fuel cell testing, material characterization, and liquid water visualization methodologies, readers are referred to the following sections of chapter 3 :

- Chapter 3.2: Fuel cell hardware and operation

- Chapter 3.3: Visualizations of liquid water

- Chapter 3.4: GDL porosity characterization by micro-computed tomography $(\mu \mathrm{CT})$

- Chapter 3.5: Calculation of liquid water saturation

- Chapter 3.6: Quantifying oxygen transport resistance.

This section summarizes the GDL materials employed for this study, existing correlations which can be used to estimate the contribution of the GDL carbon fiber substrate to oxygen transportation, and the methodologies used to separate the carbon fiber substrate contribution of oxygen transport resistance from the total measured resistance.

\subsubsection{GDL materials}

Three GDL materials were chosen for this study, all of which are commercially available from Sigracet ${ }^{\circledR}$. The first two materials are SGL 25 BC and SGL 29 BC, both of which are bi-layered GDLs that include MPLs. The third selected material is SGL 25 BA, a PTFE-treated carbon fiber

paper substrate without an MPL. The GDL material properties are summarized in Table 5-1. In all builds, identical gas diffusion layers were used on both the anode and cathode sides of the fuel cell. The desired GDL compression was achieved using rigid PEN gaskets as spacers. 
Table 5-1: GDL materials and properties

\begin{tabular}{cccc}
\hline GDL Name & SGL 25 BC & SGL 29 BC & SGL 25 BA \\
\hline Uncompressed thickness $(\mu \mathrm{m})^{*}$ & 235 & 235 & 190 \\
MPL thickness $(\mu \mathrm{m})^{\mathrm{a}}$ & 60 & 50 & - \\
Areal weight $\left(\mathrm{g} / \mathrm{m}^{2}\right)^{*}$ & 86 & 90 & 40 \\
PTFE load of backing $($ wt. \%) & 5 & 5 & 5 \\
PTFE content of MPL $($ wt. \%) & & & - \\
PEN spacer thickness for & 188 & 188 & 150 \\
compression $(\mu \mathrm{m})^{\mathrm{b}}$ & & & \\
\hline
\end{tabular}

${ }^{\text {a }}$ MPL thickness was determined based on micro computed tomography scans as described in chapter 3.3.

${ }^{\mathrm{b}}$ GDLs are compressed to the thickness of the spacers less the thickness of the catalyst coating of the CCM, which is approximately $15 \mu \mathrm{m}$.

*From manufacturer specifications.

${ }^{+}$From manufacturer white paper [91].

The phase-differentiated through-plane volume-fraction profiles for the three materials in this thesis are presented in Figure 5-2. The green area in Figure 5-2, including both the solid and hashed portions, represents the total open pore space available for gas transport. The solid green macro effective pore fraction represents the fraction of void voxels identified by the $\mu \mathrm{CT}$ segmentation procedure outlined in chapter 3.4. The hashed regions in Figure 5-2 (a) and (b) depict the micro effective pore fraction, which is the pore fraction of the MPL assuming a 50\% MPL porosity. 

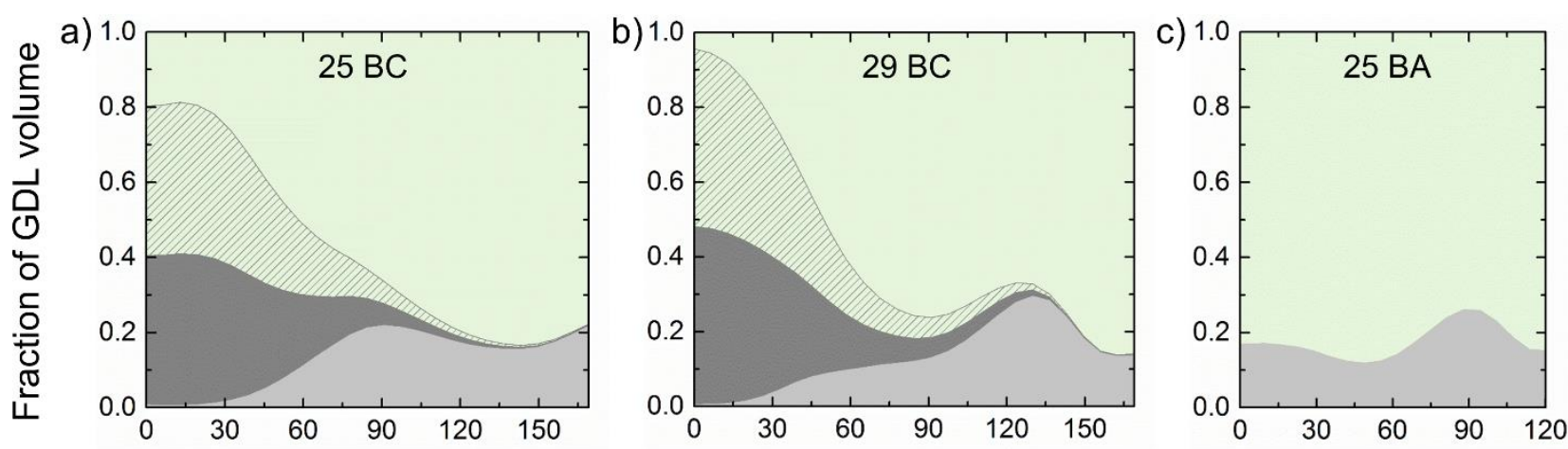

Through-plane $(x)$ position $[\mu \mathrm{m}]$

Fiber solid fraction

Micro effective pore fraction (MPL)

MPL solid fraction

Macro effective pore fraction

Figure 5-2: Through-plane porosity characterization for a) SGL 25 BC, b) SGL 29 BC, and c) SGL $25 \mathrm{BA}$. The zero position on the $\mathrm{x}$-axis corresponds to the CL/MPL interface. The macro effective pore fraction represents the fraction of void voxels identified by the $\mu \mathrm{CT}$ segmentation procedure outlined in chapter 3. The micro effective pore fraction represents the pore fraction of the MPL assuming a 50\% MPL porosity

\subsubsection{Correlations for GDL substrate effective diffusivity}

The carbon fiber substrate resistance $R_{C F}\left[\mathrm{~s} \cdot \mathrm{cm}^{-1}\right]$ from Equation (5.3) can be estimated from the substrate effective diffusivity, $D_{C F}^{\text {eff }}\left[\mathrm{cm}^{2} \cdot \mathrm{s}^{-1}\right]$, using Equation (5.4) [33,77]:

$$
R_{C F}=\left(\frac{f h_{C F}}{D_{C F}^{e f f}}\right)
$$

where $h_{C F}[\mathrm{~cm}]$ is the thickness of the carbon fiber substrate, and $f$ is a shape factor to account for the extra in-plane distance the oxygen molecules must travel due to the geometry of the flow 
field. The shape factor is a function of the land and channel dimensions, the substrate thickness, and the anisotropy of the effective diffusivity in the GDL [77].

Since the carbon fiber substrate was partially saturated with liquid water in the majority of the experiments in this study, the effective diffusion coefficient of oxygen, $D_{C F}^{e f f}$, was not constant. To compare existing correlations in literature to our experimental results, $D_{C F}^{e f f}$ was estimated for a range of substrate saturation levels using the correlations listed in Table 5-2. Using Equation (5.4), $R_{C F}$ was calculated from these estimations of effective diffusivity.

Table 5-2: Existing models from the literature for GDL effective diffusivity based on open porosity. The void fraction $\varepsilon_{e f f}$ represents the effective pore fraction in the dry or partiallysaturated GDL substrate.

\begin{tabular}{|c|c|}
\hline Correlation name & Equation \\
\hline $\begin{array}{c}\text { Bruggeman [107] } \\
\text { correlation: }\end{array}$ & $D_{C F}^{\text {eff }} / D_{\text {bulk }}=\left(\varepsilon_{\text {eff }}\right)^{1.5}$ \\
\hline $\begin{array}{c}\text { Modified Bruggeman } \\
\text { [33] correlation }(\mathbf{n}=\mathbf{3 . 5})\end{array}$ & $D_{C F}^{\text {eff }} / D_{\text {bulk }}=\left(\varepsilon_{\text {eff }}\right)^{3.5}$ \\
\hline $\begin{array}{c}\text { Zamel et al [108] carbon } \\
\text { fiber paper correlation }\end{array}$ & $D_{C F}^{\text {eff }} / D_{\text {bulk }}=\left(\varepsilon_{\text {eff }}-0.24\right)^{1.83}$ \\
\hline
\end{tabular}

The value $\varepsilon_{e f f}$ in Table 5-2 is the effective pore fraction in the carbon fiber region, defined in chapter 3.5. The quantity $D_{\text {bulk }}\left[\mathrm{cm}^{2} \cdot \mathrm{s}^{-1}\right]$, is the diffusion coefficient of oxygen in the multicomponent gas mixture at the cathode, assumed to contain $\mathrm{O}_{2}, \mathrm{~N}_{2}$, and $\mathrm{H}_{2} \mathrm{O}$ vapour. 


\subsubsection{Calculation of the bulk diffusion coefficient}

In this work, the following equation presented by Wilke [109] is used to calculate the diffusion coefficient of oxygen in the multicomponent gas mixture:

$$
D_{1-\text { mixture }}=\frac{1}{\frac{x_{2}^{\prime}}{D_{12}}+\frac{x_{3}^{\prime}}{D_{13}}+\cdots+\frac{x_{n}^{\prime}}{D_{1 n}}}
$$

Where $x_{n}^{\prime}$ is the mole fraction of component $n$ evaluated on a component-1-free basis, as shown in Equation (5.9):

$$
x_{2}^{\prime}=\frac{x_{2}}{x_{2}+x_{3}+\cdots+x_{n}}=\frac{x_{2}}{1-x_{1}}
$$

Based on equation (5.8), the diffusion coefficient of oxygen in the PEM fuel cell cathode gas mixture, $D_{\text {bulk }}\left[\mathrm{cm}^{2} \cdot \mathrm{s}^{-1}\right]$, can be calculated as follows:

$$
D_{\text {bulk }}=\frac{1}{\frac{x_{N}^{\prime}}{D_{O N}}+\frac{x_{W}^{\prime}}{D_{O W}}}
$$

Where $x_{N}^{\prime}$ and $x_{N}^{\prime}$ are the mole fractions of nitrogen and water vapour calculated using equation (5.9). The individual binary diffusion coefficients $D_{O W}$ and $D_{O N}\left[\mathrm{~cm}^{2} \cdot \mathrm{s}^{-1}\right]$, for oxygen in nitrogen and water vapour, respectively, were calculated based on Chapman-Enskog kinetic theory according to Equation (5.9) [110]:

$$
D_{A B}=0.0018583 \sqrt{T^{3}\left(\frac{1}{M_{A}}+\frac{1}{M_{B}}\right)} \frac{1}{p \sigma_{A B}^{2} \Omega_{D, A B}},
$$


Where $p[\mathrm{~atm}]$ is the total pressure, $T[\mathrm{~K}]$ is the temperature, and $M_{A}$ and $M_{B}$ are the component molecular weights. The dimensionless quantity $\Omega_{D, A B}$ is the collision integral for diffusion, which is tabulated in reference [110] as a function of the dimensionless temperature $\kappa T / \varepsilon_{A B}$, where

$\kappa\left[J \cdot K^{-1}\right]$ is the Boltzmann constant. The quantities $\sigma_{A B}[\AA]$ in Equation (5.9) and $\varepsilon_{A B}\left[J^{-1}\right]$ in the dimensionless temperature are the Lennard-Jones parameters for the interaction of one molecule of $A$ and one molecule of $B$ [110].

\subsubsection{Calculation of the shape factor, $f$}

The shape factor $f$ in Equation (5.4) converts the 2-dimensional anisotropic diffusive flux through the GDL substrate into an equivalent one-dimensional problem by adjusting the carbon fiber thickness, $h_{C F}[\mathrm{~cm}]$ to an equivalent thickness $f h_{C F}[\mathrm{~cm}]$. The shape factor is a function of the anisotropy of the effective diffusion coefficient in the material and the ratio of flow field channel width to flow field land with. Baker et al [77] define a dimensionless parameter for each of these factors. The ratio of land width to channel width, $\beta$, is calculated as follows:

$$
\beta=\frac{b}{a}
$$

Where $b[\mathrm{~cm}]$ is the land half-width and $a[\mathrm{~cm}]$ is the channel half-width. The dimensionless measure of diffusion coefficient anisotropy, $\lambda$, is calculated as:

$$
\lambda=\sqrt{D_{y}^{G D L} / D_{x}^{G D L}} \frac{h_{C F}}{a},
$$


Where $D_{y}^{G D L}$ and $D_{x}^{G D L}\left[\mathrm{~cm}^{2} \cdot \mathrm{s}^{-1}\right]$ are the in-plane and through-plane diffusion coefficients, respectively, in the substrate. The ratio of in-plane to through-plane diffusion coefficients in carbon fiber paper diffusion media were determined by Fluckiger et al [111] as a function of compression. Using their results for SGL 25 AA in conjunction with the average substrate porosities determined by the $\mu \mathrm{CT}$ characterizations in this study, the ratio $D_{y}^{G D L} / D_{x}^{G D L}$ was assumed to be 1.1 for SGL 25 BA and 1.3 for each of SGL 25 BC and SGL 29 BC.

For a ratio of $\beta=1$, Baker et al [77] developed a curve fit for the shape factor $f$ as a function of $\lambda$ as follows:

$$
f(\lambda, 1)=1+0.803 e^{-1.17 \lambda}+0.197 e^{-0.164 \lambda},
$$

Using the curve fit in Equation (5.14), a shape factor of 1.6 was calculated for SGL 25 BA, 25 BC, and $29 \mathrm{BC}$ for the purposes of this study.

\subsubsection{Estimation of MPL transport resistance}

To estimate the contribution of the MPL layer to the total measured transport resistance, the dry transport resistance measured for each of $25 \mathrm{BC}$ and $29 \mathrm{BC}$ was compared to the dry transport resistance for SGL $25 \mathrm{BA}$. The calculated transport resistances from the limiting current experiments with cathode inlet conditions of $80 \% \mathrm{RH}$ and a $0.01 \mathrm{O}_{2}$ mole fraction were used to calculate the MPL transport resistance as follows: 


$$
R_{M P L}=\left(R_{T, d r y}\right)_{\text {with MPL }}-\left(R_{T, d r y}\right)_{\text {no MPL }}
$$

Where $\left(R_{T, d r y}\right)_{\text {with MPL }}$ and $\left(R_{T, d r y}\right)_{\text {no MPL }}$ are the measured transport resistance of the bi-layered GDL and the substrate-only GDL, respectively. Assuming one-dimensional transport through the MPL, the MPL effective diffusion coefficient can be calculated from $R_{M P L}$ according to Equation (5.16).

$$
D_{M P L}^{e f f}=\left(\frac{R_{M P L}}{h_{M P L}}\right)
$$

Where $h_{M P L}[\mathrm{~cm}]$ is the MPL thickness. The MPL effective diffusivity $\alpha_{M P L}$ can be calculated according to Equation (5.17).

$$
\alpha_{M P L}=\frac{D_{M P L}^{e f f}}{D_{\text {bulk }}}
$$

Where $D_{\text {bulk }}\left[\mathrm{cm}^{2} \cdot \mathrm{s}^{-1}\right]$ is the bulk diffusion coefficient of oxygen in the cathode gas mixture.

\subsubsection{Estimation of catalyst layer transport resistance}

The pressure-independent transport resistance $R_{P I}$ has been assumed as a reasonable approximation of $R_{C L}$ (chapter 5.3). To find $R_{P I}$, limiting current experiments were conducted to find $R_{T}$ at a low $\mathrm{O}_{2}$ mole fraction (0.01) across several pressures ranging from ambient to $300 \mathrm{kPa}-$ absolute. The $\mathrm{O}_{2}$ mole fraction was chosen to limit current density, preventing liquid water condensation. 
If oxygen, nitrogen, and water vapour mole fractions are kept constant, $R_{P I}\left[\mathrm{~s} \cdot \mathrm{cm}^{-1}\right]$ is the extrapolated intercept of $R_{T}$ plotted as a function of pressure. Holding the mole fractions constant, however, would require adjusting vapour partial pressure at a fixed cell temperature, therefore affecting relative humidity. Cathode $\mathrm{RH}$ has been shown to impact the ionomer hydration in the catalyst layer, which affects measured transport resistance $[78,104]$. To avoid this complication, in these experiments the oxygen mole fraction and relative humidity have been held constant while adjusting the $\mathrm{N}_{2}$ balance gas fraction slightly to suit. As a result, the oxygen diffusivity in the gas mixture is pressure-dependent in this methodology. However, at a given pressure, the oxygen diffusivity (calculated as described in 5.4.2.1) varies less than $1 \%$ between $0 \% \mathrm{RH}$ and $100 \% \mathrm{RH}$. Therefore, the extrapolated zero-pressure intercept was assumed to be a reasonable estimation of $R_{P I}$, even with RH held constant.

\subsection{Summary of experiments}

Limiting current measurements were conducted across ranges of both cathode inlet gas relative humidity and oxygen concentration. The full set of measurement conditions are summarized in Table 5-3. For each dry inlet oxygen fraction listed in each row of Table 5-3, a limiting current measurement was made with simultaneous liquid water thickness measurement with the gas humidified to each inlet relative humidity level listed in the corresponding cell in the right-hand column. Liquid water saturation was quantified during limiting current operation using synchrotron X-ray radiography, as described in chapter 3.3. Transport resistances were calculated from the measured limiting current densities as outlined in chapter 3.6. 
Table 5-3: Summary of cathode inlet relative humidity and inlet oxygen mole fractions used for limiting current experiments

\begin{tabular}{|l|l|l|}
\hline \multicolumn{1}{|c|}{ GDL Sample } & \multicolumn{1}{|c|}{$\begin{array}{c}\text { Dry inlet oxygen mole } \\
\text { fraction }\end{array}$} & \multicolumn{1}{c|}{ Cathode inlet RH } \\
\hline \multirow{2}{*}{ SGL 25 BC } & $0.01,0.1,0.21$ & $0 \%, 50 \%, 80 \%, 100 \%$ \\
\cline { 2 - 3 } & $0.02,0.05,0.16$ & $80 \%$ \\
\hline \multirow{2}{*}{ SGL 29 BC } & $0.01,0.1,0.21$ & $0 \%, 50 \%, 80 \%, 100 \%$ \\
\cline { 2 - 3 } SGL 25 BA & $0.02,0.05,0.16$ & $80 \%$ \\
\hline
\end{tabular}

\subsection{Results and discussion}

\subsubsection{Oxygen transport resistance}

Figure 5-3 shows the measured transport resistances against limiting current density for a) SGL 25 BC and b) SGL 29 BC. To understand the trends revealed in Figure 5-3, the following analysis will focus on three main current density ranges: low current densities $\left(<0.5 \mathrm{~A} \cdot \mathrm{cm}^{-2}\right)$, intermediate

current densities $\left(1.5-2.1 \mathrm{~A} \cdot \mathrm{cm}^{-2}\right)$, and high current densities $\left(>3.0 \mathrm{~A} \cdot \mathrm{cm}^{-2}\right)$. The level of limiting current density was determined by the concentration of oxygen in the cathode feed gas. 

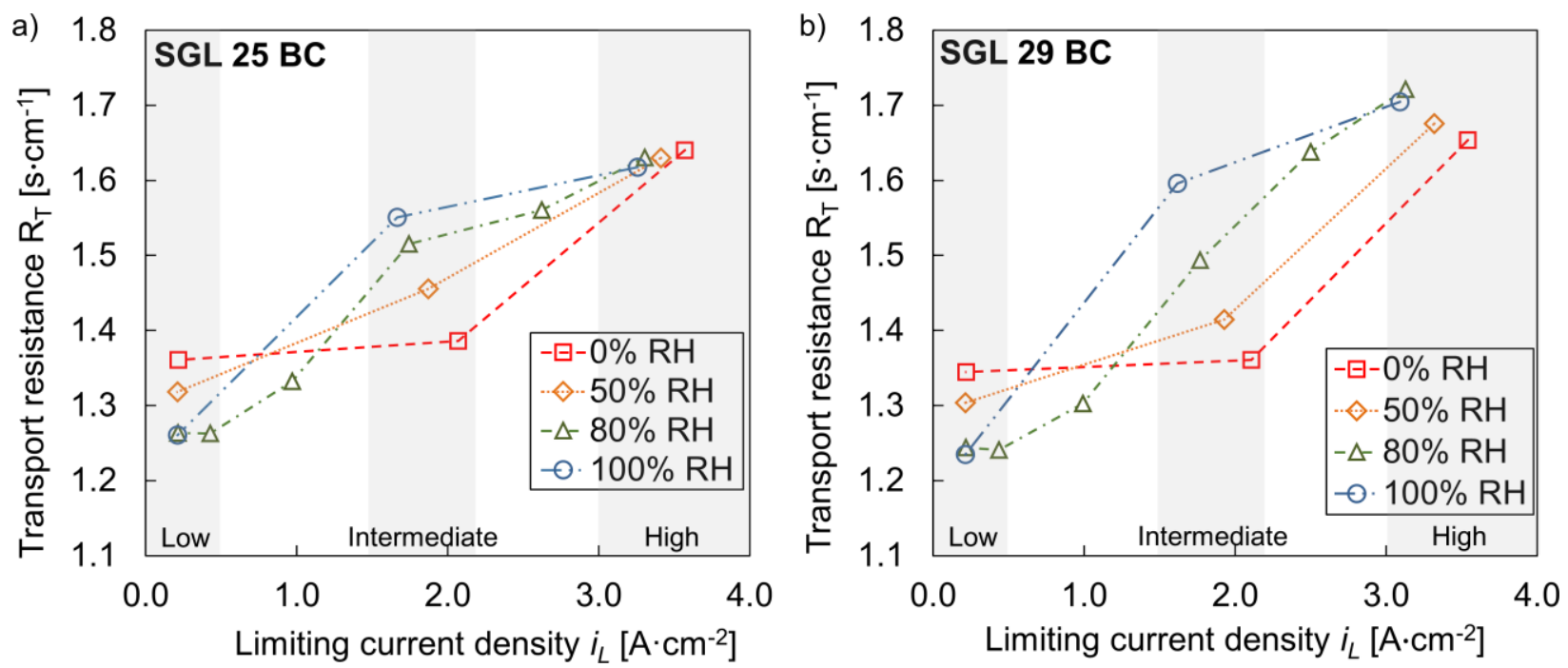

Figure 5-3: Oxygen transport resistance versus limiting current density for a) SGL 25 BC and b) SGL 29 BC. Lower limiting current densities correspond to experiments with lower inlet oxygen concentrations. Humidity levels are indicated by symbol shape, line style and colour. Low, intermediate, and high current density regimes are indicated by shading.

To summarize the sensitivity of $R_{T}$ to cathode inlet $\mathrm{RH}$, Table 5-4 indicates the measured transport resistances at the $0 \% \mathrm{RH}$ and $100 \% \mathrm{RH}$ test cases at each of the low, intermediate, and high current density ranges. 
Table 5-4: Measured oxygen transport resistances during experiments conducted with minimal $(0 \%)$ and maximal $(100 \%)$ cathode inlet relative humidity.

\begin{tabular}{|c|c|c|c|}
\hline $\begin{array}{c}\text { GDL } \\
\text { material }\end{array}$ & $\begin{array}{c}\text { Current density } \\
\text { range }\end{array}$ & $\begin{array}{c}\boldsymbol{R}_{\boldsymbol{T}} \text { measured at } \\
\mathbf{0 \%} \mathbf{R H}\left[\mathbf{s} \cdot \mathbf{c m}^{-\mathbf{1}}\right]\end{array}$ & $\begin{array}{c}\boldsymbol{R}_{\boldsymbol{T}} \text { measured at 100\% } \\
\mathbf{R H}\left[\mathbf{s} \cdot \mathbf{c m}^{-\mathbf{1}}\right]\end{array}$ \\
\hline \multirow{4}{*}{ SGL 25 BC } & $\begin{array}{c}\text { Low } i \\
\left(x_{O_{2}}^{d r y-i n}=0.01\right)\end{array}$ & 1.361 & 1.261 \\
\cline { 2 - 4 } & $\begin{array}{c}\text { Intermediate } i \\
\left(x_{O_{2}}^{d r y-i n}=0.10\right)\end{array}$ & 1.386 & 1.551 \\
\cline { 2 - 4 } & $\begin{array}{c}\text { High } i \\
\left(x_{O_{2}}^{d r y-i n}=0.21\right)\end{array}$ & 1.640 & 1.618 \\
\hline \multirow{3}{*}{ SGL 29 BC } & $\begin{array}{c}\text { Low } i \\
\left(x_{O_{2}}^{d r y-i n}=0.01\right)\end{array}$ & 1.345 & 1.235 \\
\cline { 2 - 4 } & $\begin{array}{c}\text { Intermediate } i \\
\left(x_{O_{2}}^{d r y-i n}=0.10\right)\end{array}$ & 1.361 & 1.596 \\
\cline { 2 - 4 } & $\left(x_{O_{2}}^{d r y-i n}=0.21\right)$ & 1.654 & 1.705 \\
\hline
\end{tabular}

At low current densities ( 0.01 oxygen mole fraction in the cathode feed) the test cases with the lowest inlet relative humidity $(0 \% \mathrm{RH})$ exhibited the largest transport resistances $(0.10$ to 0.11 $\mathrm{s} / \mathrm{cm}$ greater than the $100 \% \mathrm{RH}$ tests). The observation of this high transport resistance agrees with findings from Xie et al [104] and $\mathrm{Oh}$ et al [78], who pointed to an increase in catalyst layer $\mathrm{O}_{2}$ transport resistance at the ionomer thin film with low RH. In the catalyst layer, oxygen molecules must dissolve and diffuse through a layer of ionomer in order to reach the surface of a platinum particle $[104,105,112,113]$. As RH decreases, the oxygen diffusion coefficient in the ionomer film decreases [114], as the decrease in water content induces Nafion shrinkage and decreases ionomer flexibility. In turn, the distance between polymer chains decreases in the film at low RH $[114,115]$, decreasing the diffusion coefficient of oxygen. 
In the intermediate and high current density ranges, liquid water accumulation is expected at limiting current $[33,81]$, resulting in elevated oxygen transport resistance through the cathode GDL. It was observed that oxygen transport resistance was strongly sensitive to relative humidity at intermediate current densities ( 0.1 mole fraction of oxygen in the cathode feed gas). In this current density range, the values of $R_{T}$ measured at $100 \% \mathrm{RH}$ were larger than those measured at $0 \%$ RH by margins of $0.165 \mathrm{~s} \cdot \mathrm{cm}^{-1}$ for SGL $25 \mathrm{BC}$ and $0.235 \mathrm{~s} \cdot \mathrm{cm}^{-1}$ for SGL $29 \mathrm{BC}$.

At high current densities $\left(>3.0 \mathrm{~A} / \mathrm{cm}^{2}\right)$, measured transport resistances were larger than other current density ranges, however $R_{T}$ varied by only 0.02 to $0.05 \mathrm{~s} / \mathrm{cm}$ across the full range of inlet $\mathrm{RH}$. To understand the observed trends in $R_{T}$ in the intermediate and high current density regimes, particularly the relatively large sensitivity of $R_{T}$ to cathode $\mathrm{RH}$ in the intermediate range, the subsequent sections investigate the liquid water content in the cathode GDL.

\subsubsection{Liquid water accumulation}

\subsubsection{Effects of cathode inlet relative humidity and current density}

Low current-density $\left(<0.5 \mathrm{~A} \cdot \mathrm{cm}^{-2}\right)$

Figure 5-4 depicts the measured liquid water saturation profiles in SGL $29 \mathrm{BC}$ with a dry inlet $\mathrm{O}_{2}$ mole fraction of 0.01 in the cathode inlet gas. The saturation was approximately zero in SGL 29 $\mathrm{BC}$ at all RH levels. This was true also in SGL $25 \mathrm{BC}$, the saturation profiles for which can be found in the Appendix. In the low current-density range of Figure 5-3 (including tests conducted with inlet $\mathrm{O}_{2}$ mole fractions of 0.01 and 0.02 ), the largest transport resistances were observed when

cathode inlet gas was introduced with low relative RH levels $(0 \%, 50 \%)$. Since liquid water was 
not observed in any low current-density tests, we can conclude that the elevated transport resistance with reduced inlet RH must originate from the catalyst layer, rather than from the GDL or channel liquid water accumulation.
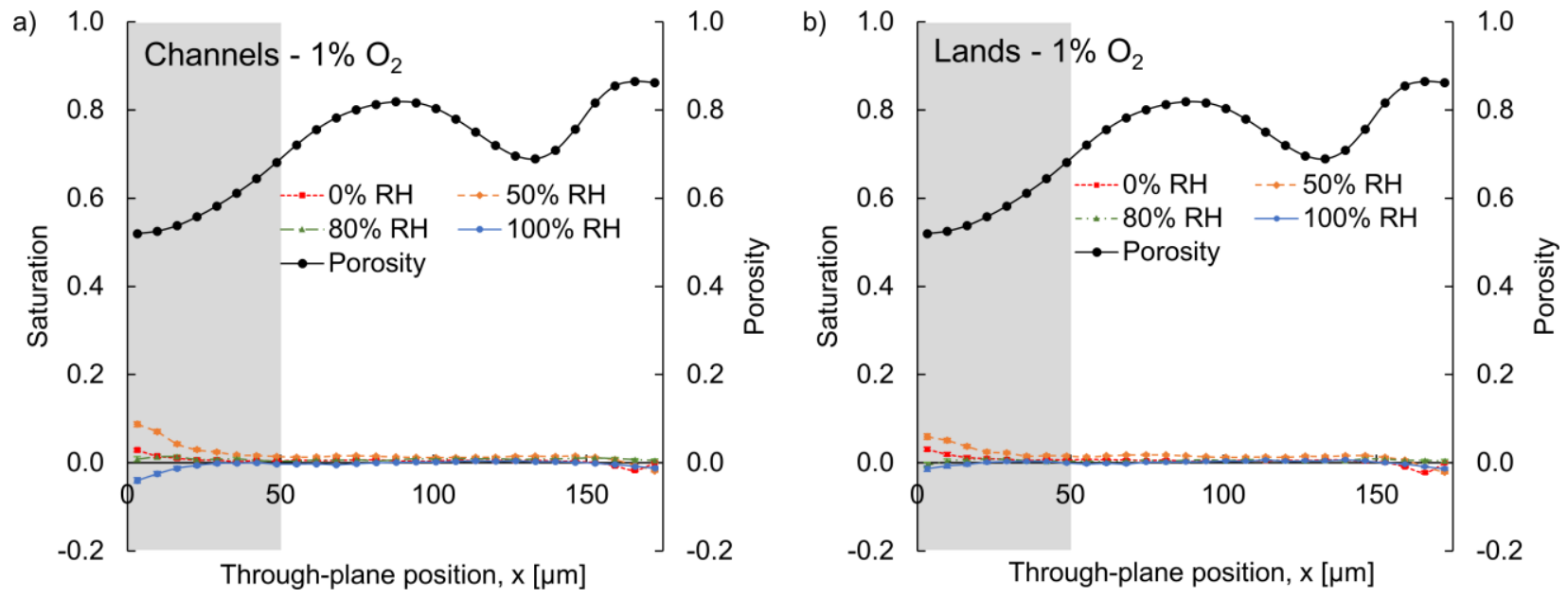

Figure 5-4: Through-plane porosity and saturation profiles in (a) the regions of the SGL 29 BC GDL above the flow field channels (max. uncertainty \pm 0.006 ) and (b) the regions of the GDL above the flow field lands (max. uncertainty \pm 0.006 ) for limiting current experiments with a 0.01 oxygen mole fraction supplied in the dry cathode gas feed, prior to humidification (indicated as $1 \% \mathrm{O}_{2}$ ). The resulting limiting current densities were below $0.5 \mathrm{~A} \cdot \mathrm{cm}^{-2}$ at all humidity levels. See the Appendix for similar figures for SGL 25 BC.

\section{Intermediate current-density $\left(1.5-2.1 \mathrm{~A} \cdot \mathrm{cm}^{-2}\right)$}

In the limiting current experiments with an $\mathrm{O}_{2}$ mole fraction of 0.1 in the pre-humidified cathode inlet gas stream $\left(1.5\right.$ to $2.1 \mathrm{~A} \cdot \mathrm{cm}^{-2}$ ), a wide range of transport resistances were observed (see Table 5-4 and Figure 5-3). In Figure 5-5, the level of liquid water saturation varied greatly depending on the cathode inlet humidification. The additional liquid water accumulation at high 
relative humidity implies that condensation or evaporation rates in the GDL were dependent on the inlet relative humidity in this current density range.
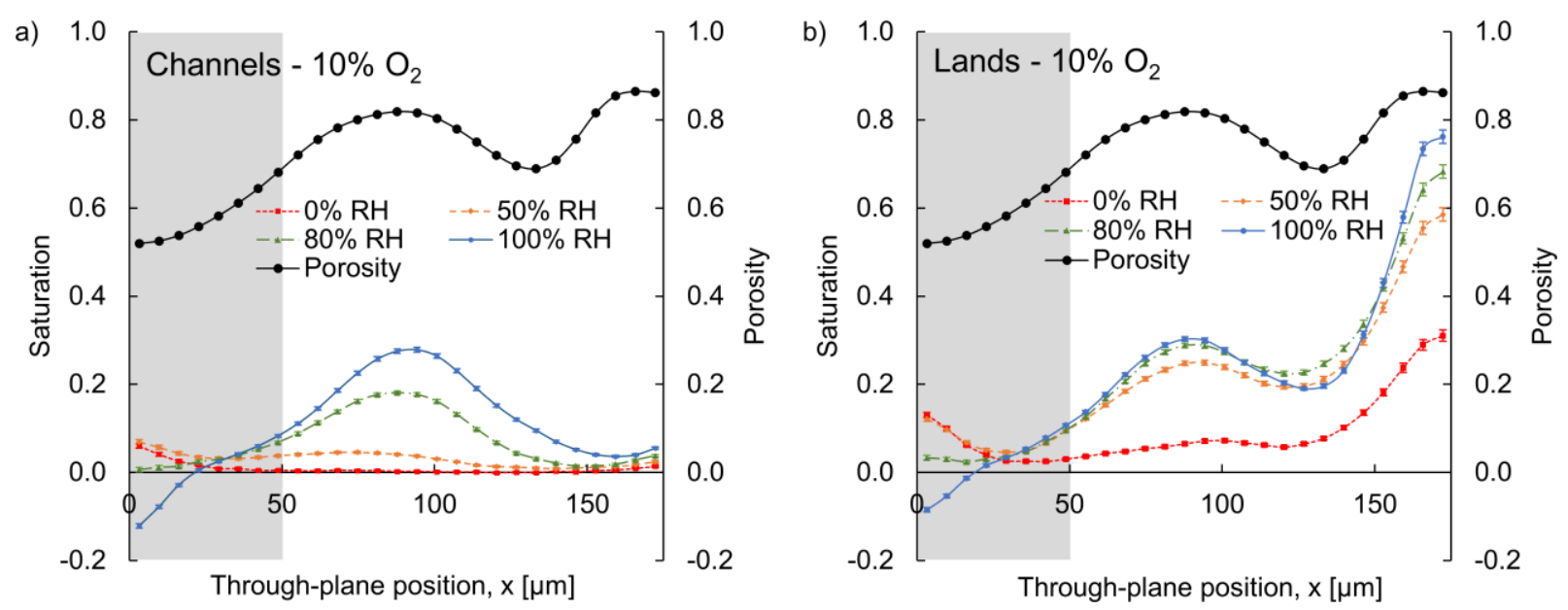

Figure 5-5: Through-plane porosity and saturation profiles in (a) the regions of the SGL 29 BC GDL above the flow field channels (max. uncertainty \pm 0.006 ) and (b) the regions of the GDL above the flow field lands (max. uncertainty \pm 0.015 ) for limiting current experiments with a 0.1 oxygen mole fraction supplied in the dry cathode gas feed, prior to humidification (indicated as $10 \% \mathrm{O}_{2}$ ). The resulting limiting current densities were between 1.5 and $2.1 \mathrm{~A} \cdot \mathrm{cm}^{-2}$. See the Appendix for similar figures for SGL $25 \mathrm{BC}$.

Figure 5-5 also indicates the tendency for the land regions of the GDL to become more saturated with liquid water than the channel regions. At $0 \%$ and $50 \% \mathrm{RH}$, there was a negligible quantity of water in the channel regions. The land regions were partially saturated in these same conditions. Overall, the difference in liquid water accumulation between land and channel regions was most pronounced between $\mathrm{x}=120 \mu \mathrm{m}$ and $\mathrm{x}=170 \mu \mathrm{m}$, in close proximity to the GDL/flow field interface. At this interface, high saturations (> 0.6) were observed adjacent to the flow field lands, 
while there was little or no water (saturation $<0.1$ ) adjacent to the flow field channels. The high saturations above the lands occurred for two reasons. Product water vapour tended to condense on the surface of the land, since cooling was provided by the temperature controlled water circulation through the flow field. Flow field lands also provided capillary wicking for the liquid water, as they have a lower surface contact angle than the PTFE coating on the substrate fibers.

\section{High current-density $\left(>3.0 \mathrm{~A} \cdot \mathrm{cm}^{-2}\right)$}

In experiments with un-diluted air at the cathode $\left(0.21 \mathrm{O}_{2}\right.$ mole fraction $)$, we achieved limiting current densities greater than $3.0 \mathrm{~A} \cdot \mathrm{cm}^{-2}$ in both SGL $25 \mathrm{BC}$ and SGL $29 \mathrm{BC}$ across all inlet RH levels. High saturations were observed across all humidity levels (Figure 5-6), especially over the land regions, where peak saturations greater than 0.6 were observed consistently at the interface between the flow field land regions (5-6b) and the GDL. Above the flow field channels (5-6a), there was a small increase in water accumulation at higher humidity. As noted in section 5.6.1 and in our previous work in chapter 4 , this increase in water content had only a small impact on transport resistance. 

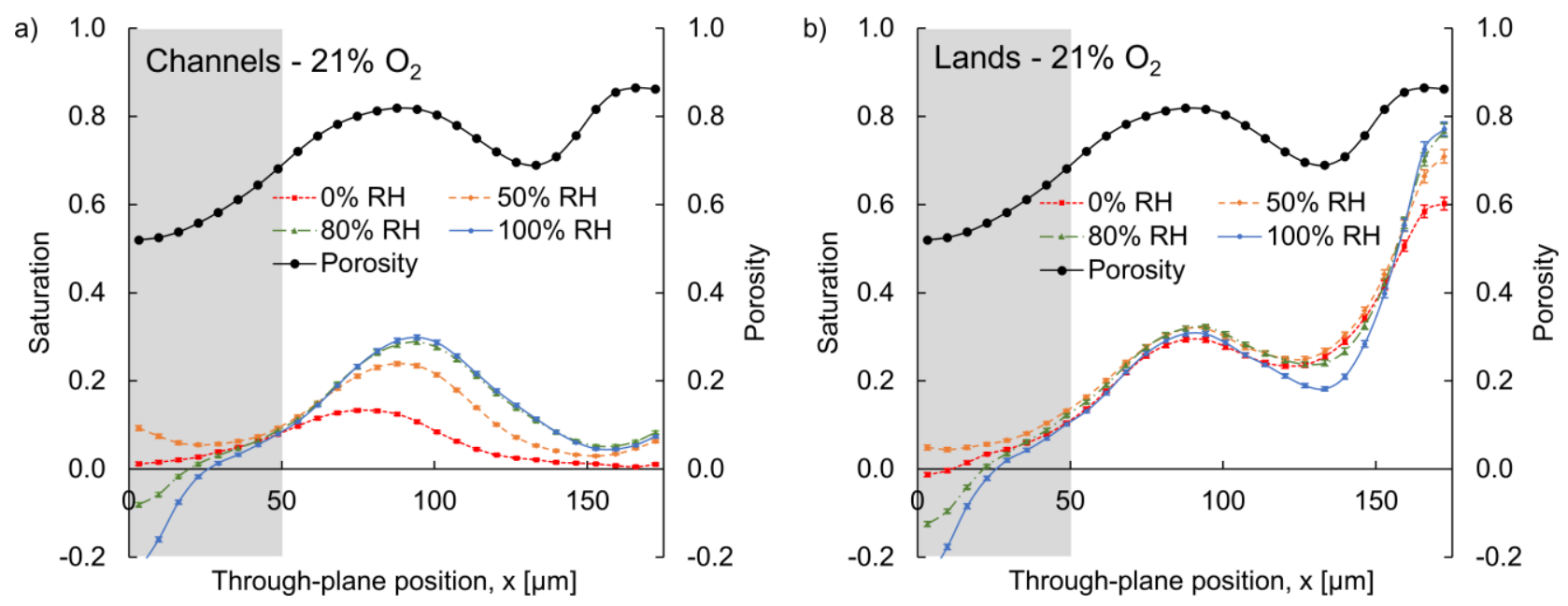

Figure 5-6: Through-plane porosity and saturation profiles in (a) the regions of the SGL 29 BC GDL above the flow field channels (max. uncertainty \pm 0.007 ) and (b) the regions of the GDL above the flow field lands (max. uncertainty \pm 0.016 ) for limiting current experiments with a 0.21 mole fraction of oxygen supplied in the dry cathode gas feed, prior to humidification (indicated as $21 \% \mathrm{O}_{2}$ ). The resulting limiting current densities were greater than $3.0 \mathrm{~A} \cdot \mathrm{cm}^{-2}$ at all humidity levels. See the Appendix for similar figures for SGL 25 BC.

With 100\% RH in the cathode feed, the saturation levels observed in Figure 5-6 for high current densities were similar (within 3.1\% local saturation at any given through-plane position) to those observed in Figure 5-5 for intermediate current densities. Similar GDL effective diffusivities are expected with similar liquid water distributions in the GDL. However, the transport resistances for the high current density level was $0.109 \mathrm{~s} \cdot \mathrm{cm}^{-1}(6.8 \%)$ larger than the resistance at the intermediate current density level. This increased transport resistance could be attributed to the mechanism of catalyst layer ionomer drying causing a reduction in oxygen diffusion coefficient, similar to what was postulated to occur at low current density and low relative humidity (section 5.6.1). In the low current-density cases, the drying would have been caused by a failure of the 
electrochemical water production to replace the water vapour driven out by the low relative humidity. In the high current-density cases, the catalyst layer ionomer drying could be a result of elevated local temperatures caused by the significant heat production resulting from high currentdensity operation with a large cathode overpotential. Loss of Nafion hydration at high temperature is expected [116], and the elevation of local temperature at the CCM in high current-density operation is well-established in literature [24,102,117].

\subsubsection{Comment on material movement}

The liquid water thickness calculation (Equation 3.5) presented in the image processing methodology is applied with the a priori assumption that the appearance of liquid water is the only change to the material in the beam path at each pixel location. The appearance of significant nonphysical liquid water values arising from the micron-sale movement of the entire fuel cell sample was prevented by applying the methodology explained in the work by Ge et al [44]. However, secondary sources of micron-scale material movement were possible, and may not have been isolated from the liquid water information. In particular, movement was detected in some experiments either at the interface between the CCM and MPL. At a particular pixel location, material movement may result in an increase in pixel intensity relative to the "dry" reference image, for example if a more attenuating material (e.g. platinum) is replaced by a less-attenuating material (e.g. MPL). Equation (3.5) will then lead to the calculation of a negative value $[24,118,119]$. While this observation is graphically indicated as negative water thickness or negative saturation in this study, the change in optical depth is in fact a physically meaningful and potentially useful indication of material displacement. It is possible to identify and diagnose delamination events and membrane swelling or shrinkage events $[118,119]$ by calculating the 
positive or negative change in optical depth relative to the reference image. The effects of material movement on liquid water quantification were confined to the pixels near material interfaces.

\subsubsection{Effect of through-plane porosity profile on liquid water accumulation}

This section demonstrates the tendency for water to accumulate preferentially in the regions of the GDL with high local porosity. Based on our $\mu \mathrm{CT}$ characterization (Figure 5-2 in section 5.4.1), the through-plane porosity profile of SGL 29 BC exhibited two local maxima in open pore space. At the $90 \mu \mathrm{m}$ position and at the GDL/flow field interface, greater than $80 \%$ of the volume in-plane was classified as void pore space in the dry GDL. SGL 29 BC exhibits a local minimum in porosity approximately $\mathrm{x}=130 \mu \mathrm{m}$. In contrast, SGL $25 \mathrm{BC}$ does not exhibit pronounced local porosity maxima.

Two specific examples were selected to demonstrate the preferential liquid water accumulation at regions of local high porosity. In each example, during limiting current operation at a particular RH and oxygen mole fraction, liquid water accumulated in a high-porosity region in SGL 29 BC or SGL 25 BA, yet liquid water was absent or present in only small quantities at the same throughplane position of SGL 25 BC, where local high-porosity regions did not exist. The chosen cathode inlet test conditions which demonstrate this liquid water behaviour were $80 \% \mathrm{RH}$ and $0 \% \mathrm{RH}$, each with an inlet $\mathrm{O}_{2}$ mole fraction of 0.1 .

The first example demonstrating preferential water accumulation in high-porosity regions is the limiting current experiment with $80 \%$ cathode $\mathrm{RH}$ and a cathode dry inlet $\mathrm{O}_{2}$ mole fraction of 0.10 , shown in Figure 5-7. In Figure 5-7, the spatially resolved through-plane profiles of MPL solid 
content, carbon fibers, water, and pore space are depicted for each of the three GDL materials while operated at limiting current. The limiting current densities achieved for the three materials in these conditions were $1.911,1.742$, and $1.766 \mathrm{~A} \cdot \mathrm{cm}^{-2}$ for SGL $25 \mathrm{BA}, 25 \mathrm{BC}$, and $29 \mathrm{BC}$ respectively. Despite using the same inlet conditions and measuring limiting current densities within a narrow range of $0.17 \mathrm{~A} \cdot \mathrm{cm}^{-2}$, the physical locations of liquid water build-up differed significantly depending on the porosity profile of the GDL. Liquid water accumulated in the central high porosity region of SGL 29 BC (indicated by the asterisk in Figure 5-7c) between the MPL and the porosity local minimum at $\mathrm{x}=130 \mu \mathrm{m}$, with a peak saturation of $18.1 \%$ at $\mathrm{x}=88 \mu \mathrm{m}$, the approximate location of the local porosity maximum. In the SGL 25 BC GDL, which did not exhibit a central high-porosity region, there was significantly less liquid water present at limiting current at $80 \% \mathrm{RH}$ and $10 \% \mathrm{O}_{2}$ in the cathode gas. A maximum saturation of $9.3 \%$ was observed at $\mathrm{x}=75 \mu \mathrm{m}$. 
a) SGL 25 BA

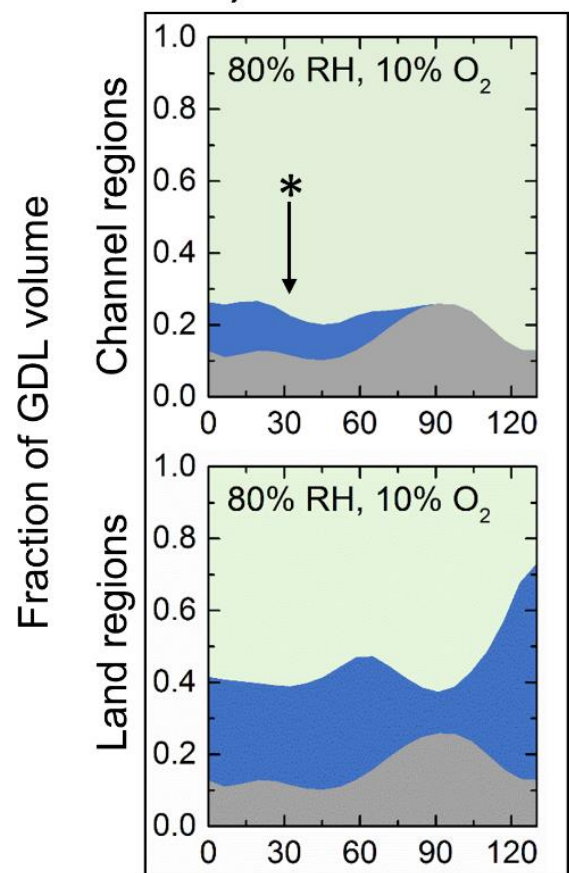

b) SGL 25 BC

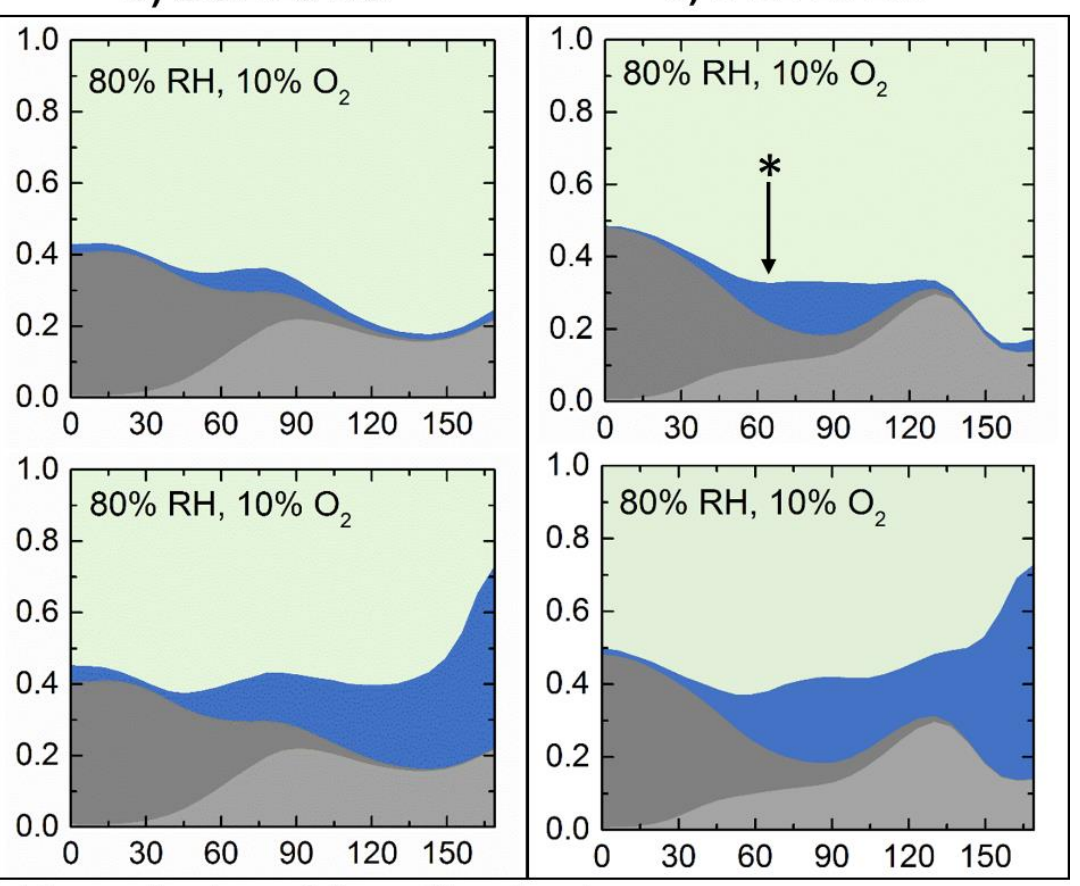

Through-plane $(\mathrm{x})$ position $[\mu \mathrm{m}]$ c) SGL 29 BC

\section{Effective pore fraction}

Figure 5-7: Through-plane distributions of solid, water, and effective pore (void) volume fractions in the SGL a) $25 \mathrm{BA}$, b) $25 \mathrm{BC}$, and c) $29 \mathrm{BC}$ GDLs during limiting current operation with cathode gas containing an oxygen mole fraction of 0.10 prior to humidification to $80 \%$ cathode inlet relative humidity. Asterisks indicate locations of high porosity where liquid water tended to accumulate preferentially.

As illustrated in Figure 5-7(a), SGL 25 BA has an extended high-porosity region between $x=0$ $\mu \mathrm{m}\left(\mathrm{CL} / \mathrm{MPL}\right.$ interface) and $\mathrm{x}=60 \mu \mathrm{m}$. At limiting current density with $80 \% \mathrm{RH}$ and $10 \% \mathrm{O}_{2}$ in the cathode, this entire high-porosity region experienced liquid water build-up (indicated by the asterisk in the top image of Figure 5-7a), with saturation levels ranging from 10.9\% to $16.5 \%$ throughout in the GDL channel regions (top image). Meanwhile, liquid water was not detected 
above the channels at the location of the local porosity minimum ( $x=90 \mu \mathrm{m}$, top image). High saturations were observed adjacent to the flow field lands in all GDLs due to lower local temperatures and the relatively low surface contact angle of the graphite flow field, as noted previously.

The second example of preferential liquid water accumulation in high-porosity regions is shown in Figure 5-8. Figure 5-8 depicts the water accumulation measurements and effective pore fraction at limiting current for $0 \%$ cathode inlet $\mathrm{RH}$ and a cathode dry inlet $\mathrm{O}_{2}$ mole fraction of 0.10 . The GDLs in Figure 5-8 are generally less saturated than in Figure 5-7, since the test case depicted in Figure 5-8 was conducted with a lower relative humidity. The high-porosity region of SGL 29 BC at the GDL/flow field interface experienced liquid water build-up (indicated by the asterisk in the bottom image of Figure 5-8b). SGL 25 BC was almost completely dry throughout under these same test conditions (Figure 5-8a). As in the case presented in Figure 5-7, liquid water was observed in a high porosity region of SGL 29 BC, however water was absent at the same position in the SGL 25 BC GDL with the same inlet relative humidity and inlet oxygen concentration. 


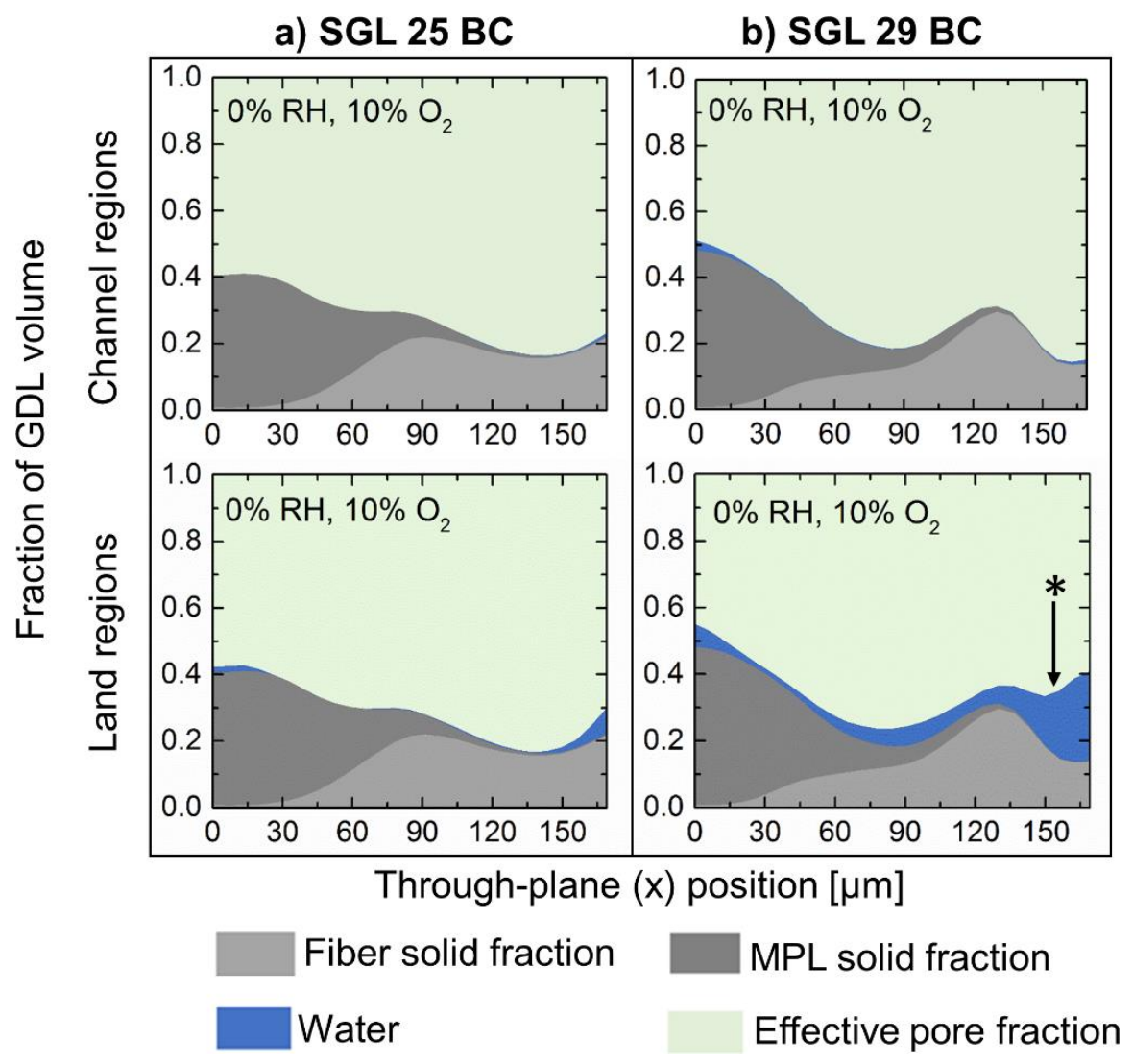

Figure 5-8: Through-plane distributions of solid, water, and effective pore (void) volume fractions in the SGL a) $25 \mathrm{BC}$, and b) $29 \mathrm{BC}$ GDLs during limiting current operation with cathode gas containing an oxygen mole fraction of 0.10 and no cathode humidification ( $0 \% \mathrm{RH})$. The asterisk indicates a location of high porosity in SGL 29 BC where liquid water tended to accumulate preferentially.

Overall, the water accumulation patterns presented in Figure 5-7 and Figure 5-8 indicate that higher porosity regions may become preferred locations for liquid water accumulation. Due to the presence of a central local maximum in porosity in SGL 29 BC, this carbon fiber substrate was more prone to water accumulation than SGL 25 BC under similar operating conditions. 
The tendency for liquid water to appear in the high porosity regions of the GDL concurs with capillary-force dominated liquid water percolation. Since the solid matrix in the substrate is comprised of fibers of a roughly constant diameter, where less solid content exists, the pore spaces and inter-pore openings (throats) can be expected to be larger. Large openings have lower entry threshold capillary pressures; therefore these regions are easier to invade via capillary-force dominated percolation. The source of the percolating liquid water may be from either the CL or the surface of the flow field lands, where water was observed to condense, leading to high local saturations.

\subsubsection{Relationship of substrate effective pore space to transport resistance}

The effective diffusivity in the GDL is a function of the open porosity and tortuosity, which are affected by the extent of liquid water saturation in the medium. In this section, the relationship between the effective pore space in the carbon fiber substrate and the substrate transport resistance is examined. Using the experimentally-derived estimations of $R_{M P L}$ and $R_{P I}$ outlined below, GDL carbon fiber substrate oxygen transport resistance was calculated as follows:

$$
R_{C F}=R_{T}-R_{M P L}-R_{P I}
$$

The experimentally determined values of $R_{C F}$ were compared to transport resistances calculated from common empirical estimations of effective diffusivity from literature $[33,107,108]$.

\subsubsection{MPL transport resistance}

The calculated MPL transport resistances for SGL 25 BC and SGL 29 BC are shown in Table 55. The MPL effective diffusivities calculated from the estimation of MPL transport resistance are 
also included in Table 5-5. The dry through-plane effective diffusivity values of 0.148 and 0.131 calculated for SGL $25 \mathrm{BC}$ and $29 \mathrm{BC}$ respectively are within the expected range of 0.04 to 0.22 reported in the literature [10,120-122] for MPL materials.

Table 5-5: Calculation of MPL contribution to total transport resistance and MPL effective diffusion coefficient in SGL 25 BC and SGL 29 BC using low $\mathrm{O}_{2}$ concentration limiting currentbased measurements of total oxygen transport resistance according to Equations (5.15) - (5.17).

\begin{tabular}{|c|c|c|c|c|}
\hline $\begin{array}{c}\text { GDL } \\
\text { SGL 25 BA }\end{array}$ & $\begin{array}{c}\boldsymbol{R}_{T, d r y} \\
{\left[\mathbf{s} \cdot \mathbf{c m}^{-1}\right]^{\mathrm{a}}}\end{array}$ & $\begin{array}{c}\boldsymbol{R}_{M P L}\left[\mathbf{s} \cdot \mathbf{c m}^{-1}\right] \\
(\text { Equation 5.15) }\end{array}$ & $\begin{array}{c}\text { MPL Thickness } \\
\boldsymbol{h}_{M P L}[\boldsymbol{\mu m}]^{\mathbf{b}}\end{array}$ & $\begin{array}{c}\boldsymbol{\alpha}_{M P L}=D_{M P L}^{\text {eff }} / D_{A B} \\
(\text { Equation 5.17) }\end{array}$ \\
\hline SGL 25 BC & 0.945 & - & - & - \\
\hline SGL 29 BC & 1.263 & 0.318 & 60 & 0.148 \\
\hline
\end{tabular}

a The transport resistance measured at $80 \% \mathrm{RH}$, at the cathode with an 0.01 inlet $\mathrm{O}_{2}$ mole fraction was taken as $R_{T, d r y}$

${ }^{\mathrm{b}}$ Based on the methodology outlined in chapter 3.4

Above, the transport resistance of a dry MPL was estimated. In the liquid water saturation profiles for SGL 29 BC in Figures 5-4 to 5-6, there was a small amount of water in the MPL (less than 7\% saturation) compared to the water accumulation observed in the carbon fiber substrate (up to $20 \%$ saturation). While small amounts of water were observed in the MPL, it has been assumed in the forthcoming analysis that the value of $R_{M P L}$ remained constant across all tests. 


\subsubsection{Pressure-independent component of transport resistance (catalyst layer)}

The catalyst layer transport resistance was estimated as the pressure-independent component of oxygen transport resistance, $R_{P I}$ (chapter 5.4.4). To isolate $R_{P I}$, limiting current experiments were conducted at a low $\mathrm{O}_{2}$ concentration $\left(0.01 \mathrm{O}_{2}\right.$ mole fraction pre-humidification) across several pressures ranging from ambient to $300 \mathrm{kPa}$-absolute and four $\mathrm{RH}$ levels. The resulting trends of transport resistance versus pressure are presented in Figure 5-9. The extrapolated intercepts at zero pressure are presented for each RH level in Table 5-6.

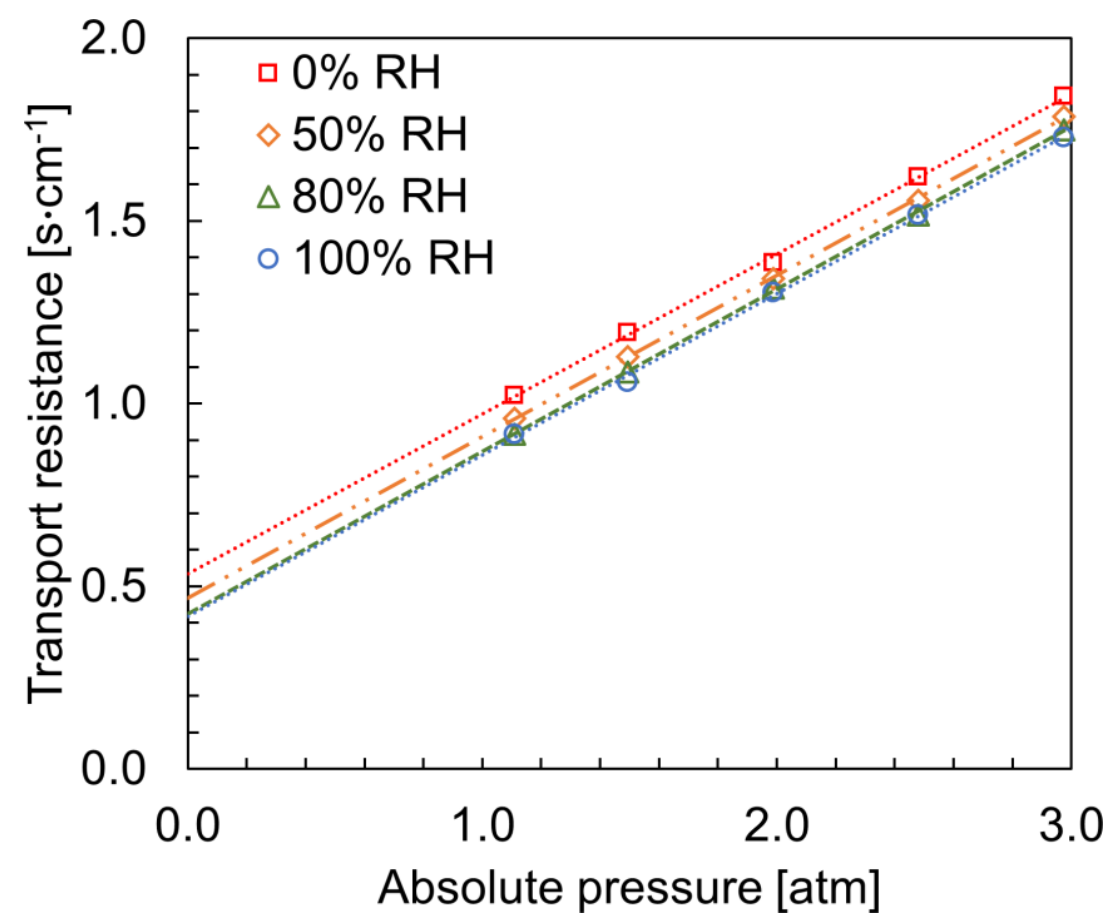

Figure 5-9: Extraction of pressure-independent component of transport resistance: total transport resistance versus absolute pressure. The extrapolated intercepts at zero pressure represents an estimate of the contribution of the catalyst layer to the total transport resistance. Experiments conducted using SGL $29 \mathrm{BC}$ with a dry inlet $\mathrm{O}_{2}$ mole fraction of 0.01 . Intercept values are presented in Table 5-6. 
Table 5-6: Pressure-independent transport resistances at 0\%, 50\%, 80\%, and 100\% RH, calculated using the extrapolated zero-pressure intercept of transport resistance plotted as a function of absolute pressure (Figure 5-9).

\begin{tabular}{|c|c|}
\hline Cathode inlet RH & $\begin{array}{c}\text { Extrapolated zero-pressure } \\
\text { intercept, } \boldsymbol{R}_{\boldsymbol{P I}}\left[\mathbf{s} \cdot \mathbf{c m}^{\mathbf{- 1}}\right]\end{array}$ \\
\hline $\mathbf{0 \%}$ & 0.534 \\
\hline $\mathbf{5 0 \%}$ & 0.468 \\
\hline $\mathbf{8 0 \%}$ & 0.424 \\
\hline $\mathbf{1 0 0 \%}$ & 0.418 \\
\hline
\end{tabular}

\subsubsection{Comparison of experimental results to correlations}

In Figure 5-10, the substrate transport resistance $R_{C F}$ corresponding to each limiting current experiment has been plotted against the effective pore fraction $\varepsilon_{e f f}$ (chapter 3.5, Equation 3.10). Using the correlations for substrate effective diffusivity in section 5.4.2, three correlation-based trends are presented in black for each GDL material. 

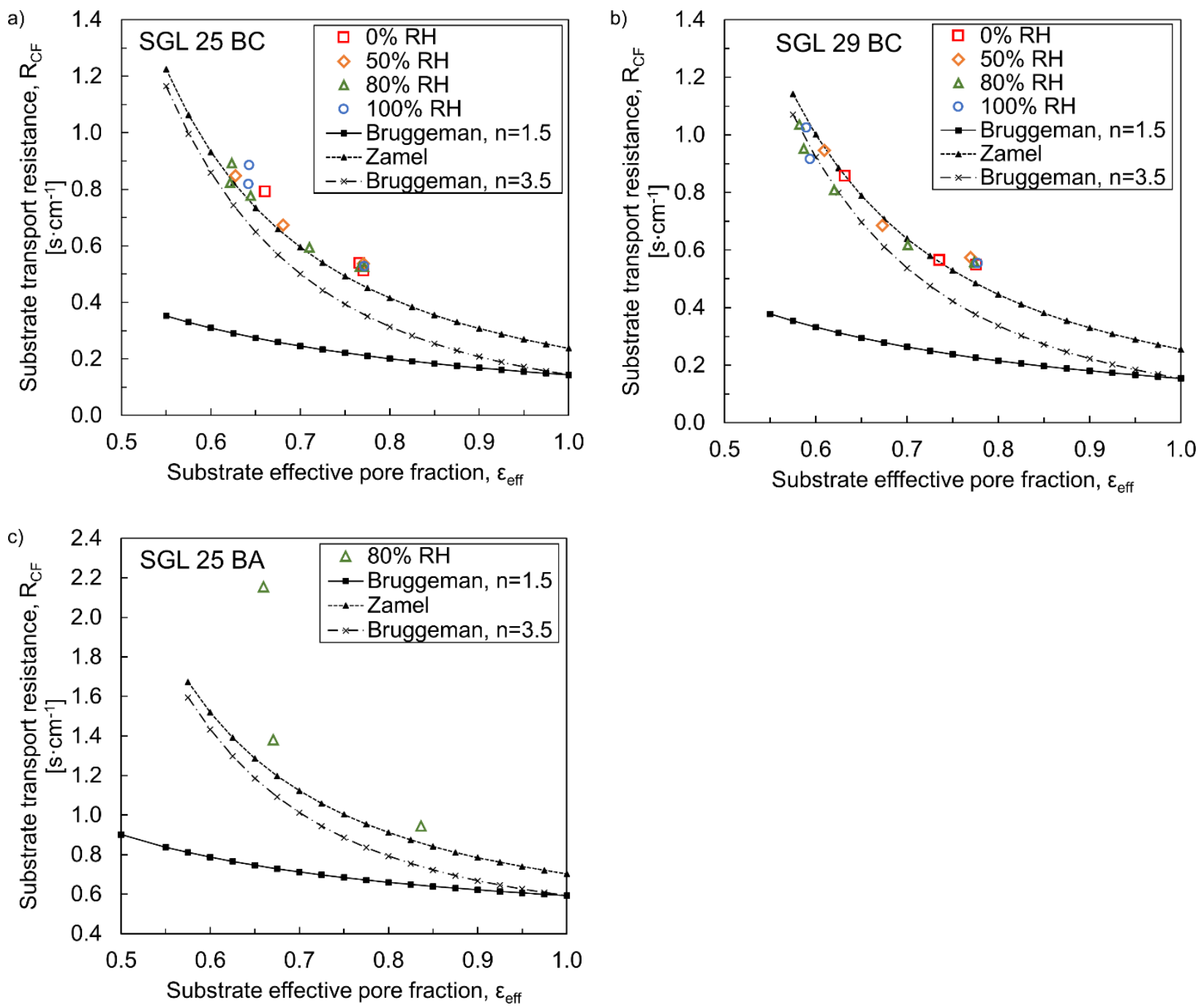

Figure 5-10: $R_{C F}$ plotted as a function of carbon fiber region effective pore fraction for a) SGL 25 BC, b) SGL 29 BC, and c) SGL 25 BA. Differing RH levels in the cathode inlet gas are indicated by symbol shape and colour. Existing correlations in literature for the relationship of transport resistance to carbon fiber void fraction are included for each GDL. An X-ray beam abnormality was experienced during the synchrotron X-ray radiography measurement for the test with a 0.21 inlet oxygen mole fraction and $100 \% \mathrm{RH}$ at the cathode. A discussion of this event can be found in the Appendix. 
For the GDL materials with MPLs (SGL 25 BC and 29 BC), there was good agreement between the measured transport resistances and the correlation predictions of GDL transport resistance using the Zamel et al. [108] correlation and the modified Bruggeman correlation [33]. These two correlations exhibit a larger curvature than the experimental data, which indicates that better tuning may be possible in one or both of the exponent ( 1.83 for the Zamel et al. correlation, 3.5 for the modified Bruggeman correlation) or in the shape factor, $f$. One source of error is from the 2dimensional nature of the liquid water saturation pattern in the GDL. As Owejan et al. noted in their study [33], the one-dimensional simplification of their partially saturated oxygen transport model exhibited poorer agreement with experimental data than the two-dimensional model used to fit their modified Bruggeman exponents. It is noteworthy that a transient beam intensity fluctuation was experienced during the experiment using SGL 25 BC with a 0.21 inlet oxygen mole fraction and $100 \% \mathrm{RH}$ at the cathode. A comment on the implication of this fluctuation on measured liquid water saturation is presented in the Appendix, section 5.8.2.1.

In SGL 25 BA (Figure 5-10c), a steep increase in transport resistance was observed between 10\% and $21 \%$ oxygen without any significant increase in liquid water accumulation. The through-plane distribution of liquid water in these cases helps elucidate the reason for the transport resistance spike. At limiting current with a $0.21 \mathrm{O}_{2}$ mole fraction, more water was present at the CL-GDL interface than with a $0.10 \mathrm{O}_{2}$ mole faction. The additional water at this interface may have caused a greater degree of flooding in the catalyst layer pores, thereby increasing the transport resistance in the CL and potentially de-activating some reaction sites. 


\subsection{Chapter summary}

In this work, reduced oxygen concentrations were used to study water accumulation and oxygen transport behaviour with varied cathode inlet RH over a wide range of current densities. Oxygen transport was quantified by use of limiting current measurements at various oxygen concentrations. In addition, we compared the water accumulation behaviour of materials with different throughplane porosity profiles (SGL 25 BA, SGL 25 BC and SGL 29 BC) at a range of current densities. Visualizations were performed using in operando synchrotron X-ray radiography to achieve 2-D spatially-resolved liquid water quantification with excellent spatial and temporal resolutions.

The measured oxygen transport resistance exhibited significant sensitivity to cathode relative humidity in the intermediate current density range $\left(1.5-2.1 \mathrm{~A} \cdot \mathrm{cm}^{-2}\right)$, achieved at limiting current with an oxygen mole fraction of 0.10 in the cathode inlet gas. Fully humidified cathode gas $(100 \%$ $\mathrm{RH})$ resulted in the largest transport resistances. The transport resistance at 100\% $\mathrm{RH}$ was greater than the transport resistance at $0 \% \mathrm{RH}$ by $0.165 \mathrm{~s} \cdot \mathrm{cm}^{-1}$ with SGL 25 BC GDLs and 0.235 $\mathrm{s} \cdot \mathrm{cm}^{-1}$ with the SGL $29 \mathrm{BC}$ GDL. The tendency for larger measurements of oxygen transport resistance at higher relative humidity levels was attributed to GDL liquid water accumulation.

Generally, liquid water was not observed in the limiting current experiments at oxygen mole fractions of 0.01 and 0.02 in the cathode inlet gas. Consistent, high liquid water saturation levels were observed in the limiting current experiments with an inlet oxygen mole fraction of 0.21 (undiluted air). 
In addition, liquid water tended to preferentially accumulate in regions of higher local porosity within the GDL. In particular, the local maxima in the substrate through-plane porosity profile of SGL 29 BC became saturated with liquid water. Under the same conditions, the SGL 25 BC substrate remained dry because it did not exhibit local porosity maxima at the same through-plane positions as SGL 29 BC.

Finally, this paper demonstrated a clear relationship between the oxygen transport resistance and GDL effective open pore space, which is the pore space that is not occupied by liquid water. Existing correlations relating porosity and saturation to GDL effective diffusivity are in good agreement with our findings.

Overall, this work includes one of the most comprehensive collections of fuel cell water accumulation information in existing literature, which represents a highly useful validation data set for numerical water and oxygen transport modelling. 
5.8 Appendix: Supplementary performance and water accumulation data

\subsubsection{Measured limiting current densities}

Table A-1: Measured limiting current densities

\begin{tabular}{|c|c|c|c|}
\hline GDL & $\begin{array}{c}\text { Relative } \\
\text { Humidity }\end{array}$ & $x_{O_{2}}^{d r y-i n}$ & $\boldsymbol{i}_{L}\left[\mathrm{~A} \cdot \mathrm{cm}^{-2}\right]$ \\
\hline \multirow{3}{*}{$25 \mathrm{BA}$} & \multirow{3}{*}{$80 \%$} & 0.01 & 0.285 \\
\hline & & 0.10 & 1.911 \\
\hline & & 0.21 & 2.499 \\
\hline \multirow{15}{*}{$25 \mathrm{BC}$} & \multirow{3}{*}{$0 \%$} & 0.01 & 0.215 \\
\hline & & 0.10 & 2.069 \\
\hline & & 0.21 & 3.568 \\
\hline & \multirow{3}{*}{$50 \%$} & 0.01 & 0.211 \\
\hline & & 0.10 & 1.872 \\
\hline & & 0.21 & 3.412 \\
\hline & \multirow{6}{*}{$80 \%$} & 0.01 & 0.213 \\
\hline & & 0.02 & 0.427 \\
\hline & & 0.05 & 0.970 \\
\hline & & 0.10 & 1.742 \\
\hline & & 0.16 & 2.623 \\
\hline & & 0.21 & 3.303 \\
\hline & \multirow{3}{*}{$100 \%$} & 0.01 & 0.209 \\
\hline & & 0.10 & 1.665 \\
\hline & & 0.21 & 3.257 \\
\hline \multirow{15}{*}{$29 \mathrm{BC}$} & \multirow{3}{*}{$0 \%$} & 0.01 & 0.218 \\
\hline & & 0.10 & 2.107 \\
\hline & & 0.21 & 3.539 \\
\hline & \multirow{3}{*}{$50 \%$} & 0.01 & 0.213 \\
\hline & & 0.10 & 1.926 \\
\hline & & 0.21 & 3.318 \\
\hline & \multirow{6}{*}{$80 \%$} & 0.01 & 0.216 \\
\hline & & 0.02 & 0.434 \\
\hline & & 0.05 & 0.992 \\
\hline & & 0.10 & 1.766 \\
\hline & & 0.16 & 2.499 \\
\hline & & 0.21 & 3.128 \\
\hline & \multirow{3}{*}{$100 \%$} & 0.01 & 0.213 \\
\hline & & 0.10 & 1.618 \\
\hline & & 0.21 & 3.090 \\
\hline
\end{tabular}




\subsubsection{Saturation profiles for SGL 25 BC}

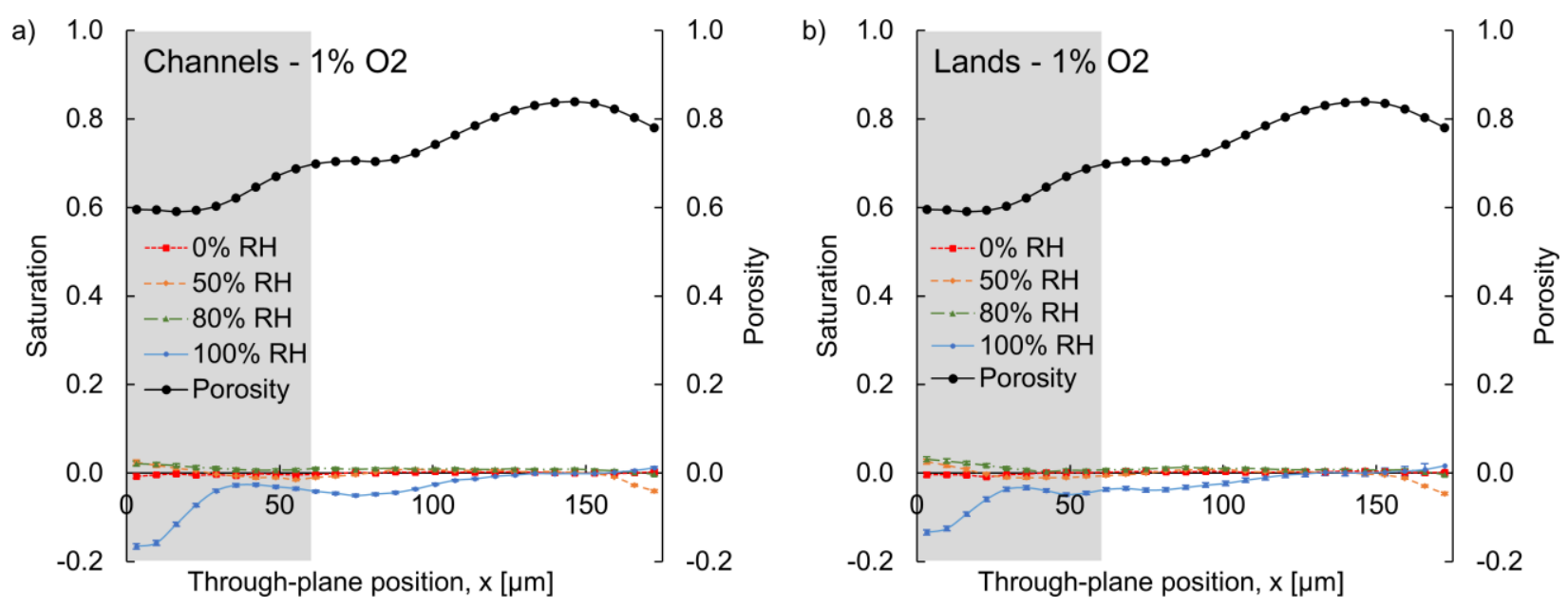

Figure A-1: Through-plane porosity and saturation profiles in (a) the regions of the SGL 25 BC GDL above the flow field channels and (b) the regions of the GDL above the flow field lands for limiting current experiments with a 0.01 oxygen mole fraction supplied in the dry cathode gas feed, prior to humidification. The resulting limiting current densities were below $0.5 \mathrm{~A} \cdot \mathrm{cm}^{-2}$ at all humidity levels.
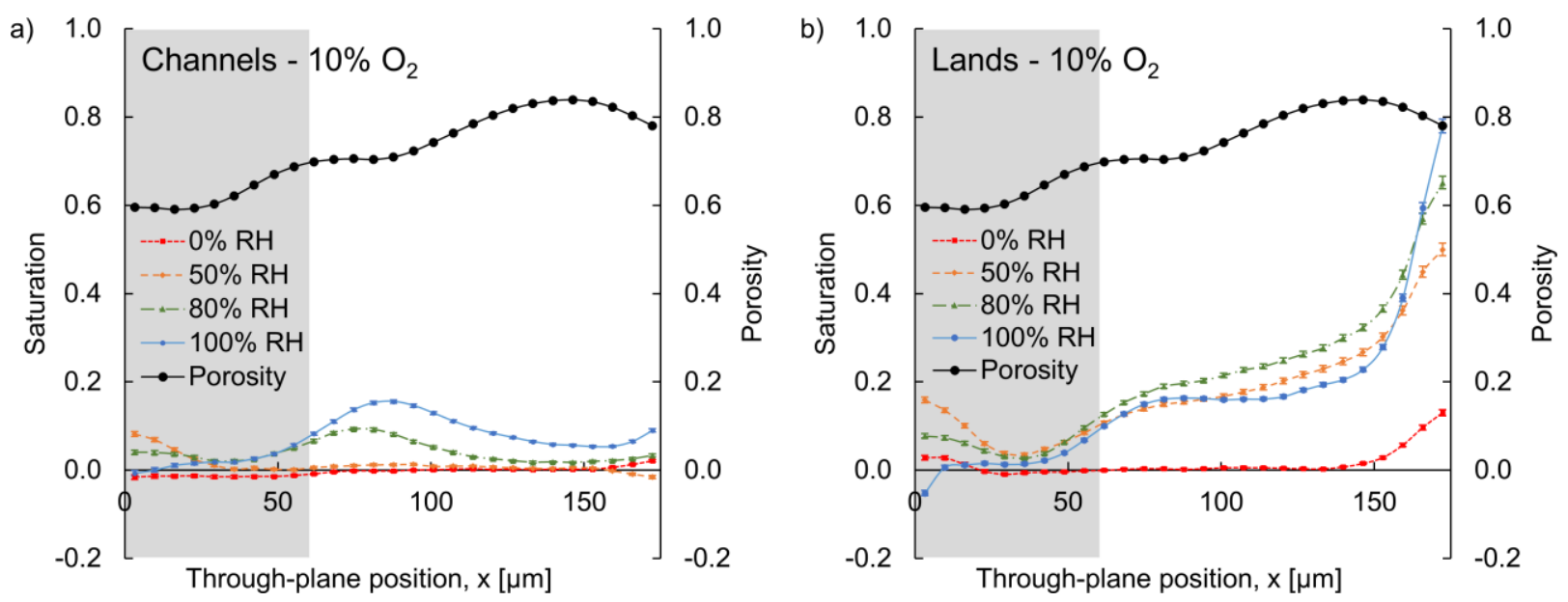

Figure A-2: Through-plane porosity and saturation profiles in (a) the regions of the SGL 25 BC GDL above the flow field channels and (b) the regions of the GDL above the flow field lands for limiting current experiments with a 0.10 oxygen mole fraction supplied in the dry cathode gas 
feed, prior to humidification. The resulting limiting current densities were between 1.5 and 2.1 $\mathrm{A} \cdot \mathrm{cm}^{-2}$ at all humidity levels.
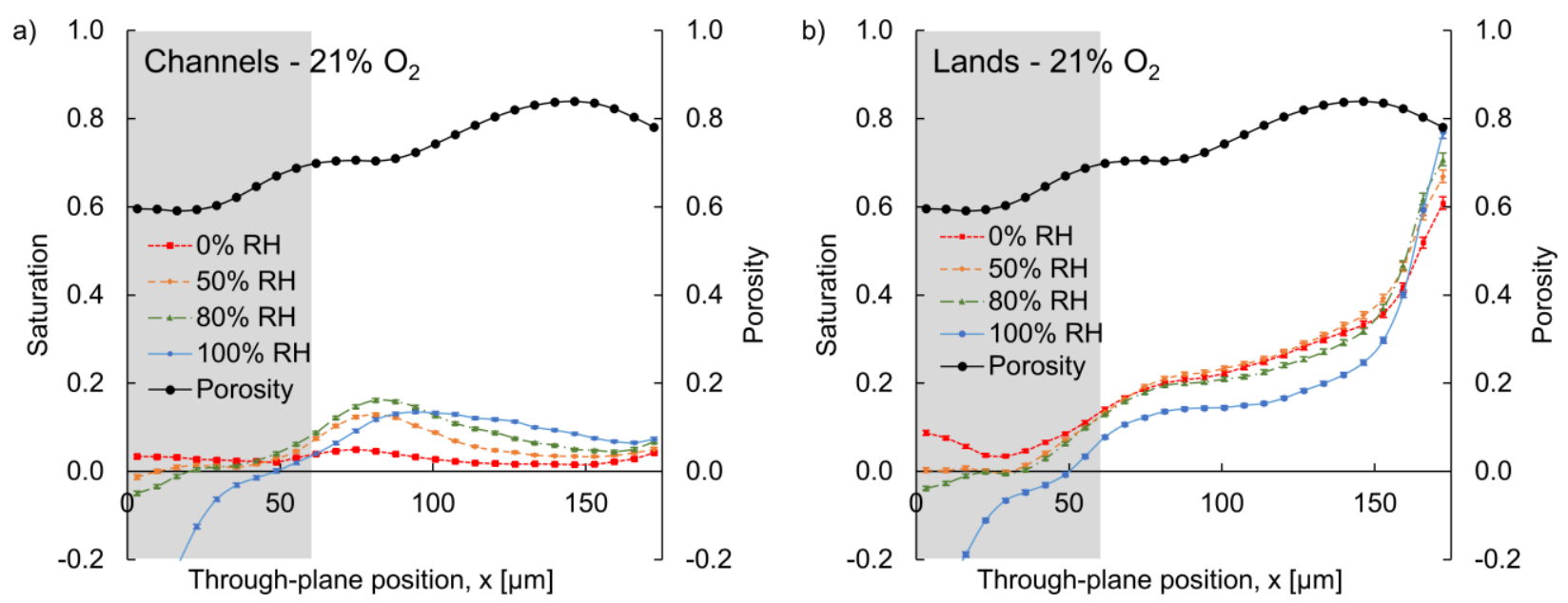

Figure A-3: Through-plane porosity and saturation profiles in (a) the regions of the SGL 25 BC GDL above the flow field channels and (b) the regions of the GDL above the flow field lands for limiting current experiments with a 0.21 oxygen mole fraction supplied in the dry cathode gas feed, prior to humidification. The resulting limiting current densities were greater than 3.0 $\mathrm{A} \cdot \mathrm{cm}^{-2}$ at all humidity levels. An X-ray beam fluctuation was experienced during the $100 \% \mathrm{RH}$ experiment, resulting in additional uncertainty in the liquid water thickness quantification for that experiment.

\subsubsection{Comment on X-ray beam intensity fluctuation}

An X-ray beam abnormality was experienced during the synchrotron X-ray radiography measurement for the test with a 0.21 inlet oxygen mole fraction and $100 \% \mathrm{RH}$ at the cathode. Specifically, a transient beam intensity increase occurred near the beginning of the experiment. Generally, the intensity of the X-ray beam decreases steadily throughout an experiment due to the logarithmic decay of the electron orbit in the synchrotron storage ring. The image processing protocol for liquid water quantification involves a step wherein the beam intensity is corrected in 
each frame to account for this gradual intensity decline. The transient beam intensity fluctuation has affected this correction, leading to additional uncertainty. The liquid water thickness bias introduced by this mechanism may not be spatially consistent.

\subsubsection{Through-plane distributions of effective space: effect of current density}

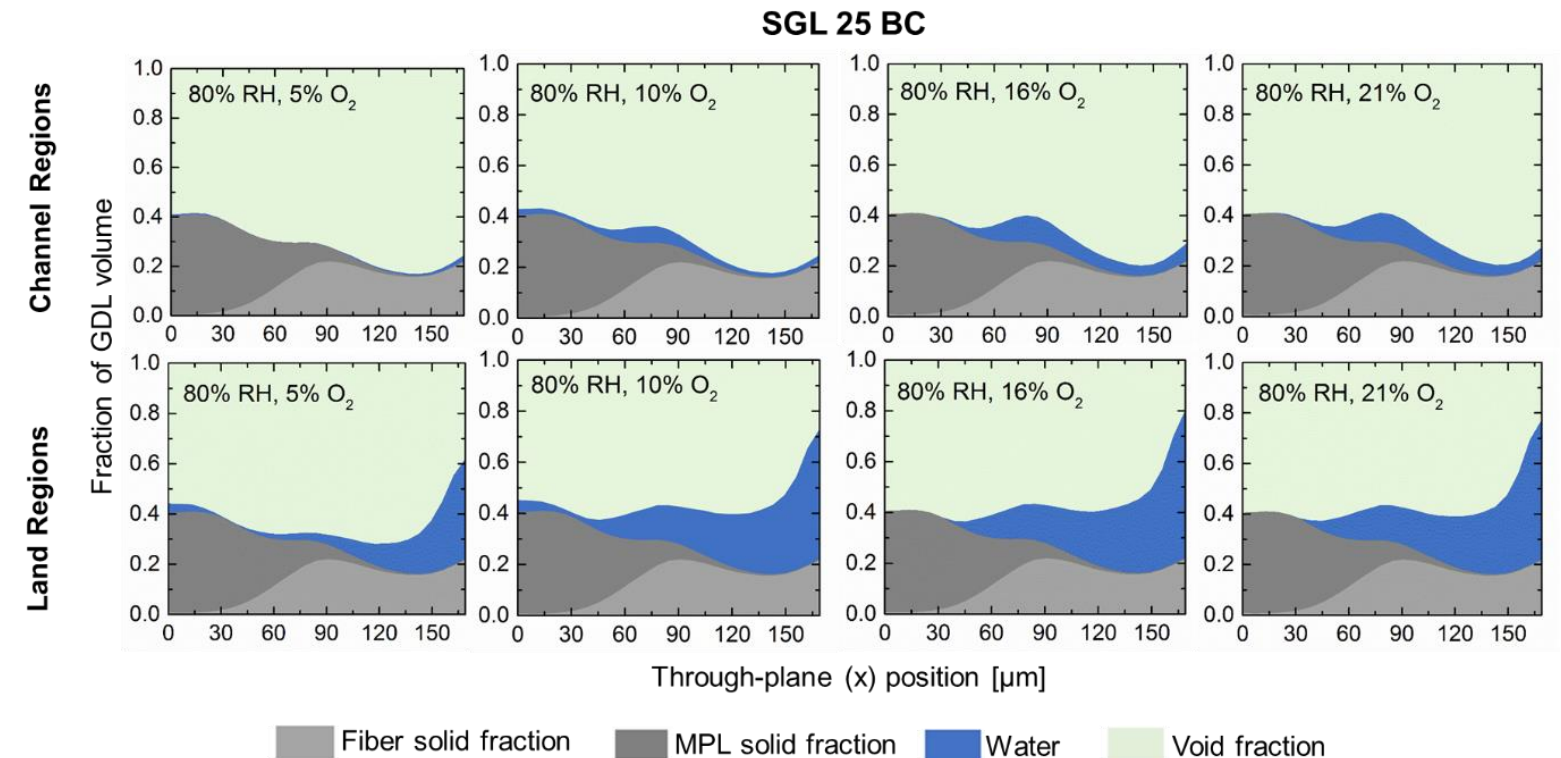

Figure A-4: Through-plane distributions of carbon fiber solid content, MPL solid content, liquid water, and effective pore space (void fraction) in SGL $25 \mathrm{BC}$ at limiting current across a range of current densities, achieved by varying oxygen mole fraction in the cathode feed. An X-ray beam fluctuation was experienced during the $100 \% \mathrm{RH}$ experiment with an $\mathrm{O}_{2}$ mole fraction of 0.21 (21\%), resulting in additional uncertainty in the liquid water thickness quantification for that experiment. 


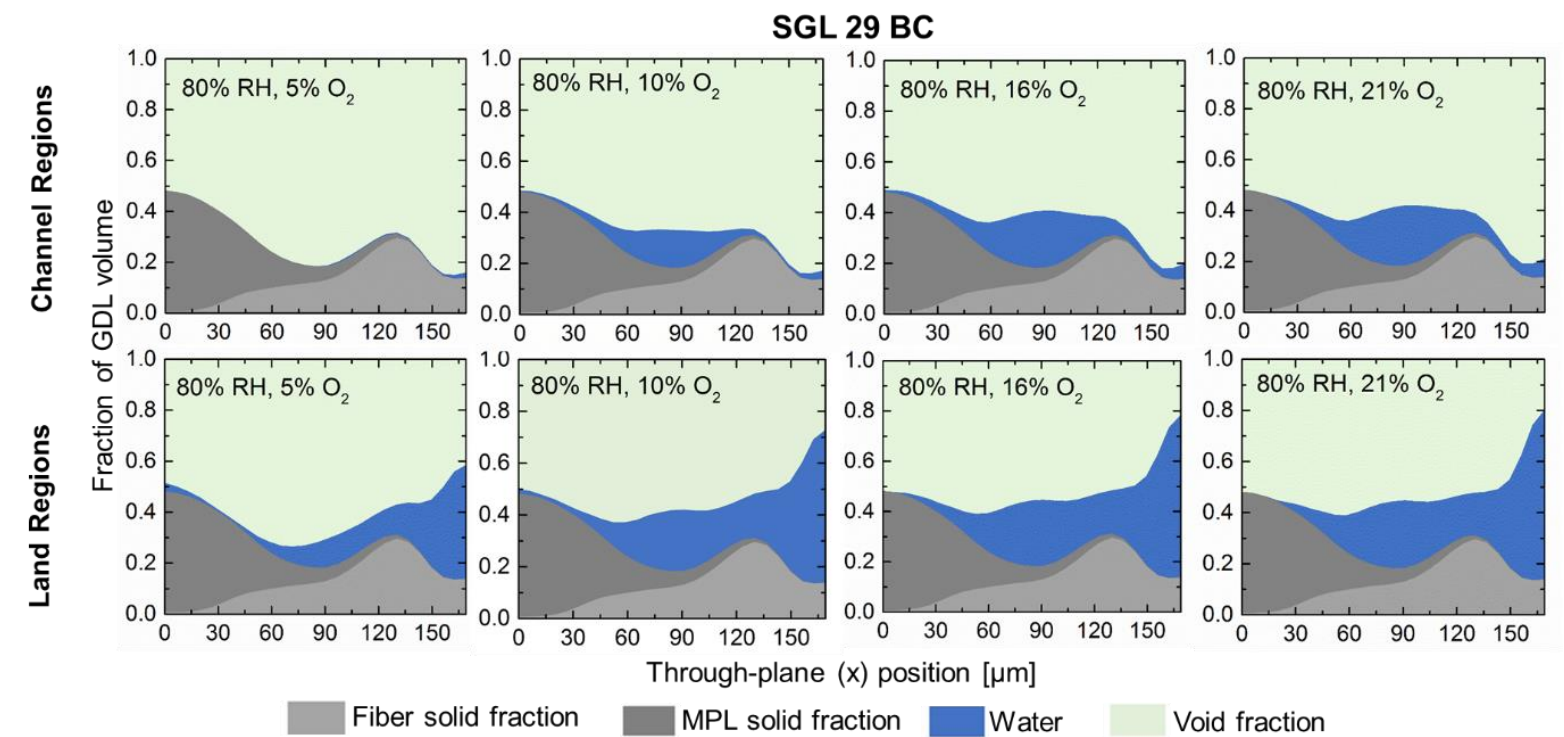

Figure A-5: Through-plane distributions of carbon fiber solid content, MPL solid content, liquid water, and effective pore space (void fraction) in SGL 29 BC at limiting current across a range of current densities, achieved by varying oxygen mole fraction in the cathode feed. 


\section{Chapter 6 Conclusions and Future Work}

In this thesis, in situ experiments were performed to investigate oxygen and water transport in a polymer electrolyte membrane (PEM) fuel cell. A literature review was conducted on PEM fuel cell reactant and product transport, with particular focus on the delivery of oxygen to the cathode catalyst layer and the accumulation of product water in the fuel cell gas diffusion layers (GDLs). The goal of this work was to investigate the effects of varied cathode reactant relative humidity (RH) and operating current density on oxygen transport resistance. The RH and current density are important considerations because they both affect the liquid water distribution in the cathode GDL. The presence of liquid water in the GDL is known to increase oxygen mass transport resistance, which leads to mass transport-related efficiency losses.

In chapter 4, the liquid water saturation in the cathode GDL of a PEM fuel cell was experimentally determined during high current densities operation using synchrotron X-ray radiography. The oxygen transport resistance in the GDL was simultaneously characterized with measurements of limiting current density. The following was discovered for PEM fuel cells operating in the high current density range (limiting current operation with un-diluted air, $>2.5 \mathrm{~A} \cdot \mathrm{cm}^{-2}$ ) at a fuel cell temperature of $60\left[{ }^{\circ} \mathrm{C}\right]$ :

- Liquid water volume in the GDL was consistently high in high current density operation at all levels of cathode inlet RH (0\%-100\%).

- The liquid water saturation was sensitive to inlet RH under cathode channels and insensitive to RH under the flow filed lands. 
- High saturation regions were observed in the GDL above the lands, which was attributed to the low local temperatures due to the relatively high thermal conductivity of the graphite lands in contact with the GDL.

- Elevated RH levels led to a higher oxygen transport resistance as compared to lower RH levels, which was attributed to the additional liquid water observed in the GDL under the channel regions.

Chapter 5 presented an extension of the work in chapter 4; wherein the combined effects of $\mathrm{RH}$ and current density on the GDL liquid water saturation and mass transport resistance were presented. The through-plane liquid water distributions in the cathode GDL were measured in situ using synchrotron X-ray radiography. GDL porosity distributions were measured using microcomputed tomography. Oxygen transport resistance was characterized by limiting current measurements with varied inlet oxygen mole fractions and $\mathrm{RH}$ conditions. In addition, the effect of the through-plane porosity profile of the GDL on the liquid water saturation distribution was probed by comparing GDL materials with similar bulk properties yet distinct porosity profiles. In summary:

- Measured oxygen transport resistance exhibited significant sensitivity to cathode RH in the intermediate current density range $\left(1.5-2.1 \mathrm{~A} \cdot \mathrm{cm}^{-2}\right)$, which was attributed to the significant variation of GDL liquid water accumulation with the change of RH.

- By comparing the liquid water saturation distributions along the through-planed direction of the tested GDL materials, it was confirmed that liquid water preferentially accumulated in regions of high local porosity. 
- The strong relationship between the oxygen transport resistance and GDL effective pore fraction was demonstrated and compared to correlations in the literature. While reasonable agreement was observed between the experimental data and the correlations, it is suggested that the fit of the correlations may be improved if the exponents and shape factors in the correlations are adjusted for the tested fuel cell design and the selected GDL materials, rather than being applied directly.

- Overall, an extensive set of concurrent performance and liquid water visualization data was presented, which can be used for validating multiphase transport models.

Additional research could be done to extend the research conducted in this thesis and provide new insights into the water and oxygen transport phenomena in PEM fuel cell. The following future research endeavours will enable progress toward the development of next-generation materials and better-informed selection of operating conditions for the minimization of mass transport-related efficiency losses in PEM fuel cell systems. In summary:

- Combine findings in this thesis with electrochemical impedance spectroscopy (EIS) to understand the implications of low-voltage operation (limiting current) on water accumulation at a given current density. Limiting current experiments involve fuel cell operation at very low cell potentials, which means that only a small portion of the reaction enthalpy change is being converted to electrical work, while a significant portion of the reaction enthalpy change is being lost as heat. This excess heat may have an impact on the temperature distribution in the cathode catalyst layer (CL) and GDL, which may in turn affect liquid water saturation. Comparing liquid water saturation distributions and mass transport resistances quantified by EIS and limiting current measurements will enable more 
nuanced interpretations of the mass transport characterization data from both methodologies.

- Examine oxygen transport resistance with decreased cathode stoichiometric ratios. In this thesis, high reactant stoichiometric ratios were maintained in order to remove water from the flow channels and ensure minimal changes in reactant concentration and $\mathrm{RH}$ along the length of the flow channel. While useful for fundamental studies of fuel cell behaviour, the stoichiometric ratios employed in this thesis were larger than what would be typically applied for automotive fuel cell operation. Decreasing stoichiometric ratios may decrease the oxygen and water vapour concentration gradients along the length of the flow channel, thus requiring a more nuanced, 2- or 3-dimensional interpretation of the measured oxygen transport resistance and liquid water saturation. In situ or quasi in situ synchrotron X-ray tomography could be useful to observe changes in liquid water saturation along the length of the flow channels. Alternatively, synchrotron X-ray radiography could be conducted in two perpendicular directions to observe separately the variation in liquid water saturation distribution across the flow field channels (y-direction) and along the flow field channels (z-direction), enabling 3-dimensional interpretations of the liquid water saturation.

- Vary fuel cell operating temperature along with cathode RH to investigate the changes in GDL liquid water saturation behaviour. While this thesis established the impact of cathode RH on liquid water condensation in the GDL, the temperature gradient in the GDL also impacts GDL condensation because the rate of water phase change (condensation or evaporation) is a function of the local temperature. This effort will extend the findings presented in this thesis to develop a more comprehensive understanding of the effect of 
fuel cell operating conditions on GDL liquid water saturation and GDL oxygen transport resistance.

- Develop or refine imaging techniques to investigate catalyst layer transport phenomena. Especially in low RH conditions, the catalyst layer poses a significant resistance to oxygen transport. Due to the nano-scale pores, ionomer film coatings, and platinum particle sizes of the catalyst layer, the synchrotron X-ray radiography-based and neutron radiographybased imaging techniques that are typically used for GDL water quantification cannot be used to detect catalyst flooding or catalyst layer hydration state.

The efforts listed above will contribute to the improvement of fuel cell numerical models for the prediction of liquid water saturation by incorporating accurate models of temperature distributions, water vapour concentration distributions, and phase change phenomena. The water accumulation and performance characterizations presented in this thesis will serve as valuable validation data for such models. Once sufficiently developed, these models will enable rapid characterization and evaluation of novel GDL material designs. Ultimately, this can lead to the development of novel GDL materials with customized properties to reduce mass transport-related efficiency losses in PEM fuel cells. 


\section{References}

[1] Braga, L., Silveira, J., Silva, M., Machin, E., Pedroso, D., and Tuna, C., Applied Thermal Engineering. 63 (2014) 354-361.

[2] U.S. Department of Energy, Office of Fossil Energy, National Energy Technology Laboratory (Ed), Fuel Cell Handbook, Seventh Edition ed., EG\&G Technical Services Inc., 2004, pp. 427.

[3] L. Cindrella, A.M. Kannan, J.F. Lin, C.W. Lin, K. Saminathan, Y. Ho, J. Wertz, J.Power Sources. 194 (2009) 146-160.

[4] S. Park, J. Lee, B.N. Popov, Int J Hydrogen Energy. 37 (2012) 5850-5865.

[5] A.Z. Weber, J. Newman, Journal of The Electrochemical Society. 152 (2005) A677-A688.

[6] J.P. Owejan, J.E. Owejan, W. Gu, T.A. Trabold, T.W. Tighe, M.F. Mathias, Journal of The Electrochemical Society. 157 (2010) B1456-B1464.

[7] J.T. Gostick, M.A. Ioannidis, M.W. Fowler, M.D. Pritzker, Electrochemistry Communications. 11 (2009) 576-579.

[8] A. Thomas, G. Maranzana, S. Didierjean, J. Dillet, O. Lottin, Int J Hydrogen Energy. 39 (2014) 2649-2658.

[9] R. Schweiss, M. Steeb, P.M. Wilde, T. Schubert, J.Power Sources. 220 (2012) 79-83.

[10] A. Nanjundappa, A.S. Alavijeh, M. El Hannach, D. Harvey, E. Kjeang, Electrochim.Acta. 110 (2013) 349-357.

[11] Migliardini, F.,Unich, A., P. Corbo, Int.J.Hydrogen Energy. 40 (2015) 5916-5927.

[12] C. Heitner-Wirguin, J.Membr.Sci. 120 (1996) 1-33.

[13] P. Choi, N.H. Jalani, R. Datta, J.Electrochem.Soc. 152 (2005) E123-E130.

[14] G.S. Hwang, M. Kaviany, J.T. Gostick, B. Kientiz, A.Z. Weber, M.H. Kim, Polymer. 52 (2011) 2584-2593.

[15] G.S. Hwang, M. Kaviany, J.H. Nam, M.H. Kim, S.Y. Son, J.Electrochem.Soc. 156 (2009) B1192-B1200.

[16] T. Thampan, S. Malhotra, H. Tang, R. Datta, J.Electrochem.Soc. 147 (2000) 3242-3250. 
[17] Y. Tabuchi, T. Shiomi, O. Aoki, N. Kubo, K. Shinohara, Electrochim.Acta. 56 (2010) 352360.

[18] T. Kotaka, Y. Tabuchi, P.P. Mukherjee, J.Power Sources. 280 (2015) 231-239.

[19] J.T. Gostick, M.A. Ioannidis, M.D. Pritzker, M.W. Fowler, J.Electrochem.Soc. 157 (2010) B563-B571.

[20] A. Bazylak, V. Berejnov, B. Markicevic, D. Sinton, N. Djilali, Electrochim.Acta. 53 (2008) $7630-7637$.

[21] M.J. Blunt, Curr. Opin. Colloid Inter. Sci. 6 (2001) 197-207.

[22] P.K. Sinha, C. Wang, Electrochim.Acta. 52 (2007) 7936-7945.

[23] C. Wang, Chem.Rev. 104 (2004) 4727-4766.

[24] N. Ge, S. Chevalier, J. Lee, R. Yip, R. Banerjee, M.G. George, H. Liu, C. Lee, M. Fazeli, P. Antonacci, Int.J.Heat Mass Transfer. 107 (2017) 418-431.

[25] A. Bazylak, Int J Hydrogen Energy. 34 (2009) 3845-3857.

[26] R. Anderson, D.P. Wilkinson, X. Bi, L. Zhang, J. Power Sources. 196 (2011) 8031-8040.

[27] D. Spernjak, A.K. Prasad, S.G. Advani, J.Power Sources. 170 (2007) 334-344.

[28] K. Tüber, D. Pócza, C. Hebling, J.Power Sources. 124 (2003) 403-414.

[29] S. Chevalier, N. Ge, J. Lee, R. Banerjee, H. Liu, M. George, P. Shrestha, D. Muirhead, J. Hinebaugh, T. Y, K. T, B. A., J.Electrochem.Soc. 2 (2017) 107-114.

[30] M.C. Hatzell, A. Turhan, S. Kim, D.S. Hussey, D.L. Jacobson, M.M. Mench, J.Electrochem.Soc. 158 (2011) B717-B726.

[31] P. Boillat, D. Kramer, B.C. Seyfang, G. Frei, E. Lehmann, G.G. Scherer, A. Wokaun, Y. Ichikawa, Y. Tasaki, K. Shinohara, Electrochem.Commun. 10 (2008) 546-550.

[32] T. Kotaka, Y. Tabuchi, U. Pasaogullari, C. Wang, Electrochim.Acta. 146 (2014) 618-629.

[33] J.P. Owejan, T.A. Trabold, M.M. Mench, Int.J.Heat Mass Transfer. 71 (2014) 585-592.

[34] S. Tsushima, S. Hirai, Progress in Energy and Combustion Science. 37 (2011) 204-220.

[35] M.A. Hickner, N.P. Siegel, K.S. Chen, D.S. Hussey, D.L. Jacobson, M. Arif, J.Electrochem.Soc. 155 (2008) B294-B302. 
[36] A.Z. Weber, M.A. Hickner, Electrochim.Acta. 53 (2008) 7668-7674.

[37] I. Manke, C. Hartnig, N. Kardjilov, M. Messerschmidt, A. Hilger, M. Strobl, W. Lehnert, J. Banhart, Appl.Phys.Lett. 92 (2008) 244101.

[38] J. Hinebaugh, J. Lee, A. Bazylak, J.Electrochem.Soc. 159 (2012) F826-F830.

[39] P. Antonacci, S. Chevalier, J. Lee, R. Yip, N. Ge, A. Bazylak, Int J Hydrogen Energy. 40 (2015) 16494-16502.

[40] P. Antonacci, S. Chevalier, J. Lee, N. Ge, J. Hinebaugh, R. Yip, Y. Tabuchi, T. Kotaka, A. Bazylak, Electrochim.Acta. 188 (2016) 888-897.

[41] J. Lee, J. Hinebaugh, A. Bazylak, J.Power Sources. 227 (2013) 123-130.

[42] S. Chevalier, N. Ge, J. Lee, P. Antonacci, R. Yip, M.G. George, H. Liu, R. Banerjee, M. Fazeli, A. Bazylak, Electrochem.Commun. 59 (2015) 16-19.

[43] J. Lee, R. Yip, P. Antonacci, N. Ge, T. Kotaka, Y. Tabuchi, A. Bazylak, J.Electrochem.Soc. 162 (2015) F669-F676.

[44] N. Ge, S. Chevalier, J. Hinebaugh, R. Yip, J. Lee, P. Antonacci, T. Kotaka, Y. Tabuchi, A. Bazylak, J. Synchrotron Rad. 23 (2016) 590-599.

[45] I. Manke, C. Hartnig, M. Grünerbel, W. Lehnert, N. Kardjilov, A. Haibel, A. Hilger, J. Banhart, H. Riesemeier, Appl.Phys.Lett. 90 (2007) 174105.

[46] I. Manke, C. Hartnig, N. Kardjilov, H. Riesemeier, J. Goebbels, R. Kuhn, P. Krüger, J. Banhart, Fuel Cells. 10 (2010) 26-34.

[47] C. Hartnig, I. Manke, R. Kuhn, N. Kardjilov, J. Banhart, W. Lehnert, Appl.Phys.Lett. 92 (2008) 134106.

[48] H. Markötter, I. Manke, P. Krüger, T. Arlt, J. Haußmann, M. Klages, H. Riesemeier, C. Hartnig, J. Scholta, J. Banhart, Electrochem.Commun. 13 (2011) 1001-1004.

[49] H. Markötter, I. Manke, H. J, T. Arlt, M. Klages, K. P, C. Hartnig, J. Scholta, R.M. B, H. Riesemeier, J. Banhart, Micro \& Nano Letters. 7 (2012) 689.

[50] H. Markötter, J. Haußmann, R. Alink, C. Tötzke, T. Arlt, M. Klages, H. Riesemeier, J. Scholta, D. Gerteisen, J. Banhart, I. Manke, Electrochem.Commun. 34 (2013) 22-24.

[51] H. Markötter, K. Dittmann, J. Haußmann, R. Alink, D. Gerteisen, H. Riesemeier, J. Scholta, J. Banhart, I. Manke, Electrochemistry Communications. 51 (2015) 133-136. 
[52] J. Haußmann, H. Markötter, R. Alink, A. Bauder, K. Dittmann, I. Manke, J. Scholta, J.Power Sources. 239 (2013) 611-622.

[53] F.N. Büchi, R. Flückiger, D. Tehlar, F. Marone, M. Stampanoni, ECS Trans. 16 (2008) 587592.

[54] T. Arlt, M. Klages, M. Messserschmidt, H. Riesemeier, J. Scholta, J. Banhart, I. Manke, ECS Electrochemistry Letters. 3 (2014) F7-F9.

[55] T. Arlt, M. Klages, M. Messerschmidt, J. Scholta, I. Manke, Energy. 118 (2017) 502-511.

[56] S. Lee, S. Kim, G. Park, C. Kim, Int. J. Hydrogen Energy. 35 (2010) 10457-10463.

[57] A. Schneider, C. Wieser, J. Roth, L. Helfen, J.Power Sources. 195 (2010) 6349-6355.

[58] J. Hinebaugh, P.R. Challa, A. Bazylak, J. Synchrotron Rad. 19 (2012) 994.

[59] N. Ge, M.G. George, J. Lee, D. Muirhead, S. Chevalier, R. Banerjee, H. Liu, T.W.

Wysokinski, G. Belev, M.A. Webb, J.Electrochem.Soc. 164 (2017) E3215-E3224.

[60] R. Banerjee, N. Ge, J. Lee, M.G. George, S. Chevalier, H. Liu, P. Shrestha, D. Muirhead, A. Bazylak, J.Electrochem.Soc. 164 (2017) F154-F162.

[61] S. Chevalier, N. Ge, J. Lee, P. Antonacci, R. Yip, M. George, H. Liu, R. Banerjee, M. Fazeli, A. Bazylak, Electrochemistry Communications. 59 (2015) 16-19.

[62] S. Alrwashdeh, I. Manke, H. Markötter, M. Klages, M. Göbel, J. Haußmann, J. Scholta, J. Banhart, ACS Nano. 11 (2017) 5944-5949.

[63] J.P. Owejan, J.E. Owejan, W. Gu, T.A. Trabold, T.W. Tighe, M.F. Mathias, J.Electrochem.Soc. 157 (2010) B1456-B1464.

[64] J. Hinebaugh, A. Bazylak, J.Electrochem.Soc. 157 (2010) 1382-90.

[65] B. Straubhaar, J. Pauchet, M. Prat, Int.J.Heat Mass Transfer. 102 (2016) 891-901.

[66] Chevalier, S., Lee, J., Ge, N., Yip, R., Antonacci, P., Tabuchi, Y., Kotaka, T., Bazylak, A., Electrochim.Acta. 210 (2016) 792-803.

[67] R. Banerjee, D. Howe, V. Mejia, S.G. Kandlikar, Int. J. of Hydrogen Energy. 39 (2014) 17791.

[68] I.S. Hussaini, C. Wang, J. Power Sources. 187 (2009) 444-451.

[69] W. He, G. Lin, T. Van Nguyen, AICHE J. 49 (2003). 
[70] D. Spernjak, A.K. Prasad, S.G. Advani, J. Power Sources. 195 (2010) 3553-3568.

[71] Z. Lu, S.G. Kandlikar, C. Rath, M. Grimm, W. Domigan, A.D. White, M. Hardbarger, J.P. Owejan, T.A. Trabold, Int J Hydrogen Energy. 34 (2009) 3445-3456.

[72] M. Grimm, E.J. See, S.G. Kandlikar, Int. J. of Hydrogen Energy. 37 (2012) 12489-12503.

[73] S.G. Kandlikar, E.J. See, R. Banerjee, J Electrochem Soc. 162 (2015) F772-F782.

[74] T. Mashio, A. Ohma, S. Yamamoto, K. Shinohara, ECS Trans. 11 (2007) 529-540.

[75] N. Nonoyama, S. Okazaki, A.Z. Weber, Y. Ikogi, T. Yoshida, J Electrochem Soc. 158 (2011) B416-B423.

[76] T.V. Reshetenko, J. St-Pierre, J. Electrochem. Soc. 161 (2014) F1089-F1100.

[77] D.R. Baker, D.A. Caulk, K.C. Neyerlin, M.W. Murphy, J.Electrochem.Soc. 156 (2009) B991-B1003.

[78] H. Oh, Y.I. Lee, G. Lee, K. Min, J.S. Yi, J. Power Sources. 345 (2017) 67-77.

[79] A.Z. Weber, J. Newman, Chem.Rev. 104 (2004) 4679-4726.

[80] H. Chu, C. Yeh, F. Chen, J.Power Sources. 123 (2003) 1-9.

[81] D.A. Caulk, D.R. Baker, J.Electrochem.Soc. 157 (2010) B1237-B1244.

[82] C. Simon, F. Hasché, D. Müller, H.A. Gasteiger, ECS Trans. 69 (2015) 1293-1302.

[83] P.A. García-Salaberri, G. Hwang, M. Vera, A.Z. Weber, J.T. Gostick, Int.J.Heat Mass Transfer. 86 (2015) 319-333.

[84] P. Deevanhxay, T. Sasabe, S. Tsushima, S. Hirai, Electrochemistry Communications. 34 (2013) 239-241.

[85] S. Chevalier, J. Lee, N. Ge, R. Yip, P. Antonacci, Y. Tabuchi, T. Kotaka, A. Bazylak, Electrochim.Acta. (2016).

[86] J.P. Owejan, J.J. Gagliardo, J.M. Sergi, S.G. Kandlikar, T.A. Trabold, Int J Hydrogen Energy. 34 (2009) 3436-3444.

[87] M.G. George, H. Liu, D. Muirhead, R. Banerjee, N. Ge, P. Shrestha, J. Lee, S. Chevalier, J. Hinebaugh, M. Messerschmidt, J.Electrochem.Soc. 164 (2017) F714-F721.

[88] H. Liu, M.G. George, R. Banerjee, N. Ge, J. Lee, D. Muirhead, P. Shrestha, S. Chevalier, J. Hinebaugh, R. Zeis, J.Electrochem.Soc. 164 (2017) F704-F713. 
[89] T.W. Wysokinski, D. Chapman, G. Adams, M. Renier, P. Suortti, W. Thomlinson, Nucl. Instrum. Meth. Phys. Res. A. 582 (2007) 73-76.

[90] R. Banerjee, J. Hinebaugh, H. Liu, R. Yip, N. Ge, A. Bazylak, Int J Hydrogen Energy. 41 (2016) 14885-14896.

[91] R. Schweiss, C. Meiser, T. Damjanovic, I. Galbiati, N. Haak, (2016).

[92] M. Andisheh-Tadbir, F.P. Orfino, E. Kjeang, J. Power Sources. 310 (2016) 61-69.

[93] H. Ostadi, P. Rama, Y. Liu, R. Chen, X.X. Zhang, K. Jiang, J.Membr.Sci. 351 (2010) 69-74.

[94] E.A. Wargo, V.P. Schulz, A. Çeçen, S.R. Kalidindi, E.C. Kumbur, Electrochim.Acta. 87 (2013) 201-212.

[95] Z. Fishman, A. Bazylak, J.Electrochem.Soc. 158 (2011) B846-B851.

[96] A. Pfrang, S. Didas, G. Tsotridis, J.Power Sources. 235 (2013) 81-86.

[97] J.T. Gostick, M.W. Fowler, M.A. Ioannidis, M.D. Pritzker, Y.M. Volfkovich, A. Sakars, J.Power Sources. 156 (2006) 375-387.

[98] J.H. Nam, M. Kaviany, Int.J.Heat Mass Transfer. 46 (2003) 4595-4611.

[99] P.K. Das, A. Grippin, A. Kwong, A.Z. Weber, J.Electrochem.Soc. 159 (2012) B489-B496.

[100] P. Gopalan, S.G. Kandlikar, J Electrochem Soc. 160 (2013) F487-F495.

[101] O.S. Burheim, H. Su, S. Pasupathi, J.G. Pharoah, B. Pollet, Int. J. Hydrogen Energy. 38 (2013) 8437-8447.

[102] J.G. Pharoah, O.S. Burheim, J.Power Sources. 195 (2010) 5235-5245.

[103] A. Thomas, G. Maranzana, S. Didierjean, J. Dillet, O. Lottin, J.Electrochem.Soc. 160 (2013) F191-F204.

[104] Z. Xie, S. Zhao, J. Gazzarri, Q. Wang, T. Navessin, S. Holdcroft, ECS Trans. 25 (2009) 1187-1192.

[105] T. Suzuki, K. Kudo, Y. Morimoto, J.Power Sources. 222 (2013) 379-389.

[106] K. Sakai, K. Sato, T. Mashio, A. Ohma, K. Yamaguchi, K. Shinohara, ECS Trans. 25 (2009) 1193-1201.

[107] D.A.G. Bruggeman, Ann. Phys. 416 (1935) 636-664. 
[108] N. Zamel, X. Li, J. Shen, Energy Fuels. 23 (2009) 6070-6078.

[109] C.R. Wilke, Chem.Eng.Prog. 46 (1950) 95-104.

[110] R.B. Bird, W.E. Stewart, E.E. Lightfoot, Chapter 17: Diffusivity and the Mechanisms of Mass Transport, Tranport Phenomena, 2nd ed., Wiley, 2007, pp. 513.

[111] R. Flückiger, S.A. Freunberger, D. Kramer, A. Wokaun, G.G. Scherer, F. Büchi N., Electrochim.Acta. 54 (2008) 551-559.

[112] A. Kongkanand, M.F. Mathias, J. Phys. Chem. Lett. 7 (2016) 1127-1137.

[113] R. Jinnouchi, K. Kudo, N. Kitano, Y. Morimoto, Electrochim.Acta. 188 (2016) 767-776.

[114] Y. Takamura, E. Nakashima, H. Yamada, A. Tasaka, M. Inaba, ECS Trans. 16 (2008) 881889.

[115] M. Schalenbach, M.A. Hoeh, J.T. Gostick, W. Lueke, D. Stolten, J. Phys. Chem. C. 119 (2015) 25156-25169.

[116] H. Ito, T. Maeda, A. Nakano, H. Takenaka, Int J Hydrogen Energy. 36 (2011) 1052710540 .

[117] A.Z. Weber, J. Newman, J.Electrochem.Soc. 153 (2006) A2205-A2214.

[118] J. Lee, S. Chevalier, R. Banerjee, P. Antonacci, N. Ge, R. Yip, T. Kotaka, Y. Tabuchi, A. Bazylak, Electrochim.Acta. 236 (2017) 161-170.

[119] S. Chevalier, N. Ge, J. Lee, M. George, H. Liu, P. Shrestha, D. Muirhead, N. Lavielle, B. Hatton, A. Bazylak, J.Power Sources. 352 (2017) 281-290.

[120] M. Andisheh-Tadbir, M. El Hannach, E. Kjeang, M. Bahrami, Int.J.Hydrogen Energy. 40 (2015) 10242-10250.

[121] E.A. Wargo, T. Kotaka, Y. Tabuchi, E.C. Kumbur, J.Power Sources. 241 (2013) 608-618.

[122] X. Zhang, Y. Gao, H. Ostadi, K. Jiang, R. Chen, Int J Hydrogen Energy. 39 (2014) 17222. 